\author{
UNIVERSIDADE DE SÃO PAULO \\ FFCLRP - DEPARTAMENTO DE FÍSICA \\ PROGRAMA DE PÓS-GRADUAÇÃO EM FÍSICA APLICADA À MEDICINA E BIOLOGIA
}

"Análise do comportamento de sensores EGFET como função do tempo, iluminação, área de superfície e temperatura"

Jessica Colnaghi Fernandes

Dissertação apresentada ao Departamento de Física da Faculdade de Filosofia, Ciências e Letras de Ribeirão Preto da USP, como parte das exigências para a obtenção de título de Mestre em Ciências.

Área de Concentração: Física Aplicada à Medicina e Biologia

RIBEIRÃO PRETO - SP 


\section{Análise do comportamento de sensores EGFET como função do tempo, iluminação, área da superfície e temperatura}

Dissertação apresentada ao Departamento de Física da Faculdade de Filosofia, Ciências e Letras de Ribeirão Preto/USP, como parte das exigências de título de Mestre em Ciências.

Área de Concentração: Física Aplicada à Medicina e Biologia.

Orientador: Prof. Associado. Marcelo Mulato

Versão Corrigida 
Autorizo a reprodução e divulgação total ou parcial deste trabalho, por qualquer meio convencional ou eletrônico, para fins de estudo e pesquisa, desde que citada a fonte.

Ficha Catalográfica

Fernandes, Jessica Colnaghi

Análise do comportamento de sensores EGFET como função do tempo, iluminação, área da superfície e temperatura. Ribeirão Preto, 2011.

110 p. : il. ; $30 \mathrm{~cm}$

Dissertação de Mestrado, apresentada ao Departamento de Física da Faculdade de Filosofia, Ciências e Letras de Ribeirão Preto/USP. Área de concentração: Física Aplicada à Medicina e Biologia.

Orientador: Mulato, Marcelo.

1. EGFET. 2. FTO. 3. Evolução no tempo. 4. Dependência da luz. 5. Dependência da área. 6. Dependência da temperatura 
Nome: FERNANDES, Jessica Colnaghi

Título: Análise do comportamento de sensores EGFET como função do tempo, iluminação, área da superfície e temperatura

Dissertação apresentada ao Departamento de Física da Faculdade de Filosofia, Ciências e Letras de Ribeirão Preto para obtenção do título de Mestre em Ciências.

Aprovado em:

Banca Examinadora

Prof. Dr.

Instituição:

Julgamento:

Assinatura:

Prof. Dr.

Instituição:

Julgamento:

Assinatura:

Prof. Dr.

Instituição:

Julgamento:

Assinatura: 
Aos meus pais por toda a confiança e dedicação durante todos esses anos.

Aos meus irmãos por todo o apoio e paciência.

Ao meu marido por tudo. 


\section{Agradecimentos}

Agradeço à todos que estiveram diretamente ou indiretamente ligados à realização deste trabalho.

À minha mãe por toda a dedicação, apoio, tolerância durante toda a minha formação. Ao meu pai pela grande influência e incitação à paixão pela Física.

À minha irmã Melissa, por todo o apoio durante esses anos da minha vida, tornando possível a minha formação. Aos meus irmãos Vanessa e Matheus por toda a convivência, discussões, brincadeiras que tivemos e que ainda teremos. Ao meu cunhado Paulo pelos domingos na ciclofaixa.

Ao meu marido Danilo, por toda a paciência, dedicação e amor.

Aos meus animais de estimação que já aprenderam tudo sobre EGFET.

Aos meus parentes que sempre estiveram presente na minha vida.

Aos colegas e amigos, Amanda, Flávio, Guilherme O., Guilherme G., Haroldo, Júlio, Mariana, Raphael, Shirlei, Suzana, Tobias.

Ao Marcílio por toda a ajuda para a realização deste trabalho.

Ao meu orientador prof. Dr. Marcelo Mulato por toda a paciência e dedicação, pela orientação e ensinamentos transmitidos.

Ao professor Dr. Ivo Alexandre Hummelgen da Universidade Federal do Paraná que nos forneceu as amostras utilizadas nessa dissertação.

À Capes pelo apoio financeiro. 


\section{Resumo}

FERNANDES, J.C.; Análise do comportamento de sensores EGFET como função do tempo, iluminação, área da superfície e temperatura, Dissertação, Departamento de Física, Faculdade de Filosofia, Ciências e Letras, USP, Ribeirão Preto, 2011. p. 110.

Palavras chaves: EGFET, FTO, evolução temporal, dependência da luz, dependência da área da membrana, dependência da temperatura da solução.

O transistor de efeito de campo de porta estendida (EGFET) é um dispositivo composto por uma membrana sensível a íons e um MOSFET comercial, que pode ser aplicado para a medição do teor de íons em uma solução. O filme fino de óxido de estanho dopado com flúor (FTO) foi utilizado como a membrana seletiva do EGFET, e todo o sistema foi utilizado como sensor de $\mathrm{pH}$. Os sensores de $\mathrm{pH}$ desenvolvidos a partir de transistores de efeito de campo (FETs) detectam o campo elétrico criado pelos íons da solução. A alteração do $\mathrm{pH}$ no organismo afeta a estrutura e a atividade das macromoléculas biológicas, por isso a detecção da alteração do pH no organismo é de grande importância. O objetivo deste trabalho foi o estudo da influência de alguns agentes externos sobre o FTO para ser utilizado como membrana sensível a íons do EGFET como sensor de $\mathrm{pH}$. O sensor padrão apresentou uma resposta linear no escuro por volta de $37 \mathrm{mV} / \mathrm{pH}$, para uma área de membrana de $230 \mathrm{~mm}^{2}$. Foram estudados o efeito da evolução da medida no tempo, o efeito da iluminação, o efeito da alteração da área de contato do filme fino de FTO com a solução de $\mathrm{pH}$ e o efeito da alteração da temperatura da solução de pH. Para as medições feitas no escuro a dependência do tempo foi diferente das medições feitas na presença de luz UV-VIS. Para pHs ácidos a presença da luz faz com que o valor da corrente $I_{d s}$ diminua em relação a mesma medição no escuro enquanto que para pHs básicos, o valor da corrente aumenta. A sensibilidade na presença da luz altera em torno de $10 \%$. Para o estudo do efeito da área foram utilizadas duas formas diferentes de medições, sendo a primeira forma utilizando diferentes áreas da mesma amostra e a segunda forma utilizando áreas diferentes para diferentes amostras. O aumento da temperatura da solução aumenta o valor da corrente do sensor em até $5 \%$ e aumenta a sensibilidade em $60 \%$. 


\begin{abstract}
FERNANDES, J.C.; Analysis of the behavior of EGFET sensor as a function of time, illumination, surface área and temperature, Dissertação, Departamento de Física, Faculdade de Filosofia, Ciências e Letras, USP, Ribeirão Preto, 2011. p. 110.

Keywords: EGFET, FTO, time evolution, light dependence, membrane area dependence, solution temperature dependence.

The extended gate field effect transistor (EGFET) is a device composed of a conventional ion sensitive electrode and a commercial MOSFET device, which can be applied for the measurement of ion content in a solution. The fluorine-doped tin oxide thin film (FTO) is used as a sensitive membrane of the EGFET, and the whole system was used as a $\mathrm{pH}$ sensor. The $\mathrm{pH}$ sensor developed from field effect transistors (FTO) detect the electric field created by the ions of the solution. Changing the $\mathrm{pH}$ in the body affects the structure and activity of biological macromolecules, and the detection of $\mathrm{pH}$ change in the body is of great importance. The aim of this paper was study the influence of some external agents in the FTO for used as ion sensitive membrane EGFET as $\mathrm{pH}$ sensor. The standard sensor presented a linear response in the dark about $37 \mathrm{mV} / \mathrm{pH}$, for a membrane area of $230 \mathrm{~mm}^{2}$. Was studied the effect of the evolution of the measure in time, the illumination effect, the effect of changing the contact area of the FTO thin film with the solution $\mathrm{pH}$ and the effect of changing the temperature of the $\mathrm{pH}$ solution. For measurements in the dark the time dependence is different than for the case under UV-VIS illumination. For acids solutions the light presence causes a current value decreases over the same measurement in the dark, whereas for basic solution the current values increases. The sensitivity in light presence changes around $10 \%$. To study the area effect two different studies was applied. The first measure was using different areas of the same sample and the second measure was using different areas of different samples. Increasing the solution temperature the current value of the sensor also increases and the sensitivity increase about $60 \%$.
\end{abstract}




\section{Lista de Figuras}

Figura 2.1 - Diagrama de bandas de energia de um diodo MOS com semicondutor do tipo $p$ e com polarização nula $(V=0)$, onde $E_{f}$ é o nível de Fermi ou potencial químico tanto do semicondutor dopado como do metal, $E_{i}$ é a energia de Fermi para o semicondutor intrínseco ou potencial químico do semicondutor intrínseco, $\mathrm{E}_{\mathrm{c}}$ é a energia mínima da banda de condução do semicondutor, $E_{v}$ é a energia máxima da banda de valência do semicondutor, $E_{g}$ é a magnitude da região de energia proibida ou band-gap $\left(E_{g}=E_{c}-E_{v}\right)$, qXi é a afinidade eletrônica do isolante, qx é a afinidade eletrônica do semicondutor, $q \Phi_{m}$ função trabalho do metal, isto é, a energia mínima necessária para retirar um elétron do metal e torná-lo um elétron livre, $q \Phi_{p}$ é a função trabalho do semicondutor, isto é, a energia mínima necessária para retirar um elétron do semicondutor e torná-lo um elétron livre e $q \Psi_{\mathrm{Bp}}$ é a diferença de energia entre o potencial químico do semicondutor intrínseco e o do semicondutor dopado (nesse caso dopado tipo $p)^{(15)}$

Figura 2.2 - Diagramas de bandas de energia de um diodo MOS com semicondutor do tipo $p$ e com polarização. A figura a) representa a configuração de acumulação, a figura b) a configuração de depleção e a figura c) a configuração de inversão ${ }^{(15)}$.......20

Figura 2.3 - Desenho esquemático de um MOSFET de substrato $p^{(12)}$.......................22

Figura 2.4 - Representação esquemática do site-binding model, onde o óxido está

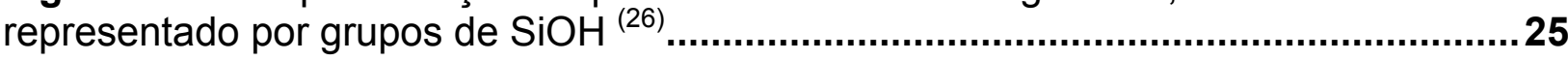

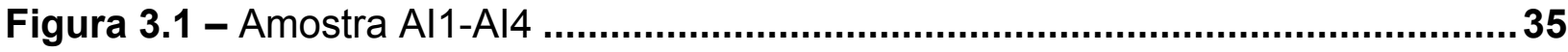

Figura 3.2 - Desenho esquemático da configuração do sistema de medições

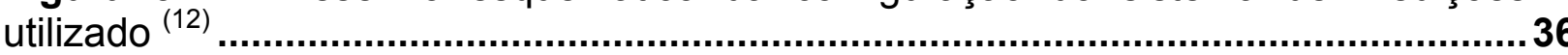

Figura 3.3 - Áreas efetivas AM1-AM4 ............................................................... 39

Figura 3.4 - Desenho esquemático para estudo do efeito da temperatura ..................41

Figura 3.5 - Resposta típica da medição VDS para vários valores de $\mathrm{pH}$..................42

Figura 3.6 - Resposta típica da medição VGS para vários valores de $\mathrm{pH}$..................42

Figura 3.7 - Resposta da medição no tempo para o pH 02........................................43

Figura 3.8 - Desenho esquemático da acomodação das cargas na presença da amostra. dV é a diferença de potencial entre os íons da superfície do sensor e os íons no interior da solução, Vref é a tensão aplicada ao eletrodo de referência e $V$ é

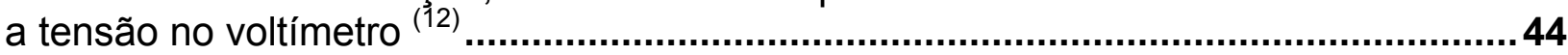

Figura 3.9 - Valor lido de $\mathrm{V}_{\mathrm{gs}}$ quando $\mathrm{I}_{\mathrm{ds}}$ possui valor de $2 \mathrm{~mA}{ }^{(12)}$..............................46

Figura 3.10- Dependência linear da tensão $V_{\text {ref }}$ em função do $p H$ quando $I_{d s}$ fixa........46

Figura 4.1 - Valor da corrente $I_{d s}$ devido à limpeza utilizada. Os pontos da figura 4.1 correspondem ao valor da corrente $I_{d s}$ quando $V_{d s}$ e $V_{g s}$ possuem valor de voltagem igual a $5 \mathrm{~V}$. As siglas LA e LN referem-se respectivamente a limpeza em solução alcalina e limpeza em solução neutra.

Figura 4.2 - Sensibilidade da amostra Al4 no escuro. Os tracejados que aparecem nos pontos são os respectivos erros ....................................................................... 52

Figura 4.3 - Medição do tempo para a amostra Al4 utilizando a) LA e b) LN...............53

Figura 4.4 - Medição no tempo no escuro da amostra Al4 para todos os valores de $\mathrm{pH}$ utilizados 
Figura 4.5 - Variação total da corrente em relação a corrente inicial. A linha tracejada é apenas um guia para os olhos. As barras de erro foram maximizadas ......57

Figura 4.6 - Corrente $I_{d s}$ em função do tempo: a) Referente à medição utilizando LA e b) referente à medição utilizando LN

Figura 4.7 - Medição no tempo para todos os valores de pHs utilizados, comparando a medição feita no claro com a medição no escuro

Figura 4.8 - Valores em módulo da variação da corrente dividido pelo valor inicial para as medições no claro e no escuro. A linha tracejada é apenas um guia para os olhos. As barras de erro foram maximizadas

Figura 4.9 - Sensibilidade da amostra Al4 quando feita a medição no claro e no escuro

Figura 4.10 - Influência da ordem de medição para a medição VDS para as quatro diferentes amostras Al1, Al2, Al3 e Al4. As siglas M1, M2 e MT significam respectivamente primeira medição VDS, segunda medição VDS e medição no tempo 66

Figura 4.11 - Influência da ordem de medição para VGS para as quatro diferentes amostras

Figura 4.12 - Valor final da corrente $I_{d s}$ para as amostras Al1, Al2, Al3 e Al4 em função da área na medição VDS para a solução tampão com pH 02

Figura 4.13 - Valor final da corrente $I_{d s}$ quando feita a medição VDS para os sistemas de medição SM2 (lado esquerdo) e SM1-D e SM1-C (lado direito)................ 72

Figura 4.14 - Medições VDS e VGS para os pHs 02, 07 e 12 feitas nas formas SM1$\mathrm{D}$ e SM1-C. As figuras (a) e (b) se referem respectivamente as medições VDS e VGS para a solução tampão com $\mathrm{pH} 02$, as figuras (c) e (d) se referem respectivamente as medições VDS e VGS para a solução tampão com pH 07 e as figuras (e) e (f) se referem respectivamente as medições VDS e VGS para a solução tampão com pH 12

Figura 4.15- Sensibilidade encontrada para cada área para cada sistema de medição

Figura 4.16 - Sensibilidade pela área para diversos materiais utilizados como membranas sensíveis do EGFET

Figura 4.17 - Sensibilidade pela área para os materiais $\mathrm{SnO}_{2}, \mathrm{SnO}_{2} / \mathrm{ITO}$ e FTO ........83

Figura 4.18 - Sensibilidade/área pela área para diferentes materiais utilizados como membrana sensível a íons do EGFET. A linha é referente ao valor máximo teórico da sensibilidade.

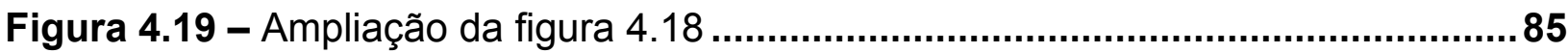

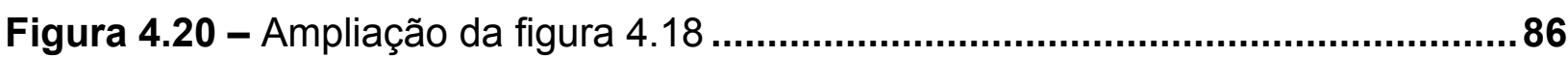

Figura 4.21 - Valor final da corrente $I_{d s}$ nas medições VDS e VGS para a solução tampão com pH 02 em função da temperatura ............................................................87

Figura 4.22 - Valor final da corrente $I_{d s}$ nas medições VDS e VGS para a solução tampão com pH 07 em função da temperatura

Figura 4.23 - Valor final da corrente $I_{d s}$ nas medições VDS e VGS para a solução tampão de $\mathrm{pH} 12$ em função da temperatura 


\section{Lista de Tabelas}

Tabela 3.1 - Dimensões das amostras Al1 - Al4 .................................................. 35

Tabela 3.2 - Áreas efetivas nos sistemas de medições SM1-D e SM1-C .....................39

Tabela 4.1 - Resumo comportamental das amostras em relação aos processos de limpeza utilizados. " $\uparrow$ " representa um valor alto e " $\downarrow$ " representa um valor baixo da grandeza em questão ${ }^{(12)}$

Tabela 4.2 - Revisão bibliográfica para comparação da sensibilidade/área para diferentes materiais utilizados como membranas sensíveis a íons no EGFET.... .81 


\section{Lista de Abreviações e Símbolos}

ISFET

EGFET

MOSFET

FTO

MOS

$E_{f}$

$E_{i}$

$E_{c}$

$E_{v}$

$E_{g}$

q

$\mathbf{X}_{\mathbf{i}}$

$\mathbf{X}$

$\Phi_{m}$

$\Phi_{p}$

$\Psi_{\mathrm{Bp}}$

FET

$\mathbf{H}^{+}$

IDS
Ion Sensitive Field Effect Transistor (Transistor De Efeito

De Campo Sensível A Íons)

Extended Gate Field Effect Transistor (Transistor de Efeito de Campo de Porta Estendida)

Metal Oxide Semiconductor Field Effect Transistor (Transistor De Efeito De Campo Metal Óxido Semicondutor)

Fluorine Tin Oxide (Óxido de Estanho Dopado com Flúor)

Metal Oxide Semiconductor (Semicondutor Metal-Óxido)

Nível De Fermi (ou Potencial Químico)

Potencial Químico Do Semicondutor Intrínseco

Energia Mínima Da Banda De Condução Do Semicondutor

Energia Máxima Da Banda De Valência Do Semicondutor

Magnitude Da Região De Energia Proibida Ou Band-Gap

Carga fundamental $\left(1,6 \times 10^{-19} \mathrm{C}\right)$

Afinidade Eletrônica Do Isolante

Afinidade Eletrônica Do Semicondutor

Função Trabalho Do Metal

FunçãoTrabalho Do Semicondutor

Diferença De Energia Entre O Potencial Químico Do Semicondutor Intrínseco E O Do Semicondutor Dopado

Field Effect Transistor (Transistor de Efeito de Campo)

Cátion Hidrogênio

Corrente Entre Drain E Source 
ox

Red

$\sigma_{0}$

$N_{S}$

$p H_{p z c}$

Sn

$\mathrm{SnO}_{2}$

Al1

Al2

Al3

Al4

$\mathrm{NaOH}$

$\mathrm{HCl}$

LED

VDS

VGS

$v_{d s}$

$\mathbf{V}_{\mathrm{gs}}$
Potencial Elétrico Na Interface Sólido/Líquido

Potencial De Referência

Constante Universal Dos Gases $\left(R=8,314 \mathrm{~J} \cdot \mathrm{mol}^{-1} \cdot \mathrm{K}^{-1}\right)$

Temperatura Absoluta $(T=298,2 \mathrm{~K})$

Sinal Da Carga lônica

Constante De Faraday $\left(\mathrm{F}=96480 \mathrm{~J} \cdot \mathrm{V}^{-1} \cdot \mathrm{mol}^{-1}\right)$

Espécies Oxidadas

Espécies Reduzidas

Densidade Superficial De Carga

Número Total De Sítios Por Unidade De Área

Ponto De Zero Carga

Estanho

Óxido De Estanho

Amostra Independente 1

Amostra Independente 2

Amostra Independente 3

Amostra Independente 4

Hidróxido De Sódio

Ácido Clorídrico

Light Emission Diode (Diodo Emissor De Luz)

Medição Alterando A Tensão Entre O Dreno E A Fonte

Medição Alterando A Tensão Entre A Porta E A Fonte

Tensão Entre O Dreno E A Fonte

Tensão Entre A Porta E A Fonte 
$I_{d s}$

AM1

AM2

AM3

AM4

SM1-D

SM1-C

$\mathrm{H}_{3} \mathrm{O}^{+}$

dV

$\mathbf{V}_{\text {ref }}$

LA

LN

$\mathrm{OH}^{-}$

$\uparrow$

$\downarrow$

dQ

$\mathrm{H}_{2} \mathrm{O}$

$I_{d s ~ f}$

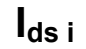

$\Delta_{\text {Ids }}$

M1

M2

MT
Corrente Entre O Dreno E A Fonte

Amostra Múltipla 1

Amostra Múltipla 2

Amostra Múltipla 3

Amostra Múltipla 4

Sistema De Medições 1 Na Forma Decrescente

Sistema De Medições 1 Na Forma Crescente

Íons Hidrônios

Diferença De Potencial

Potencial De Referência

Limpeza Alcalina

Limpeza Neutra

Íons Hidroxilas

Alta Velocidade De Carregamento Das Cargas Na

Superfície Da Amostra

Baixa Velocidade De Carregamento Das Cargas Na

Superfície Da Amostra

Variação De Cargas

Moléculas De Água

Valor Final Da Corrente Entre O Dreno E A Fonte

Valor Inicial Da Corrente Entre O Dreno E A Fonte

Variação Da Corrente Entre O Dreno E A Fonte

Primeira Medição

Segunda Medição

Medição No Tempo 
Óxido De Zinco

ITO

Indium Tin Oxide (Óxido De Estanho Dopado Com Índio)

ITO/ Si

Óxido De Estanho Dopado Com Índio Em Substrato De Silício

$\mathrm{ITO} / \mathrm{SiO}_{2} / \mathrm{Si}$

Óxido De Estanho Dopado Com Índio Em Substrato De Óxido De Silício E Silício

$\mathrm{SnO}_{2} / \mathrm{ITO}$

Óxido De Estanho Em Substrato De Óxido De Estanho Dopado Com Índio

Polipirrol/SnO $/ 2$ ITO Polipirrol Em Substrato De Óxido De E Estanho E Silício

$\mathrm{Si}_{3} \mathrm{~N}_{4}$

Nitrato De Silício 


\section{Sumário}

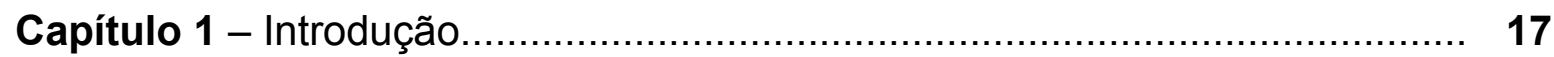

Capítulo 2 - Dispositivos por efeito de campo...................................... 19

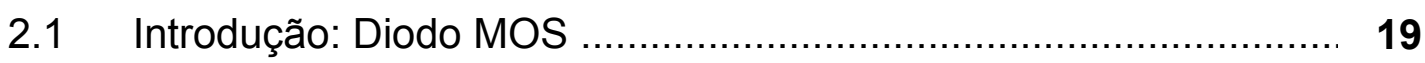

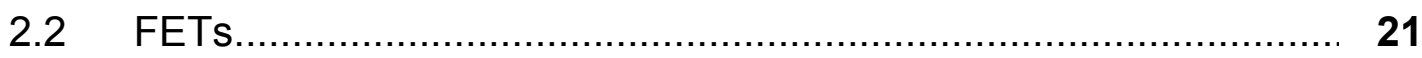

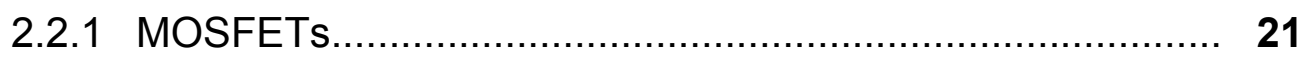

2.2.2 Eletrodos íon seletivos........................................... 22

2.2.2.1 ISFETS ................................................... 22

2.2 .3 EGFETs............................................................. 23

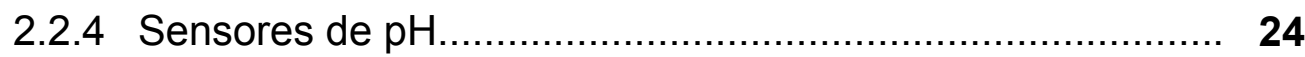

2.2.5 Site-binding Model............................................. 25

2.3 Adsorção....................................................................... 30

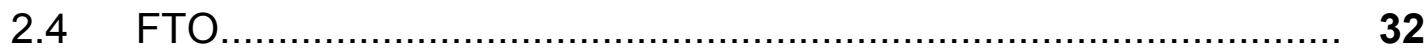

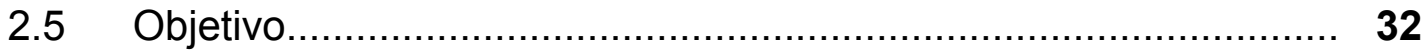

Capítulo 3 - Materiais e Métodos.............................................. 34

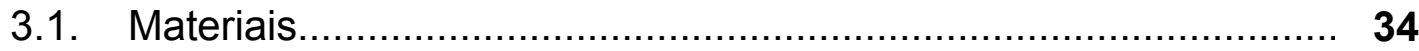

3.1.1. Amostras.......................................................... 34

3.1.2. Outros Materiais e Equipamentos Utilizados.................. 35

3.2. Métodos................................................................. 37

3.2.1. Preparação das Amostras...................................... 37

3.2.2. Medições........................................................... 37

3.2.2.1. Tempo............................................ 38

3.2.2.2. Iluminação...................................... 38

3.2.2.3. Áreas.............................................. 38

3.2.2.3.1. Mesma Amostra............................. 38

3.2.2.3.2. Diferentes Amostras....................... 40

3.2.2.4. Temperatura.................................... 40

3.3. Procedimentos de Coleta e Análises dos Dados...................... 41

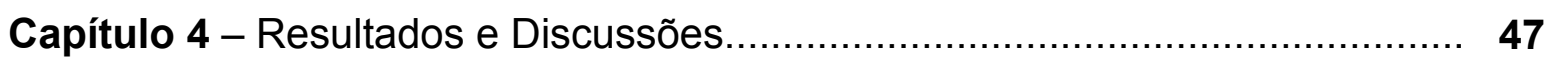


4.1. Influência do sistema de limpeza........................................ 46

4.2. Influência do tempo....................................................... 51

4.3. Influência da luz.......................................................... 57

4.4. Influência da ordem de medição......................................... 65

4.5. Influência da área de superfície da amostra............................69 69

4.6. Influência da temperatura........................................... 86

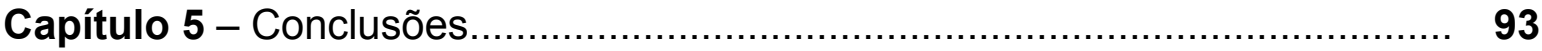

Referências Bibliográficas............................................................ 94

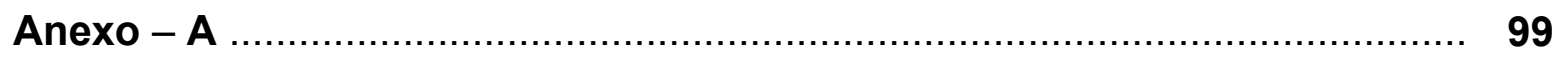




\section{Capítulo 1 - Introdução}

O transistor por efeito de campo foi empregado pela primeira vez para medidas neurofisiológicas por Bergveld em $1970{ }^{(1)}$. A partir disso os transistores por efeito de campo sensíveis a íons (ISFETS) estão sendo desenvolvidos em um novo tipo de eletrodo químico-sensível. Diversos estudos teóricos e experimentais têm sido publicados para descrever o comportamento desses dispositivos eletrônicos químico-sensíveis ${ }^{(2)}$. Dióxido de silício $\left(\mathrm{SiO}_{2}\right)$ foi primeiramente utilizado como dielétrico sensível a $\mathrm{pH}$ para o ISFET ${ }^{(3)}$. Subseqüentemente foram utilizados $\mathrm{Al}_{2} \mathrm{O}_{3}, \mathrm{Si}_{3} \mathrm{~N}_{4}, \mathrm{Ta}_{2} \mathrm{O}_{5}$ e $\mathrm{SnO}_{2}$ como dielétricos sensíveis a pH devido a sua alta resposta em função do $\mathrm{pH}^{(4 ; 5 ; 6 ; 7)}$.

O ISFET é de alto custo e difícil fabricação. Para minimizar esses problemas utiliza-se o EGFET (extended gate field effect transistor) que é nada mais que uma porta estendida ligada a um MOSFET comercial por um fio ${ }^{(8 ; 9)}$. Essa porta estendida pode ser uma membrana sensível a íons e assim é construído um sensor de $\mathrm{pH}$.

Diversos estudos e desenvolvimento de sensores avançam rapidamente devido ao grande crescimento de aplicações em diferentes áreas, como clínica química e processos industriais. Além disso, a determinação dos valores de $\mathrm{pH}$ é uma das tarefas mais importantes em química analítica ${ }^{(10)}$. A medida de $\mathrm{pH}$ é um dos procedimentos mais importantes e mais freqüentes para a bioquímica, pois o $\mathrm{pH}$ afeta a estrutura e a atividade das macromoléculas biológicas, como por exemplo a atividade catalítica das enzimas ${ }^{(11)}$. As medidas de $\mathrm{pH}$ do sangue e da urina são comumente empregadas no diagnóstico médico ${ }^{(12)}$.

A busca por uma membrana sensível a íons otimizada para utilização com o EGFET ainda implica em vários estudos. Uma boa alternativa para essa membrana é a utilização do FTO, que é um material transparente e com várias aplicações tecnológicas, tais como sensores de gás e o uso em células solares (13).

O objetivo deste trabalho é o estudo da influência de alguns parâmetros sobre o FTO para ser utilizado como membrana sensível a íons do EGFET. Os tópicos abordados neste trabalho são a evolução na resposta da corrente em 
função do tempo, a influência da iluminação no sistema utilizado, o efeito da alteração da área de contato da membrana com a solução utilizada e o efeito da alteração da temperatura da solução utilizada na resposta do sensor.

Este trabalho está dividido em 5 capítulos, sendo o capítulo 1 uma breve introdução, o capítulo 2 uma apresentação teórica dos dispositivos e materiais utilizados, o capítulo 3 referente aos materiais e métodos utilizados, mostrando o funcionamento do dispositivo utilizado e explicando cada tipo de medição, o capítulo 4 corresponde aos resultados e toda a discussão sobre eles e o capítulo 5 as conclusões obtidas a partir dos resultados.

Finalmente, são listadas as referências bibliográficas utilizadas para a realização desse trabalho. 


\section{Capítulo 2 - Dispositivos por efeito de campo}

\subsection{Introdução: Capacitor MOS}

O capacitor MOS (metal-oxide-semiconductor diode) é o dispositivo mais utilizado no estudo de superfícies semicondutoras ${ }^{(14)}$. Ele consiste em uma junção metal-óxido-semicondutor como mostra a figura 2.1:

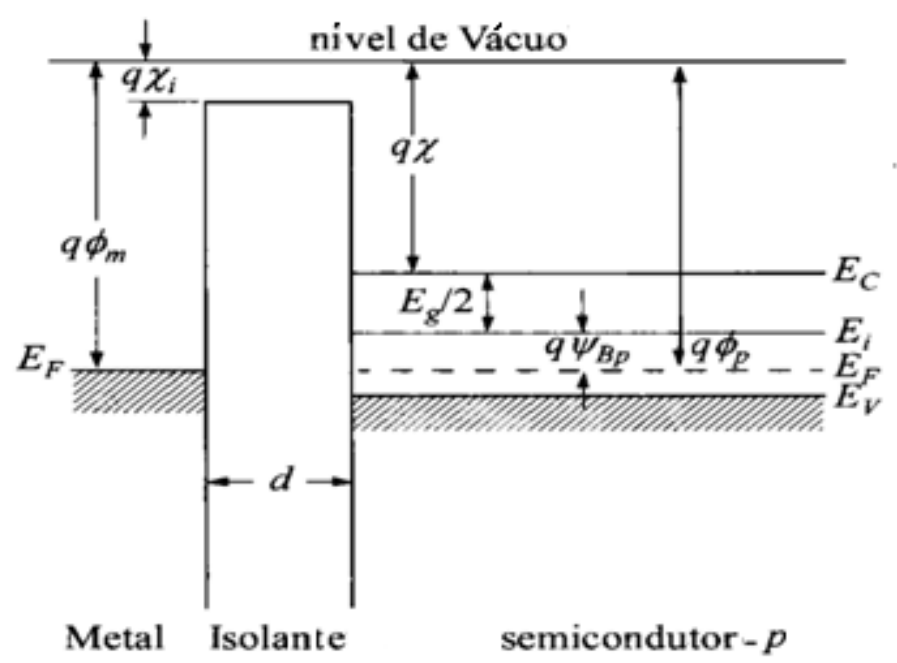

Figura 2.1: Diagrama de bandas de energia de um diodo MOS com semicondutor do tipo $p$ e com polarização nula $(V=0)$, onde $E_{f}$ é o nível de Fermi ou potencial químico tanto do semicondutor dopado como do metal, $E_{i}$ é a energia de Fermi para o semicondutor intrínseco ou potencial químico do semicondutor intrínseco, $\mathrm{E}_{\mathrm{c}}$ é a energia mínima da banda de condução do semicondutor, $E_{v}$ é a energia máxima da banda de valência do semicondutor, $E_{g}$ é a magnitude da região de energia proibida ou band-gap $\left(E_{g}=E_{c}-E_{v}\right)$, qX é a afinidade eletrônica do isolante, qX é a afinidade eletrônica do semicondutor, $q \Phi_{m}$ função trabalho do metal, isto é, a energia mínima necessária para retirar um elétron do metal e torná-lo um elétron livre, $q \Phi_{p}$ é a função trabalho do semicondutor, isto é, a energia mínima necessária para retirar um elétron do semicondutor e torná-lo um elétron livre e $\mathrm{q} \Psi_{\mathrm{Bp}}$ é a diferença de energia entre o potencial químico do semicondutor intrínseco e o do semicondutor dopado (nesse caso dopado tipo p) ${ }^{(15)}$

As únicas cargas que podem existir na estrutura sem polarização são as cargas do semicondutor e a cargas da superfície do metal adjacente ao isolante, sendo que estas possuem polaridades opostas às cargas do semicondutor. Ao aplicarmos uma determinada voltagem no metal podem ocorrer três possíveis configurações, como mostra a figura 2.2: 


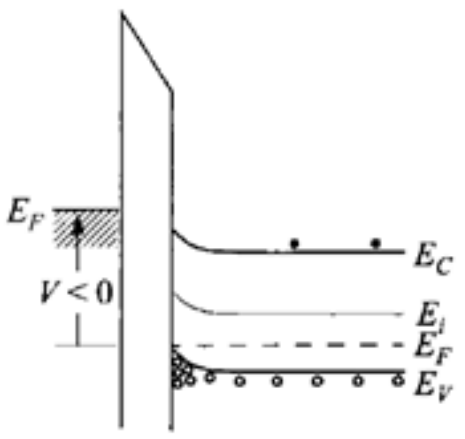

a) Acumulacão

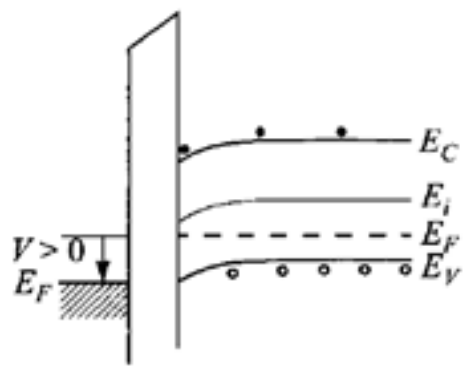

b) Depleção

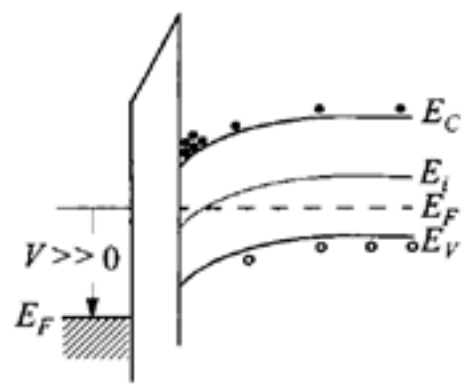

c) Inversão

Figura 2.2: Diagramas de bandas de energia de um diodo MOS com semicondutor do tipo $p$ e com polarização. A figura a) representa a configuração de acumulação, a figura b) a configuração de depleção e a figura c) a configuração de inversão ${ }^{(15)}$

Quando uma voltagem negativa $(\mathrm{V}<0)$ é aplicada ao metal os portadores majoritários do semicondutor tipo $\mathrm{p}$, chamados de buracos, irão se acumular na região adjacente ao óxido. Quando isso ocorre, o semicondutor tipo $\mathrm{p}$ se assemelha a um semicondutor altamente dopado chamado de $\mathrm{p}^{+}$. Como não há passagem de corrente na estrutura entre o semicondutor e o metal devido ao óxido ser isolante, o nível de Fermi do semicondutor não se altera então as bandas de condução e de valência, e consequentemente a energia de Fermi intrínseca, se deslocam como mostrado na figura 2.2-a. Sendo assim, essa nova configuração recebe o nome de acumulação.

Quando aplicada uma voltagem positiva $(\mathrm{V}>0)$ ao metal ocorre um aumento da região de depleção do semicondutor como mostrado na figura 2.2b. Essa nova configuração recebe o nome de depleção. Quando aplicada uma voltagem muito alta no metal ( $V>>0)$, as bandas de condução e de valência, e consequentemente a energia de Fermi intrínseca, chegarão à configuração da figura 2.2-c, isto é, o nível de Fermi para o metal é tão baixo que os elétrons da banda de condução do semicondutor serão atraídos para a região adjacente ao óxido até que essa região passe a ter características de um semicondutor do tipo n, e por isso, essa configuração é chamada de inversão.

Quando aplicamos um campo elétrico perpendicular ao plano da folha na região de inversão, construímos um condutor de resistência extremamente baixa, que podemos chamar de canal tipo ${ }^{(15)}$. Com isso, montamos uma 
configuração de um dispositivo que tem como princípio de funcionamento o campo elétrico aplicado à ele.

\subsection{FETs}

Os FETs (Field Effect Transistor), que é uma sigla em inglês para transistor de efeito de campo, têm como característica básica o controle de uma corrente por um campo elétrico aplicado. Esses transistores de efeito de campo possuem três terminais chamados "gate" ou porta, "drain" ou dreno e "source" ou fonte.

A vantagem prática dos FETs que os tornam cada vez mais comuns é a sua alta impedância de entrada. Portanto, não necessitam de praticamente nenhuma corrente de entrada no gate para o controle de corrente do dreno.

Como a corrente nesses dispositivos é transportada predominantemente por carreadores de somente uma polaridade são chamados de dispositivos unipolares. Um dos dispositivos mais importantes baseados em efeito de campo é o dispositivo semicondutor chamado MOSFET (Metal-oxidesemiconductor Field Effect Transistor).

\subsubsection{MOSFETS}

MOSFET é a sigla em inglês para transistor de efeito de campo metalóxido-semicondutor. É o dispositivo mais importante para a construção de circuitos integrados em larga escala.

O MOSFET é um dispositivo de quatro terminais, sendo estes a fonte, o dreno, a porta e o substrato. Ele consiste de um substrato semicondutor que pode ser do tipo $\mathrm{p}$ ou tipo $\mathrm{n}$, neste caso estamos considerando um substrato semicondutor tipo $\mathrm{p}$, e formam-se então duas regiões tipo $\mathrm{n}^{+}$chamadas de fonte e dreno. O contato metálico no isolante é chamado de gate ou porta, como mostrado na figura 2.3. 


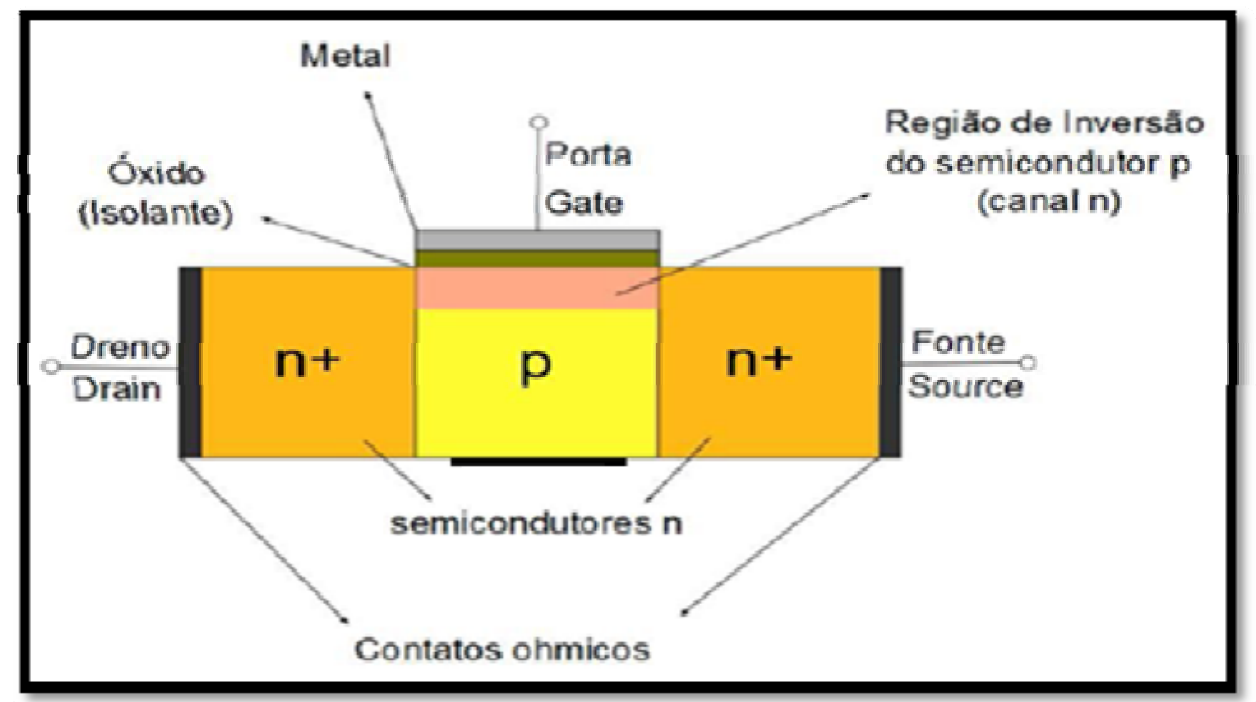

Figura 2.3: Desenho esquemático de um MOSFET de substrato $\mathrm{p}^{(12)}$

O gate do MOSFET é isolado do resto do corpo do transistor pelo óxido, e por isso o MOSFET tem como característica o controle da corrente entre o dreno e a fonte devido a uma variação de um sinal de tensão no gate do componente. Na figura 2.3 o MOSFET está representado por somente três terminais pois o quarto terminal está interligado internamente a fonte e portanto ligado ao terra.

\subsubsection{Eletrodos íon seletivos}

Eletrodos íon seletivos são sensores eletroquímicos que permitem a determinação potenciométrica da atividade de espécies iônicas na presença de outros íons. A membrana sensitiva é a parte mais importante desses sensores (16). No entanto, esses eletrodos íon seletivos podem sofrer interferência de outros íons ${ }^{(17)}$. Uma evolução dos eletrodos íon seletivos são os transistores ISFETs .

\subsubsection{ISFETs}

O transistor de efeito de campo sensível a íons (ISFETs) é um dispositivo integrado composto por um eletrodo sensível a íons convencional e um MOSFET. O ISFET é basicamente um MOSFET, porém possui uma membrana sensível a íons no lugar do gate de metal. Essa membrana sensível a íons fica em contato diretamente com a solução eletrolítica. 
O ISFET combina a detecção de íons através da membrana seletiva e a transformação do potencial sentido na superfície pela membrana ${ }^{(18)}$. Pela alteração do campo elétrico na interface isolante-semicondutor que ocorre devido à concentração de íons presentes na solução, modula-se então a intensidade da corrente elétrica através do MOSFET ${ }^{(19)}$.

A teoria empregada para explicar a interação da membrana quando entra em contato com o eletrólito é a que leva em consideração o comportamento eletrólito-isolante-semicondutor e possui como sigla EIS (electrolyte-insulator-semiconductor) ${ }^{(17 ; 20 ; 21 ; 22 ; 23)}$. Essa teoria é a base do funcionamento do ISFET, onde o comportamento EIS irá contribuir com novos termos na tensão de limiar ISFET, e considera a contribuição da dupla camada formada pelos íons que se ligam nos sítios de ligação. Essa dupla camada também é conhecida como dupla camada de Gouy-Chapman-Stern ${ }^{20 ; 21 ; 22 ; 23)}$.

A importância do uso do ISFET pode ser atribuída a sua capacidade de miniaturização e a possibilidade de usar processos de microfabricação ${ }^{(19)}$. No entanto, o ISFET apresenta alguns problemas como, por exemplo, a dificuldade de encapsulamento, pois o gate que é a membrana seletiva do dispositivo precisa entrar em contato direto com a solução, mas o corpo do transistor não pode entrar em contato com a solução, sendo este problema mais expressivo para componentes miniaturizados. A construção do transistor não é fácil e possui alto custo, não há possibilidade de troca da membrana sensível a íons para novos estudos, entre outros.

\subsubsection{EGFETs}

O transistor de efeito de campo com porta estendida (EGFET) é uma variação do ISFET onde a membrana sensível a íons agora é conectada a um MOSFET comercial. Essa configuração traz diversos benefícios em relação ao ISFET, como a não necessidade de encapsulamento, pois como o próprio nome sugere o gate ou porta é estendido e conectado a um MOSFET comercial, fazendo também com que sua construção seja fácil e de baixo custo. A membrana seletiva pode ser trocada e portanto o mesmo EGFET pode ser reutilizado diversas vezes e para diferentes estudos. Portanto a utilização 
desse transistor é uma ótima alternativa para sanar as dificuldades da utilização do ISFET como sensor de íons.

\subsubsection{Sensores de $\mathrm{pH}$}

Os sensores de $\mathrm{pH}$ desenvolvidos a partir dos FETs detectam o campo elétrico criado pelos íons $\mathrm{H}^{+}$da solução. A mudança do potencial entre o eletrólito e a membrana sensível a íons que ocorre devido a mudança de concentração de pH no eletrólito é que vai modular a intensidade da corrente no MOSFET $^{(19)}$.

A maioria dos sensores de íons são sensores potenciométricos, isto é, a técnica de medição utilizada é caracterizada pelo potencial entre os eletrodos $(24 ; 25)$. O potencial elétrico na interface sólido/líquido em função da concentração de íons a ser determinada é medida de acordo com a equação de Nernst ${ }^{(26)}$ :

$$
\mathrm{E}=E_{0}+\left(\frac{R T}{n F}\right) \ln \frac{[O x]}{[R e d]}
$$

Onde $\mathrm{E}$ é o potencial a ser medido, $\mathrm{E}_{0}$ é o potencial de referência, $\mathrm{R}$ é a constante universal dos gases $\left(R=8,314 \mathrm{~J} \cdot \mathrm{mol}^{-1} \cdot \mathrm{K}^{-1}\right)$, $\mathrm{T}$ é a temperatura absoluta ( $T=298,2 \mathrm{~K}$ ), $\mathrm{n}$ é o sinal da carga iônica, isto é, se $\mathrm{n}=1$ o íon que se difunde é um cátion e se $n=-1$ o íon que se difunde é um ânion, $F$ a constante de Faraday $\left(\mathrm{F}=96480 \mathrm{~J} . \mathrm{V}^{-1} \cdot \mathrm{mol}^{-1}\right),[O x]$ é a concentração das espécies oxidadas e [Red] é a concentração das espécies reduzidas ${ }^{(10 ; 26)}$.

A equação (2.1) mostra que o potencial gerado é diretamente proporcional ao logaritmo da concentração da solução analítica e devido a essa relação logarítmica do potencial é possível detectar um vasto espectro de concentrações diferentes da solução analítica.

Entre as propriedades do sensor de $\mathrm{pH}$ a sensibilidade é uma das mais importantes. Pela teoria Nernstiana, espera-se que os dispositivos que trabalhem por efeito de campo tenham sensibilidade máxima da ordem de 59,2 $\mathrm{mV} / \mathrm{pH}$ e ainda respondam linearmente na faixa de $\mathrm{pH}$ de 02 a $12^{(27 ; 28 ; 29)}$. 
A detecção da alteração do $\mathrm{pH}$ no organismo é de suma importância pois $\mathrm{opH}$ afeta a estrutura e a atividade das macromoléculas biológicas. $\mathrm{O} \mathrm{pH}$ é de grande importância para que ocorra a atividade enzimática. $\mathrm{Na}$ área médica utiliza-se medidas de $\mathrm{pH}$ do sangue e da urina para diagnósticos médicos ${ }^{(11)}$. Por isso, é de grande importância a construção de um biossensor miniaturizado de $\mathrm{pH}$ para utilização médica.

\subsubsection{Site-binding Model}

O modelo de sítio de ligação (site-binding model) descreve o mecanismo responsável pelo aparecimento do potencial de superfície na membrana devido a variação do $\mathrm{pH}$ da solução. A descrição desse modelo é baseada no equilíbrio entre os sítios da superfície e os íons $\mathrm{H}^{+}$presentes na solução ${ }^{(23)}$.

A superfície de qualquer óxido metálico sempre contém grupos hidroxilas. Esses grupos podem doar ou aceitar prótons da solução, deixando a superfície negativamente ou positivamente carregada, respectivamente. A figura 2.4 mostra um desenho esquemático dessa interface óxido/eletrólito.

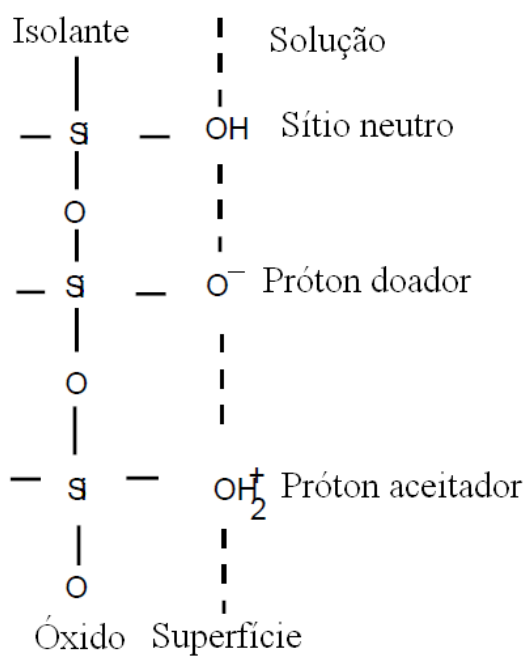

Figura 2.4: Representação esquemática do site-binding model, onde o óxido está representado por grupos de $\mathrm{SiOH}^{(26)}$.

Utilizando a notação A para representar o material sensível da membrana que se ligará ao íon a ser medido, esse modelo pode ser descrito pelas reações químicas na superfície abaixo:

$$
\mathrm{AOH}_{2}^{+} \stackrel{K_{a}}{\leftrightarrow} \mathrm{AOH}+\mathrm{H}_{S}^{+}
$$




$$
A O H \stackrel{K_{b}}{\leftrightarrow} A O^{-}+H_{S}^{+}
$$

Os termos $\mathrm{A}-\mathrm{OH}_{2}^{+}, \mathrm{A}-\mathrm{OH}$ e $\mathrm{AO}^{-}$representam os sítios de superfície positivo, neutro e negativo respectivamente. $\mathrm{O}$ termo $H_{S}^{+}$representa os íons $\mathrm{H}^{+}$ da solução.

As reações (2.2) e (2.3) indicam que o sítio originalmente neutro pode se associar a um próton da solução e tornar-se um sítio positivo ou então ceder um próton a solução e então tornar-se um sítio negativo. Por essa razão são chamados de sítios anfóteros ${ }^{(26)}$.

O comportamento ácido ou básico do sítio neutro $\mathrm{A}-\mathrm{OH}$ é caracterizado pelas constantes de equilíbrio $\mathrm{K}_{\mathrm{a}}$ e $\mathrm{K}_{\mathrm{b}}$ respectivamente.

$$
\begin{gathered}
K_{a}=\frac{[A O H]\left[H^{+}\right]_{S}}{\left[A O H_{2}^{+}\right]} \\
K_{b}=\frac{\left[A O^{-}\right]\left[H^{+}\right]_{S}}{[A O H]}
\end{gathered}
$$

$[\mathrm{A}-\mathrm{OH}],\left[\mathrm{A}-\mathrm{OH}_{2}^{+}\right]$e $\left[\mathrm{A}-\mathrm{O}^{-}\right]$referem-se ao número de sítios por área e $\left[\mathrm{H}^{+}\right]_{\mathrm{s}}$ é a atividade de íons $\mathrm{H}^{+}$. O coeficiente da atividade está incluso na constante de dissociação. Os valores de K são chamados de valores intrínsicos pois são válidos somente no equilíbrio químico na interface óxido-eletrólito.

O potencial que modula a corrente do dreno $\left(\psi_{0}\right)$ em função da variação do $\mathrm{pH}$ pode ser descrito como a diferença entre o potencial da superfície da membrana $\left(\psi_{S}\right)$ e o potencial da solução $\left(\psi_{B}\right)$.

$$
\psi_{0}=\psi_{S}+\psi_{B}
$$

A atividade do próton da solução $a_{H B^{+}}$pode ser relacionada à atividade do próton na vizinhança direta da superfície do óxido $a_{H S^{+}}$pela equação de Boltzmann.

$$
a_{H S}=a_{H B} e^{\left(-\frac{q \psi_{0}}{K T}\right)}
$$

Assim como os termos $\left[\mathrm{H}^{+}\right]_{\mathrm{S}}$ e $\left[\mathrm{H}^{+}\right]_{\mathrm{B}}$, que representam respectivamente as concentrações de prótons na superfície e na solução, como mostra a equação (2.8).

$$
\left[H^{+}\right]_{S}=\left[H^{+}\right]_{B} e^{\left(-\frac{q \psi_{0}}{K T}\right)}
$$


Sendo $\mathrm{q}$ a carga elementar, $\mathrm{K}$ a constante de Boltzmann, $\mathrm{T}$ a temperatura absoluta e $\psi_{0}$ o potencial de superfície dependendo do $\mathrm{pH}^{(26)}$.

O potencial é gerado pela densidade de carga e a densidade superficial de carga $\sigma_{0}\left(\mathrm{C} / \mathrm{m}^{2}\right)$ é dada por:

$$
\sigma_{0}=q\left(\left[A O H_{2}^{+}\right]-\left[A O^{-}\right]\right)=-q B
$$

$\mathrm{O}$ termo $\mathrm{B}$ representa a diferença entre o número de grupos carregados negativamente e o número de grupos carregados positivamente em mol por unidade de área. Já o número total de sítios por unidade de área, que serão o número total de sítios de ligação com os íons desejados é dado por:

$$
N_{S}=[\mathrm{AOH}]+\left[\mathrm{AOH}_{2}^{+}\right]+\left[\mathrm{AO}^{-}\right]
$$

A resposta do sensor depende de $\mathrm{N}_{\mathrm{s}}$, pois quando maior o valor de $\mathrm{N}_{\mathrm{s}}$ maior a sensibilidade do $\mathrm{pH}$ e mais linear é a resposta ${ }^{(28 ; 30 ; 31)}$.

A relação entre $\Psi_{0}, \sigma_{0}$ e $\left[H^{+}\right]_{B}$ pode ser determinada através das equações (2.4) a (2.10) em termos de $\mathrm{K}_{\mathrm{a}}, \mathrm{K}_{\mathrm{b}}$ e $\mathrm{N}_{\mathrm{s}}$, os quais são os parâmetros que caracterizam a superfície óxida.

$$
\ln \left[H^{+}\right]_{B}-\ln \left(\frac{K_{b}}{K_{a}}\right)^{1 / 2}=\frac{q \psi}{K T}+\sinh ^{-1} \frac{\sigma_{0}}{q N_{S}}\left(\frac{q \psi}{K T} \frac{1}{\beta}\right)
$$

$O$ efeito da atividade do próton superficial na densidade de carga superficial pode ser calculado a partir da equação (2.09) e é expresso pela equação (2.12).

$$
\frac{\partial \sigma_{0}}{\partial p H_{S}}=-q \frac{\partial B}{\partial p H_{S}}=-q \beta_{\text {int }}
$$

$\beta_{\text {int }}$ representa a capacidade de acumular informações de cargas na superfície do óxido. A mudança na alteração da atividade da carga é expressa em seu pH correspondente e então, a mudança resultante em $\sigma_{0}$ é expressa no número de grupos $\beta_{\text {int. }}$ A carga superficial $\left(\sigma_{0}\right)$ está balanceada por uma carga equivalente oposta no eletrólito $\left(\sigma_{\mathrm{dl}}\right)$ devido a neutralidade de cargas. Essa densidade se encontra na dupla camada. Essas densidades de cargas paralelas formam a capacitância de dupla camada $C_{d \mid l}$. A diferença de potencial sobre essa capacitância é igual à diferença entre o potencial da superfície do óxido e da solução e a relação entre essas densidades de carga é dada pela equação (2.13).

$$
\sigma_{d l}=-\sigma_{0}=-\psi_{0} C_{d l}
$$


Essa capacitância pode ser calculada pelo modelo de Gouy-ChapmanStern. Neste modelo, a capacitância consiste em uma rede de uma série da capacitâncias da camada de Helmholtz (capacitância de Stern) e da capacitância da camada difusa. O modelo da camada de Helmholtz define que os íons da solução possuem um tamanho finito e que seus centros não podem se aproximar da superfície mais do que o seu raio iônico incluindo uma possível camada de água. A camada difusa começa a partir dessa distância e contém a mesma quantidade de cargas, mas com sinais opostos as cargas da superfície do óxido.

A equação (2.13) descreve de uma forma mais direta a relação entre $\Psi_{0}$ e o $\mathrm{pH}$.

A capacitância diferencial da dupla camada, que é a capacidade da dupla camada armazenar carga em resposta a uma pequena carga de superfície, é dada pela equação (2.15).

$$
C_{d i f}=-\frac{\partial \sigma_{d l}}{\partial \psi_{0}}=\frac{\partial \sigma_{0}}{\partial \psi_{0}}
$$

Combinando as relações (2.12), onde aparece a densidade superficial de cargas, com (2.14) encontramos a equação (2.15) e depois com a relação de Boltzmann obtêm-se a atividade do próton na superfície e a diferença entre o valor do $\mathrm{pH}$ na superfície e na solução, ambos dados pelas equações (2.7) acima e (2.16) abaixo respectivamente.

$$
\begin{gathered}
\frac{\partial \psi_{0}}{\partial p H_{S}}=\frac{\partial \psi_{0}}{\partial \sigma_{0}} \cdot \frac{\partial \sigma_{0}}{\partial p H_{S}}=\frac{-q \beta_{i n t}}{C_{d i f}} \\
a_{H S}=a_{H B} e^{\left(-\frac{q \psi_{0}}{K T}\right)} \\
\left(p H_{S}-p H_{B}\right)=\left(\frac{q \psi_{0}}{K T}\right)
\end{gathered}
$$

$\mathrm{O}$ resultado é a expressão geral para a sensibilidade ao $\mathrm{pH}$ para $\mathrm{o}$ ISFET.

$$
\frac{\partial \psi_{0}}{\partial p H_{B}}=-2,3 \frac{K T}{q} \alpha
$$

Onde $\quad \alpha=\frac{1}{\frac{2,3 K T C_{d i f}}{q^{2} \beta_{\text {int }}}+1}$. Esse parâmetro representa a sensibilidade que varia entre 0 e 1 , dependendo da capacidade de acumular informações de 
cargas na superfície $\beta_{\text {int }}$ da superfície do óxido e da capacidade diferencial da dupla camada $C_{\text {dif }}$.

Se $\alpha=1$, o ISFET apresenta sensibilidade Nernstiana $(59,2 \mathrm{mV} / \mathrm{pH})$.

Quando $\psi_{0}=0$ o valor do $\mathrm{pH}$ pode ser obtido pela equação (2.18).

$$
p H_{p z c}=-\log _{10}\left(K_{a} K_{B}\right)^{1 / 2}=\frac{1}{2}\left(p K_{a}+p K_{b}\right)
$$

Este valor é denominado como $\mathrm{pH}$ no ponto de zero carga ou ponto isoelétrico, isto é, o número de íons sensíveis negativos é igual ao número de íons sensíveis positivos, pois o fato de $\Psi_{0}=0$ implica em $\sigma_{0}=0 . \mathrm{pK}_{\mathrm{a}}=$ $\log _{10}\left(K_{a}\right)$ e $p K_{b}=-\log _{10}\left(K_{b}\right)$.

Portanto, a equação final pode ser descrita na forma:

$$
2,303\left(p H_{p z c}-p H\right)=\frac{q \psi}{K T}+\sinh ^{-1}\left(\frac{q \psi}{K T} \frac{1}{\beta}\right)
$$

Sendo $\beta$ um parâmetro que caracteriza a sensibilidade do óxido ao $\mathrm{pH}$ da solução.

$$
\beta=\frac{2 q 2 N_{S}}{C_{d l} K T}\left(\frac{K_{b}}{K_{a}}\right)^{1 / 2}
$$

Sendo $\mathrm{C}_{\mathrm{dl}}$ a capacitância da dupla camada por unidade de área da superfície isolante.

A equação (2.19) é uma aproximação para superfícies, tais como óxidos, onde o número de sítios é suficientemente alto para assegurar que a densidade de carga nunca se aproxime do máximo valor na faixa de $\mathrm{pH}$ utilizada.

A sensibilidade em termos do parâmetro $\beta$ que é um parâmetro que caracteriza a sensibilidade do óxido em função do $\mathrm{pH}$ pode ser descrito da seguinte forma:

$$
S=\frac{\partial \psi_{0}}{\partial\left(p H_{p z c}-p H\right)}=2,3\left(\frac{K T}{q}\right) \frac{\beta}{\beta+1}
$$

Em membranas onde a interação com os íons da solução forem descritos pelo método de associação e dissociação do grupo anfótero, essas equações são válidas ${ }^{(19)}$.

\subsection{Adsorção}

A adsorção é um fenômeno físico-químico de transferência no qual os componentes que estão em fase líquida ou gasosa (adsorvatos) são 
transferidos para a superfície de uma fase sólida (adsorvente). A remoção das moléculas a partir da superfície é chamada de dessorção. A migração destes componentes de uma fase para outra tem como força motriz a diferença de concentrações entre o fluído e a superfície do adsorvente. Devido à existência de forças atrativas não compensadas na superfície do adsorvente, as moléculas da fase fluída são atraídas para a zona interfacial ${ }^{(32 ; 33 ; 34 ; 35)}$.

O equilíbrio termodinâmico é controlado pela seletividade do adsorvente e pela seletividade cinética, ou seja, pela difusão da fase fluida nos poros do adsorvente ${ }^{(32 ; 36)}$. As forças que atraem o adsorvato podem ser físicas ou químicas. A adsorção física ou fisiossorção constitui a maioria dos processos de purificação e separação. Nesse processo a adsorção é sempre reversível e exotérmica. Normalmente se observa mais de uma camada de adsorvato sobre a superfície do adsorvente. As forças que atuam nessa adsorção física são as forças de repulsão e dispersão de van der Waals e as interações eletrostáticas de polarização, dipolo e quadrupolo. A energia liberada é relativamente baixa já que as moléculas estão mais fracamente ligadas à superfície. $O$ equilíbrio é encontrado rapidamente ${ }^{(32 ; 34 ; 37 ; 38)}$.

$\mathrm{Na}$ adsorção química ou quimiossorção as moléculas do adsorvato reagem quimicamente com a superfície do adsorvente através da formação de ligações químicas e tendem a se acomodarem em sítios que propiciem o maior número de coordenação possível com o substrato. Nesse fenômeno de superfície os elétrons entre as moléculas e o sólido experimentam reordenamento e os orbitais respectivos mudam de forma, de modo a simular uma reação química. Nessa adsorção ocorre somente a formação de uma camada sobre a superfície sólida ${ }^{(32 ; 34 ; 39)}$. A adsorção química é denominada dissociativa quando ocorre a ruptura de ligações entre átomos da molécula adsorvida ${ }^{(32 ; 40)}$.

Os fenômenos de adsorção são resultados de uma combinação entre os tipos de forças envolvidas nas adsorções física e química. Os fatores que influenciam no processo de adsorção são: a área superficial, as propriedades do adsorvente e do adsorvato, a temperatura do sistema e o pH do meio.

A intensidade da adsorção é proporcional à área superficial específica. Para partículas maiores, a resistência à difusão é maior e grande parte da superfície interna da partícula não é disponibilizada para adsorção ${ }^{(32 ; 41)}$. A 
natureza físico-química do adsorvente é um fator determinante. A capacidade e a velocidade de adsorção dependem da área superficial específica, porosidade, volume específico de poros, distribuição de tamanho de poros, dos grupos funcionais presentes na superfície do adsorvente e da natureza do material precursor $^{(32 ; 39 ; 42)}$. O tamanho da molécula do adsorvato é sempre importante quando a velocidade de adsorção depende do transporte intraparticular. Outra característica de forte influência do adsorvato é a sua polaridade, pois o soluto polar terá maior afinidade ou com o solvente ou com o adsorvente ${ }^{(32 ; 39)}$.

Em processos de adsorção, o efeito da temperatura sobre o sistema afeta principalmente a constante de velocidade de adsorção. Um aumento na temperatura pode ocasionar um aumento de energia cinética e na mobilidade das moléculas do adsorvato e ainda provocar um aumento na taxa de difusão intrapartícula do adsorvato ${ }^{(32 ; 43)}$. O aumento na temperatura pode afetar a solubilidade e o potencial químico do adsorvato. Desta forma, a alteração na temperatura de um processo conduz a uma mudança na capacidade de adsorção ${ }^{(44)}$.

$\mathrm{O}$ pH afeta a adsorção na medida em que determina o grau de ionização de compostos ácidos ou básicos. A intensidade desse efeito pode ser maior ou menor conforme o adsorvente, uma vez que as cargas da superfície do adsorvente dependem da sua composição e das características da superfície. Um índice conveniente da tendência de uma superfície se tornar positivamente ou negativamente carregada em função do $\mathrm{pH}$ é o valor do $\mathrm{pH}$ no ponto chamado de carga zero $\left(\mathrm{pH}_{\mathrm{pcz}}\right)$ onde a carga líquida do adsorvente é nula. Para valores de $\mathrm{pH}$ inferiores a esse ponto de carga zero a carga superficial é positiva e a adsorção de ânions é favorecida. Já para valores de $\mathrm{pH}$ superiores ao ponto de zero carga a carga superficial é negativa e a adsorção de cátions é favorecida ${ }^{(32 ; 45 ; 46)}$.

\subsection{FTO}

Para a construção de um biossensor de pH utilizando EGFET, é necessário a escolha de um material para ser utilizado como membrana sensível a íons e portanto, sensível a variação de $\mathrm{pH}$, para o EGFET, e que possua alta condutividade elétrica e que seja composto com um bom número 
de sítios para que seja possível agregar moléculas para funcionalização do filme. O FTO, sigla em inglês para óxido de estanho dopado com flúor, é uma boa alternativa para utilização como membrana sensível para o EGFET.

O estanho (Sn) possui como forma mais comum encontrada na natureza a cassiterita, que é o óxido de estanho $\left(\mathrm{SnO}_{2}\right)$. Esse material possui forma cristalina e é um material semicondutor do tipo-n, onde sua condutividade elétrica é causada por buracos na subrede de oxigênio. $\mathrm{O} \mathrm{SnO}_{2}$ possui gap de energia em torno de $3,6 \mathrm{eV}^{(47)}$.

Existe uma ampla utilização do $\mathrm{SnO}_{2}$ como filme fino em substrato de vidro sendo geralmente dopado com o intuito de diminuir a resistividade dos filmes finos, ocorrendo assim um aumento da condutividade desses filmes. A dopagem pode ser realizada com o flúor devido à similaridade entre os raios atômicos do flúor e do oxigênio $\left(\mathrm{O}_{2}\right)$, podendo então substituir o oxigênio pelo flúor no óxido de estanho agindo agora como doador de um elétron livre por átomo substituído ${ }^{(48)}$.

O FTO é um material transparente e possui várias aplicações tecnológicas, como por exemplo, o uso em células solares, dispositivos eletroluminescentes, sensores de gás, superfícies eletrocrômicas, etc ${ }^{(49)}$.

\subsection{Objetivo}

Este trabalho possui como objetivo o estudo da influência de agentes externos nas medidas de corrente e sensibilidade de filmes finos de FTO depositados sobre substrato de vidro para serem utilizados como membranas sensíveis a íons $\mathrm{H}^{+}$utilizando o EGFET. As considerações estudadas são: I) a evolução da medida no tempo; II) o efeito da iluminação; III) o efeito da alteração da área de contato do filme fino de FTO com a solução de pH; e IV) o efeito da alteração da temperatura da solução de $\mathrm{pH}$.

A utilização de filmes finos de FTO como membranas seletivas do EGFET é de grande importância na área biomédica. Todos os esforços deste trabalho têm como objetivo futuro otmizar os parâmetros para a utilização como biossensor de $\mathrm{pH}$ para uso médico, agilizando o diagnóstico de diversas doenças. 


\section{Capítulo 3 - Materiais e Métodos}

\subsection{Materiais}

\subsubsection{Amostras}

As amostras foram utilizadas como a membrana sensível a íons do EGFET e eram compostas de FTO depositado sobre um substrato de vidro feito de lâmina de microscópio comum, sendo o FTO depositado pelo método

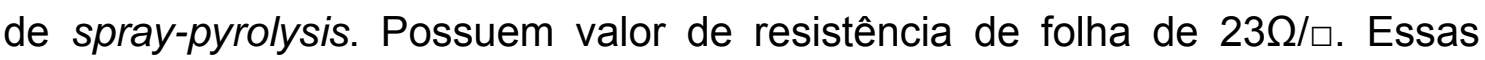
amostras foram fornecidas pelo professor Ivo Alexandre Hummelgen do Departamento de Física da Universidade Federal do Paraná.

As amostras foram produzidas a partir de uma lâmina de vidro com o FTO depositado. Essa lâmina foi cortada em diferentes tamanhos, sendo uma amostra com seis milímetros de largura e dez milímetros de comprimento, que foi chamada de amostra Al1, uma amostra com dezesseis milímetros de largura superior e doze e meio de largura inferior e dez milímetros de comprimento, chamada de amostra Al2, outra com dez milímetros de largura e vinte milímetros de comprimento, chamada de amostra $\mathrm{Al} 3$ e a última com dez milímetros de largura e vinte e seis milímetros de comprimento, sendo chamada de amostra Al4, como mostrado na figura 3.1. A sigla Al foi escolhida para facilitar o entendimento dos resultados e significa Amostra Independente. Em todas as amostras o contato elétrico entre o fio e o filme foi feito colando-se um fio de cobre no filme com cola condutora feita a base de partículas de prata. Este contato elétrico foi isolado com um adesivo epóxi para que não entrasse em contato com a solução. Para todas as amostras esse isolamento possuía três milímetros de largura. A área efetiva total de cada amostra está apresentada na tabela 3.1. 

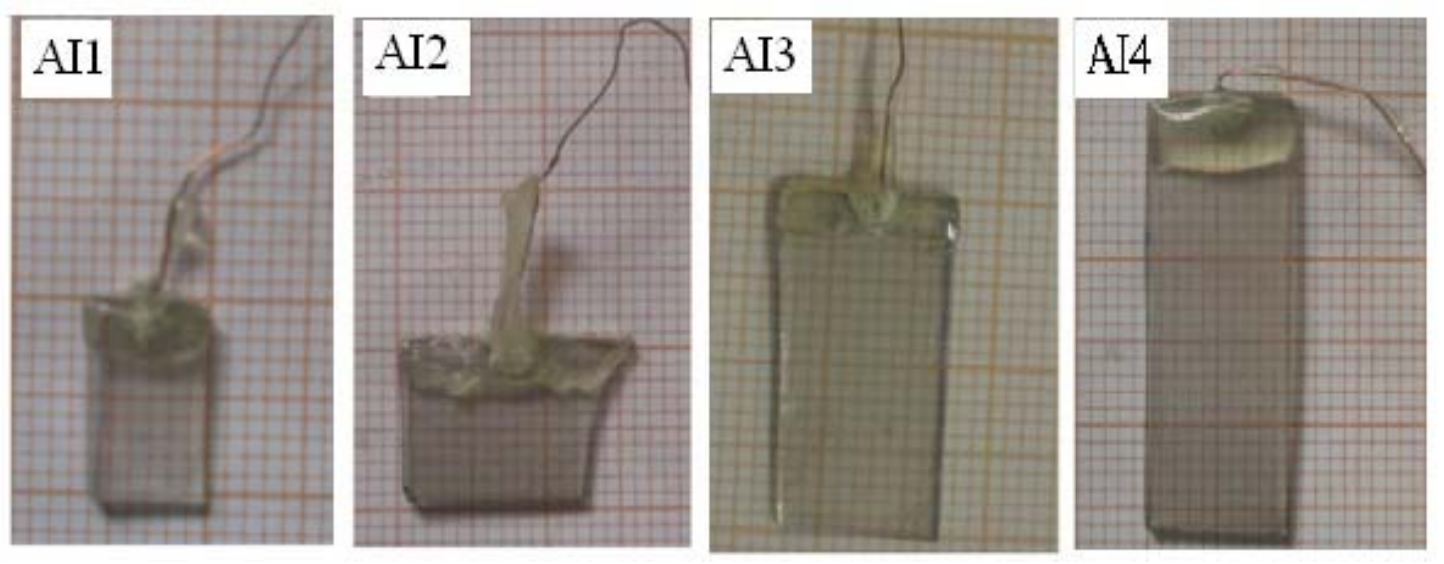

Figura 3.1: Amostras Al1 - Al4

\begin{tabular}{|c|c|c|c|c|c|}
\hline Amostra & $\begin{array}{c}\text { Largura }\left(\mathrm{mm}^{2}\right) \\
\left( \pm 0,25 \mathrm{~mm}^{2}\right)\end{array}$ & $\begin{array}{c}\text { Comprimento } \\
\left(\mathrm{mm}^{2}\right) \\
\left( \pm 0,25 \mathrm{~mm}^{2}\right)\end{array}$ & $\begin{array}{c}\text { Área Total } \\
\left(\mathrm{mm}^{2}\right) \\
\left( \pm 0,25 \mathrm{~mm}^{2}\right)\end{array}$ & $\begin{array}{c}\text { Área Epóxi } \\
\left(\mathrm{mm}^{2}\right) \\
\left( \pm 0,25 \mathrm{~mm}^{2}\right)\end{array}$ & $\begin{array}{c}\text { Área Efetiva } \\
\left(\mathrm{mm}^{2}\right) \\
\left( \pm 0,25 \mathrm{~mm}^{2}\right)\end{array}$ \\
\hline Al1 & 6 & 10 & 60 & 18 & 42 \\
\hline Al2 & $\begin{array}{c}16 \text { (superior) } \\
12,5 \text { (inferior) }\end{array}$ & 10 & 142,5 & 42,75 & 99,75 \\
\hline Al3 & 10 & 20 & 200 & 30 & 170 \\
\hline Al4 & 10 & 26 & 260 & 30 & 230 \\
\hline
\end{tabular}

Tabela 3.1: Dimensões das amostras Al1 - Al4

\subsubsection{Outros Materiais e Equipamentos Utilizados}

As soluções utilizadas nos experimentos foram soluções tampão da marca Cinética. Essas soluções foram utilizadas para mergulhar os filmes de FTO e o eletrodo de referência como mostra a figura 3.2. Foram utilizadas soluções tampão com diferentes pHs, sendo utilizados os pHs 2, 4, 6, 7, 8, 10 e 12.

Para a realização das medições as amostras eram totalmente mergulhadas na solução tampão, deixando-se de fora somente a parte que continha a cola epóxi. 


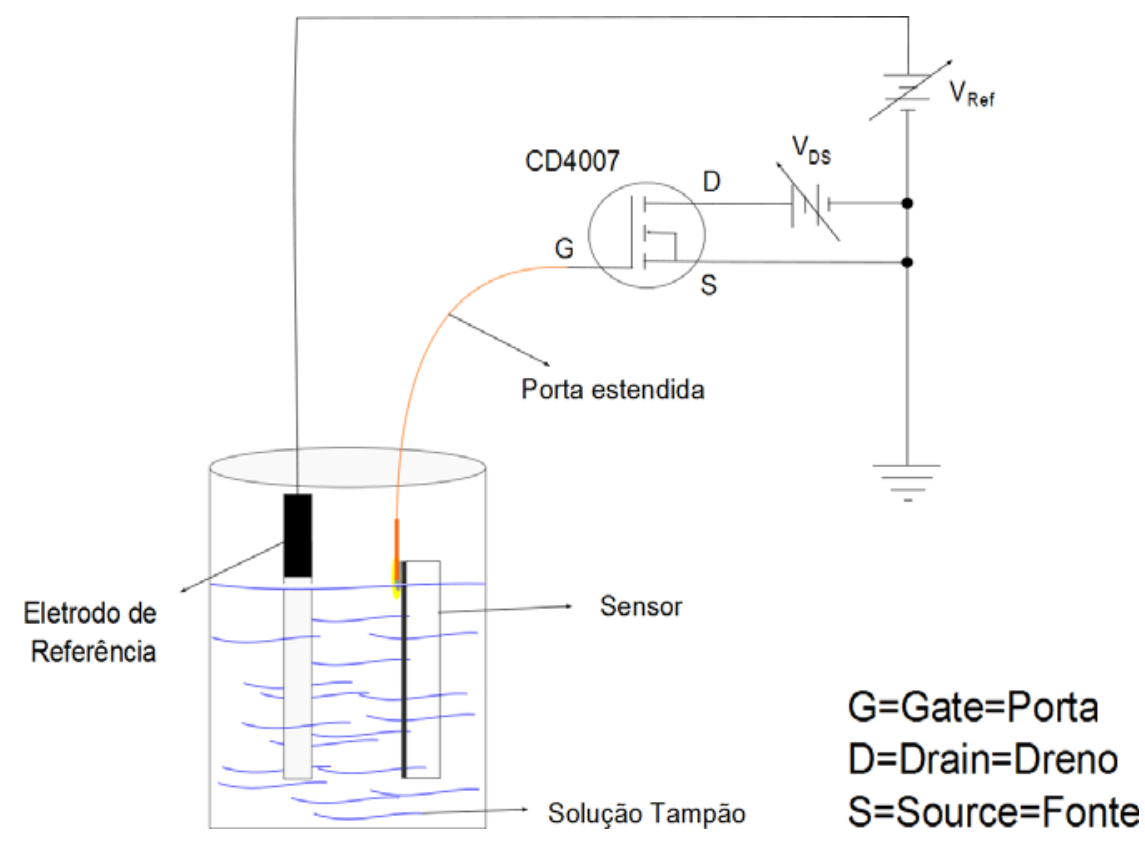

Figura 3.2: Desenho esquemático da configuração do sistema de medições utilizado ${ }^{(12)}$

O MOSFET comercial utilizado para a confecção do EGFET foi o CD4007 da Texas Instruments, sendo composto de seis MOSFETs internos (três de canal $\mathrm{n}$ e três de canal $\mathrm{p}$ ), mas só foi utilizado um dos MOSFETs de canal n. O datasheet do CD4007 está anexo no apêndice A.

O amperímetro utilizado foi o Data Aquisition HP 34970A e o Agilent E3646A Dual Output DC Power Supplies foi utilizado tanto para as fontes variáveis de tensão continua como para a obtenção do terra virtual. Ambos os equipamentos foram interligados a um computador que recebia os dados obtidos pelos equipamentos, sendo estes dados tratados com o programa OriginPro 8, do qual possuímos a devida licença.

A manutenção dos valores dos $\mathrm{pHs}$ utilizados foi feita com um pHmetro e quando necessário titulou-se as soluções tampão com uma solução de $\mathrm{NaOH}$ ou $\mathrm{HCl} 0,1 \mathrm{M}$.

Para o estudo do efeito da iluminação foram utilizados 14 LEDs brancos com $5 \mathrm{~mm}$ de diâmetro cada conectados a uma fonte de tensão variável. A fonte de tensão variável é da marca Instrutherm DC Power Supply FA-3005. Os dados utilizados durante as medições foram: tensão de $6 \mathrm{~V}$, corrente de $20 \mathrm{~mA}$ e potência de $120 \mathrm{~mW}$. 
Para o estudo do efeito da temperatura utilizou-se um agitador magnético com aquecimento da marca Fisatom, modelo 752A.

Todas as medições foram realizadas dentro de uma caixa hermeticamente isolada para que não houvesse influência da luz externa.

\subsection{Métodos}

\subsubsection{Preparação das Amostras}

As amostras foram lavadas com água deionizada tipo Milli-DI por um aparelho da marca MILLIPORE. Esse aparelho assegura a resistência da água filtrada de $\geq 1 \mathrm{M} \Omega$.cm. As amostras eram limpas com água deionizada corrente por 15 minutos para completa retirada de excesso de íons provenientes das soluções tampão utilizadas durante as medições anteriores. As amostras eram limpas sempre antes de qualquer medição e entre duas medições consecutivas para assegurar as mesmas condições iniciais. A secagem das amostras era feita através de uma mangueira conectada na saída de uma bomba de vácuo da marca Tecnal TE-058. Na ponta dessa mangueira estava conectada uma ponteira de plástico de pipeta com algodão dentro da ponteira para filtrar possíveis sujeiras. Durante toda a manipulação das amostras foram utilizadas luvas de látex sem adição de talco, para não haver contaminação das amostras.

\subsubsection{Medições}

Foram feitas basicamente três tipos de medições. A primeira chamada de VDS é feita variando-se a tensão entre o dreno e a fonte do transistor $\left(V_{d s}\right)$ e mantendo-se fixa a voltagem entre o gate e a fonte $\left(V_{g s}\right)$ e então obtendo-se e anotando-se a corrente entre o dreno e a fonte, sendo esta corrente chamada de $I_{\text {ds. }}$. A segunda medição chamada de VGS, que é feita variando-se a tensão entre o gate e a fonte do transistor $\left(V_{g s}\right)$ e mantendo a tensão entre dreno e a fonte fixa $\left(V_{d s}\right)$ e assim obtendo-se e anotando-se a corrente entre o dreno e a fonte $\left(I_{d s}\right)$. A terceira medição, chamada de medição no tempo, fixou-se um 
valor diferente de zero para as voltagens $V_{d s}$ e $V_{g s}$ e mediu-se a corrente $I_{d s}$ continuamente por um determinado período de tempo.

\subsubsection{Tempo}

A medição no tempo foi realizada mantendo tanto $V_{d s}$ quanto $V_{g s}$ fixas em 5V. Ao aplicar as duas tensões ao mesmo tempo fazia-se a leitura do valor da corrente $I_{d s}$. Essa medição se repetia copiosamente até chegar ao número de pontos escolhido. Cada ponto era medido a um intervalo de 1 segundo. Foram utilizados 600 pontos, sendo o tempo total de medição de 10 minutos.

\subsubsection{Iluminação}

Para o estudo do efeito da iluminação as medições foram realizadas tanto no escuro (dentro da caixa hermeticamente fechada) quanto no claro (dentro da caixa hermeticamente fechada porém com a fonte de iluminação ligada). Essa medição chamada medição no claro mostra a influência que a luz UV-VIS exerce sobre o filme. A fonte de iluminação poderia ser ligada ou desligada sem que fosse necessária a abertura da caixa.

\subsubsection{3. Áreas}

As medições referentes ao estudo das áreas foram feitas de duas formas diferentes.

\subsection{Mesma Amostra}

Utilizou-se somente a amostra Al4. Com uma caneta foram marcadas na parte lateral do vidro da amostra (sem contato com o filme de FTO) diferentes áreas, como mostrado na tabela 3.2. 


\begin{tabular}{|c|c|}
\hline Nome & Área $\left(\mathrm{mm}^{2} \pm 0,25 \mathrm{~mm}^{2}\right)$ \\
\hline AM1 & 60 \\
\hline AM2 & 120 \\
\hline AM3 & 170 \\
\hline AM4 & 230 \\
\hline
\end{tabular}

Tabela 3.2: Áreas efetivas nos sistemas de medições SM1-D e SM1-C

As amostras eram mergulhadas na solução tampão de duas formas diferentes, sendo a primeira forma chamada de medição SM1-D (Sistema de Medições 1 na forma Decrescente, pois vai da maior área para a menor área) onde a amostra Al4 era totalmente mergulhada na solução tampão e então era feita a medição (chamada de medição AM4, de Amostra Múltipla), depois se retirava uma parte da amostra da solução tampão até que se chegasse a primeira marca, diminuindo então a superfície de contato do filme com a solução e então realizava-se a medição, chamada de medição $A M 3$, depois retirava-se novamente mais um pedaço da amostra até a segunda marca diminuindo-se mais ainda a superfície de contato com a solução tampão e fazia-se a medição, chamada de medição AM2 e por fim retirava-se mais um pedaço da amostra até a última marca e fazia-se a medição, nomeada de medição AM1, como mostra na figura 3.3.

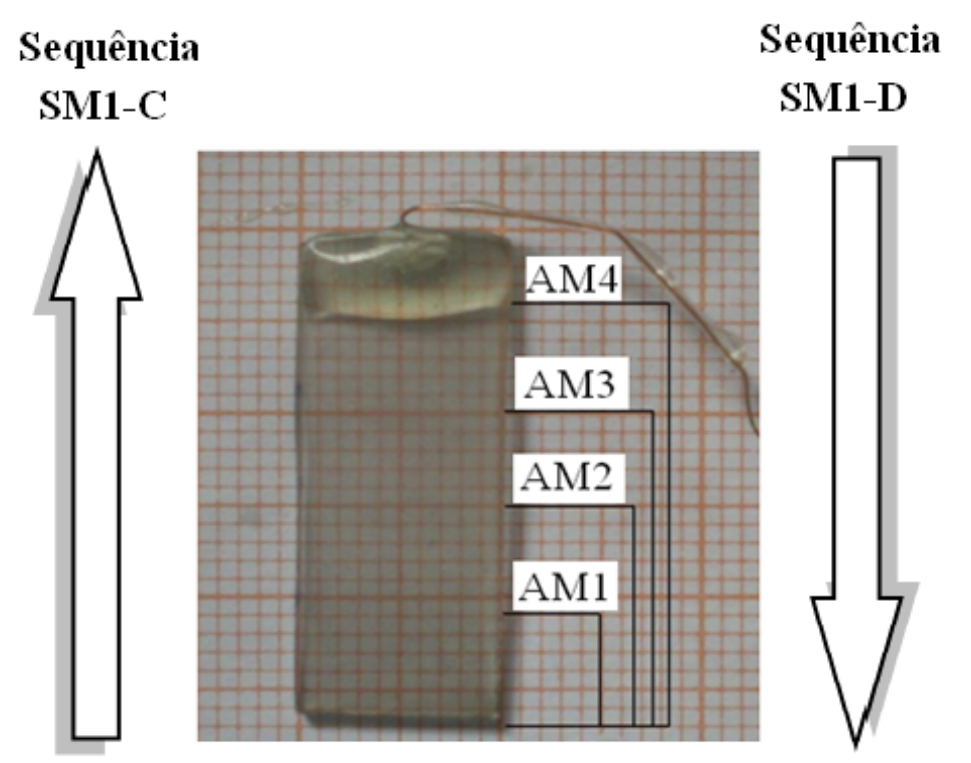

Figura 3.3: Áreas efetivas AM1 - AM4 
A segunda forma, chamada de SM1-C (Sistema de Medições 1 na forma Crescente, pois vai da menor área para a maior área), é o inverso da primeira medição, explicada acima. Primeiro mergulhava-se somente um pequeno pedaço da amostra na solução tampão, até que se chegasse ao que chamamos de última marca e fazia-se a medição, chamada então de medição AM1, depois se inseria mais um pedaço da amostra na solução tampão até a chamada segunda marca, aumentando-se assim a superfície de contato do filme com a solução tampão e realizava-se a medição, chamada então de medição AM2, depois se inseria mais um pedaço da amostra na solução tampão até a chamada primeira marca, aumentando-se mais ainda a superfície de contato do filme com a solução tampão e realizava-se a medição, chamada de medição AM3, e por último, inseria-se toda a amostra na solução tampão, deixando toda a sua superfície de contato disponível em contato com a solução tampão e então realizava-se a medição, chamada então de medição AM4.

\subsection{Diferentes Amostras}

Já nesse conjunto de medições foram utilizadas quatro amostras de tamanhos diferentes, as chamada amostras Al1, Al2, Al3 e Al4. Essas amostras, por possuírem diferentes tamanhos, foram colocadas inteiras na solução tampão, exceto a área com a cola epóxi que contém o contato metálico, e então foi realizada a medição.

\subsubsection{Temperatura}

A fim de se estudar o efeito da variação da temperatura na resposta do sensor utilizado foi construído o esquema de medições como mostra a figura 3.4: 


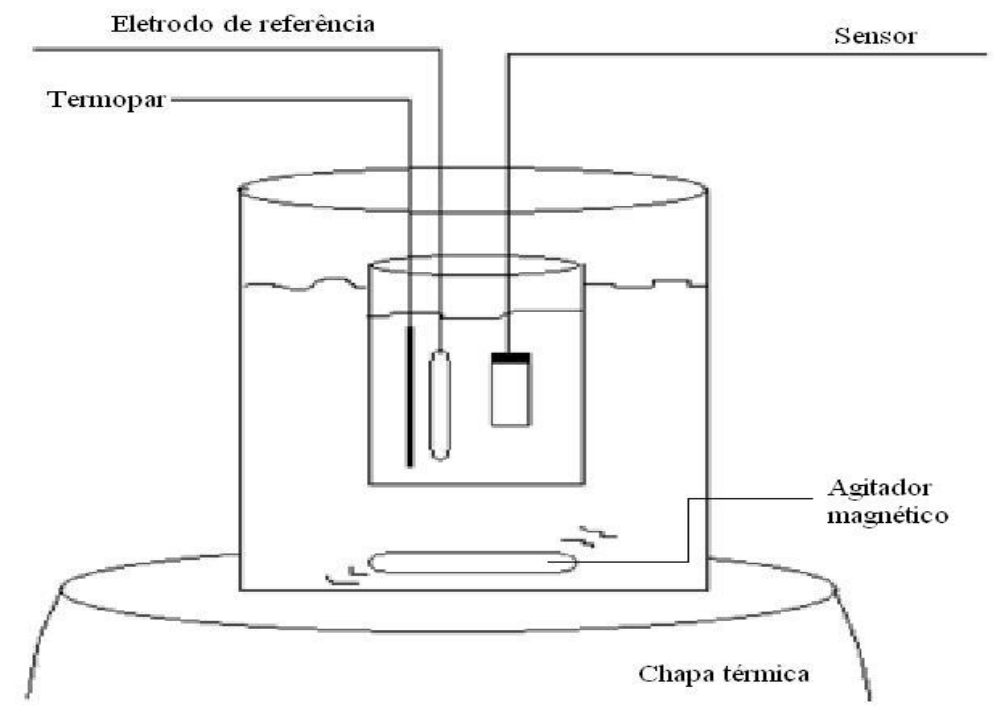

Figura 3.4: Desenho esquemático para estudo do efeito da temperatura

Como verificado pelo esquema da figura acima, o sensor, o eletrodo de referência e o termopar foram colocados dentro da solução tampão. Este conjunto estava submerso em outro béquer contendo água e um agitador térmico. Todo esse conjunto então estava em cima de uma chapa térmica que também possui agitador magnético. A chapa térmica fornecia a temperatura desejada, que era verificada pelo termopar, e o agitador magnético tinha como função manter toda a água em uma mesma temperatura, garantindo assim que toda a solução tampão estava em uma mesma temperatura. Todo esse aparato estava dentro de uma caixa hermeticamente fechada para a medição não sofrer influência da luz externa.

Todas as medições realizadas, exceto a medição em função da temperatura, foram feitas a $25^{\circ} \mathrm{C}$.

\subsection{Procedimentos de Coleta e Análises dos Dados}

Os valores máximos de tensão utilizados nas medições foram de $5 \mathrm{~V}$. $\mathrm{Na}$ medição chamada VDS o valor da tensão variava de 0 a $5 \mathrm{~V}$ mantendo o valor de $V_{g s}$ fixo em $5 \mathrm{~V}$. Já a medição $V G S$ o valor da tensão variava de 0 a $5 \mathrm{~V}$ mantendo o valor de $V_{\text {ds }}$ fixo em $5 \mathrm{~V}$. Esses valores foram escolhidos devido à melhor relação sinal/ruído encontrada para esse dispositivo, como pode ser verificada na referência (12), p.38-39. 
Após a realização das medições os dados foram analisados utilizando o programa OriginPro 8. As respostas típicas obtidas para cada tipo de medição são observadas nas figuras 3.5, 3.6 e 3.7 .

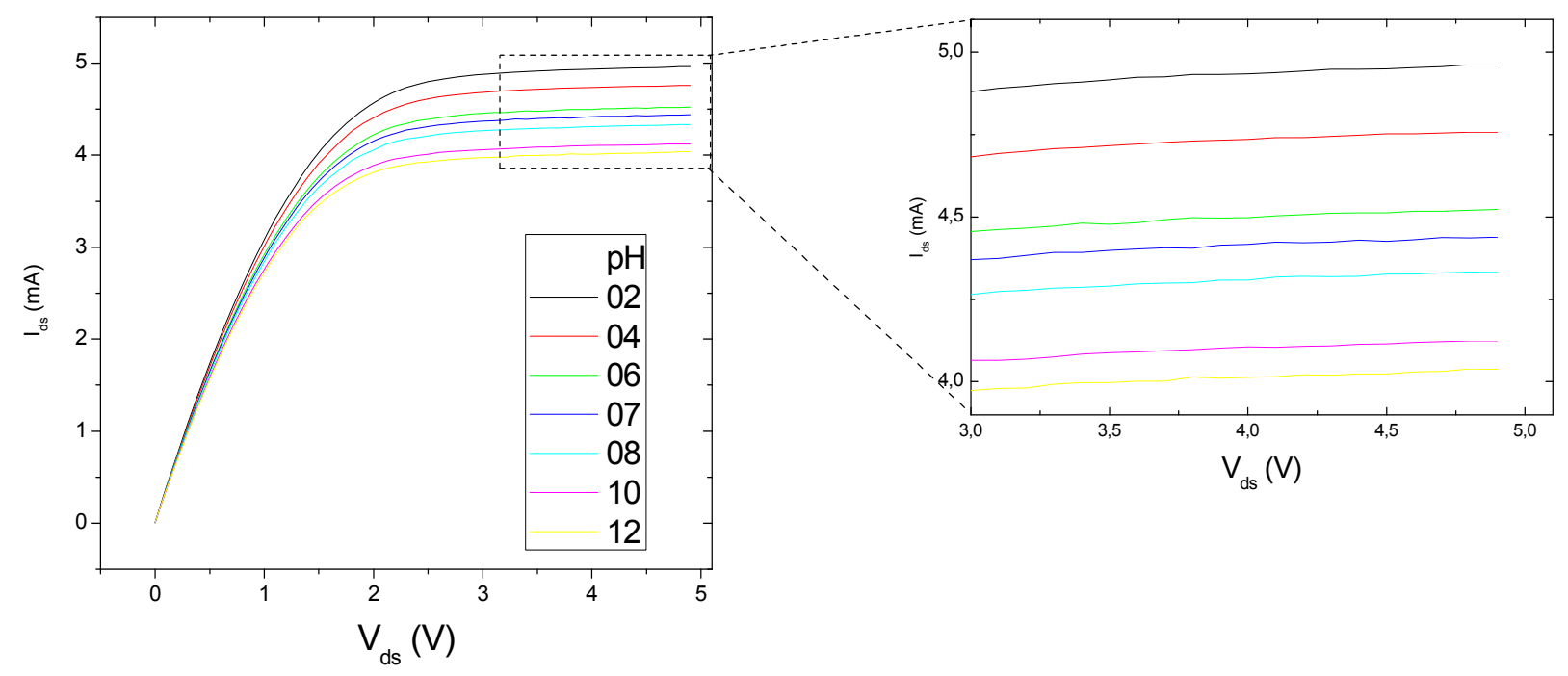

Figura 3.5: Resposta típica da medição VDS para vários valores de $\mathrm{pH}$

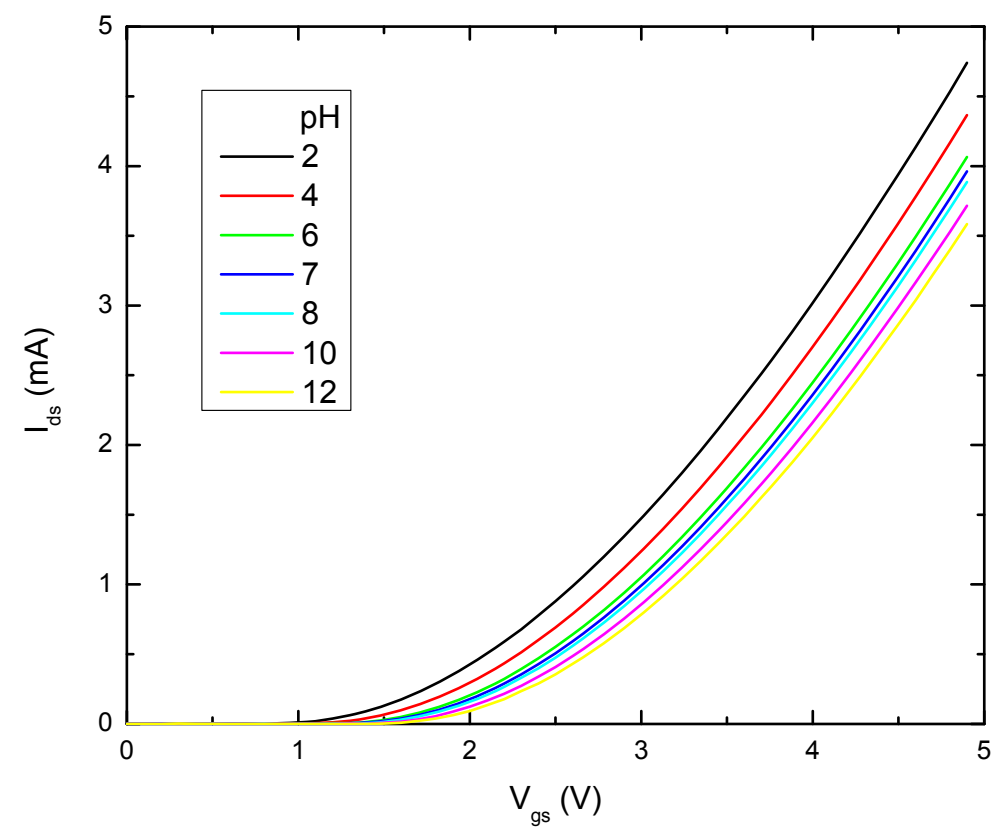

Figura 3.6: Resposta típica da medição VGS para vários valores de pH 


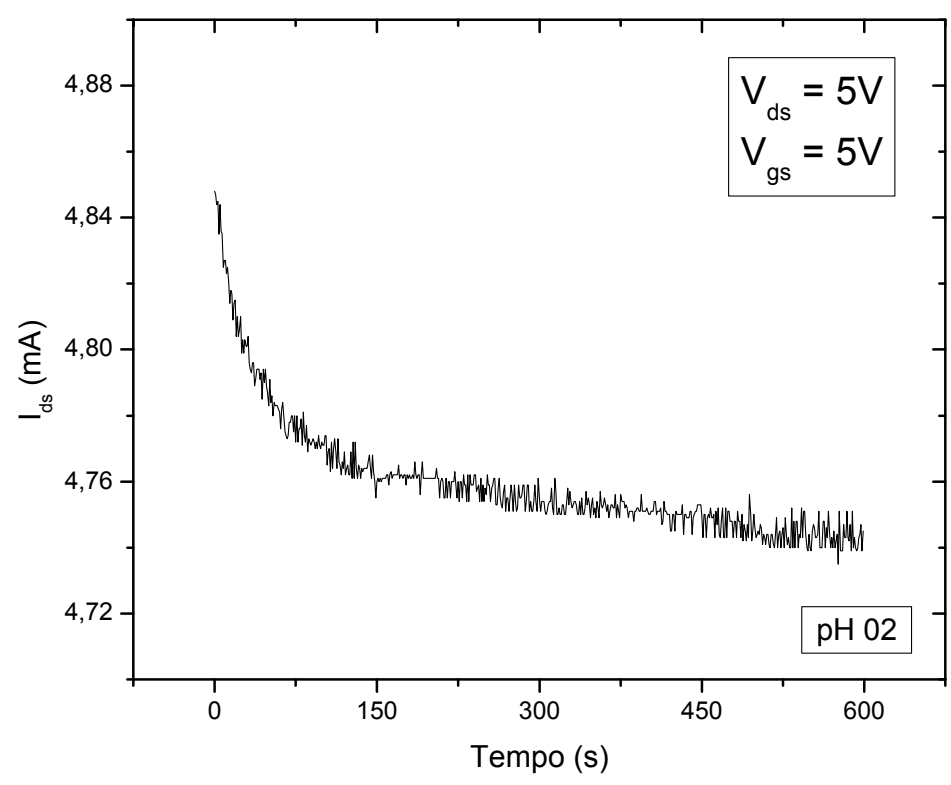

Figura 3.7: Resposta da medição no tempo para o pH 02

As figuras 3.5 e 3.6 mostram a resposta do EGFET em relação ao sistema de medições utilizado e a dependência que existe em função do $\mathrm{pH}$ utilizado. A figura 3.5 é a resposta típica quando fazemos a medição chamada VDS e a figura 3.6 é a resposta típica quando fazemos a medição chamada VGS. A parte evidenciada na figura 3.5 é a parte onde a corrente $I_{d s}$ já está saturada. Quanto maior a concentração de íons $\mathrm{H}^{+}$na solução maior será a resposta em corrente do sensor. As cargas dentro da solução analítica na presença da amostra utilizada se distribuem como mostrado na figura 3.8. 


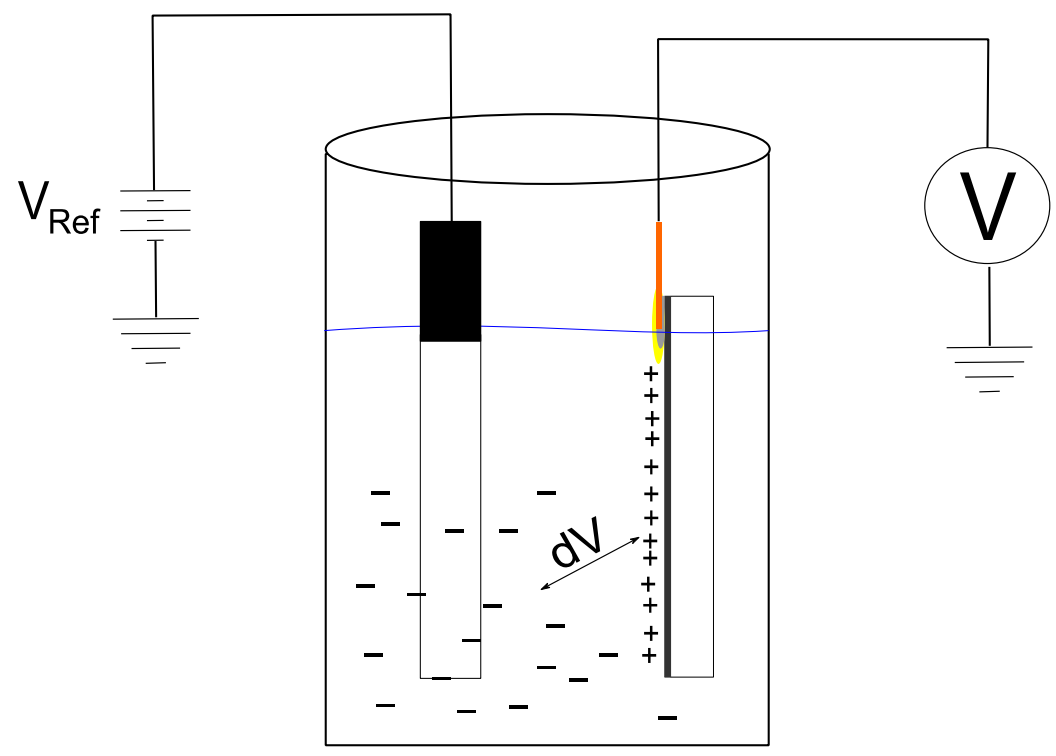

Figura 3.8: Desenho esquemático da acomodação das cargas na presença da amostra. dV é a diferença de potencial entre os íons da superfície do sensor e os íons no interior da solução, Vref é a tensão aplicada ao eletrodo de referência e $V$ é a tensão no voltímetro. ${ }^{(12)}$

Existe uma tendência a óxidos se ligarem a íons hidroxilas. Segundo a literatura (12) quando a amostra entra em contato com moléculas de água, tanto da solução quanto as do processo de limpeza, essas moléculas de água são atraídas para a superfície da amostra pelo óxido de estanho. Essas moléculas de água formam uma espécie de folha d'água eletricamente neutra e serve como sítios livres de ligação capazes de adsorver íons $\mathrm{H}^{+}$, formando íons hidrônios $\left(\mathrm{H}_{3} \mathrm{O}^{+}\right)$, e toda essa região adjacente a superfície da amostra envolvida pela folha d'água e pelos íons adsorvidos nessa folha formarão uma camada chamada de dupla camada ${ }^{(19 ; 20 ; 21 ; 22 ; 23)}$.

De uma forma mais simples, as cargas positivas se deslocam para perto do filme criando uma barreira de cargas positivas entre o filme e a solução, fazendo com que no interior da solução exista um excesso de cargas negativas, como mostrado na figura 3.8. Como ocorre essa separação de cargas existirá então uma diferença de potencial entre a superfície do filme e o interior da solução, chamada de dV. Quando aplicada uma diferença de potencial a solução pelo eletrodo de referência com relação ao terra, obtemos o chamado $V_{\text {ref. }}$ Portanto, o valor "lido" da diferença de potencial da amostra em relação ao terra $\left(V_{g s}\right)$ será o valor do $V_{\text {ref }}$ acrescido do valor $d V\left(V_{g s}=V_{\text {ref }}+d V\right)$. 
Portanto, quanto maior a oferta de íons $\mathrm{H}^{+}$, maior será $\mathrm{dV}$ e a corrente medida terá uma maior amplitude, como verificado nas figuras 3.5 e 3.6.

A figura 3.7 é a resposta típica obtida quando fazemos a medição chamada medição no tempo. Nessa medição, como já explicado anteriormente, mantêm-se fixas as voltagens $V_{g s}$ e $V_{d s}$ e mede-se a corrente repetidamente por um determinado intervalo de tempo.

A figura 3.5 possui uma região de saturação do transistor. Essa região tem a corrente $I_{d s}$ explicada pelas seguintes equações ${ }^{(13)}$ :

Na região de saturação ${ }^{(13)}$ :

$$
I_{D S}=\frac{\mu_{0} C_{O X}}{2} \cdot \frac{W}{L} \cdot\left(V_{R e f}-V_{T}\right)^{2} \cdot\left(1+\lambda V_{D S}\right)
$$

Onde $\mu_{0}$ é a mobilidade eletrônica do canal do transistor, $C_{O X}$ é a capacitância devido a presença do óxido no gate por unidade de área, $\frac{W}{L}$ é a razão espessura/comprimento do canal do transistor, $V_{R e f}$ é a tensão aplicada ao eletrodo de referência, $V_{T}$ é a tensão devido a adsorção dos íons $\mathrm{H}^{+}$do sensor, $\lambda$ é o fator de modulação do comprimento do canal do transistor e $V_{D S}$ é a tensão aplicada entre o dreno e a fonte. A equação (3.1) pode ser reescrita na forma ${ }^{(13)}$ :

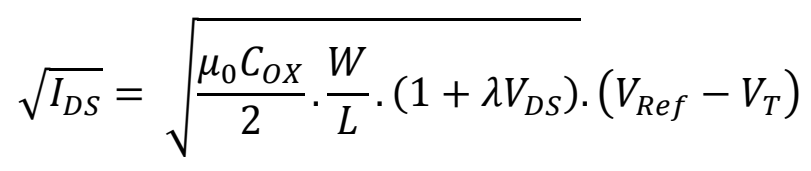

Portanto, pela equação (3.2) podemos observar que a relação entre a raiz quadrada da corrente $I_{d s}$ e a tensão de referência $V_{\text {ref }}$ é linear. Quando plotamos o gráfico de $\sqrt{I_{D S}}$ pelo valor do $\mathrm{pH}$ podemos verificar a linearidade da região de saturação e a sensibilidade do sensor, que está associada à inclinação da reta que une os pontos. Quanto maior o espaçamento médio entre as linhas do gráfico, maior a sensibilidade do sensor. 
Para adquirirmos a sensibilidade do sensor em unidades de $\mathrm{mV} / \mathrm{pH}$ utilizamos o gráfico da medição de $\mathrm{V}_{\mathrm{gs}}$, como mostrado na figura 3.9. A região linear de $\mathrm{V}_{\mathrm{gs}}$ depende linearmente do $\mathrm{pH}$, quando fixado o valor da corrente $I_{\mathrm{ds}}$.

Fixa-se um ponto na região linear (neste caso foi fixado $I_{\text {ds }}$ igual a $2 \mathrm{~mA}$ ) e o valor correspondente de $V_{g s}$ no ponto escolhido é plotado em função do valor do $\mathrm{pH}$ como mostrado na figura 3.10. Quando fazemos o ajuste linear dos pontos obtemos a sensibilidade do sensor como sendo o valor da tangente.

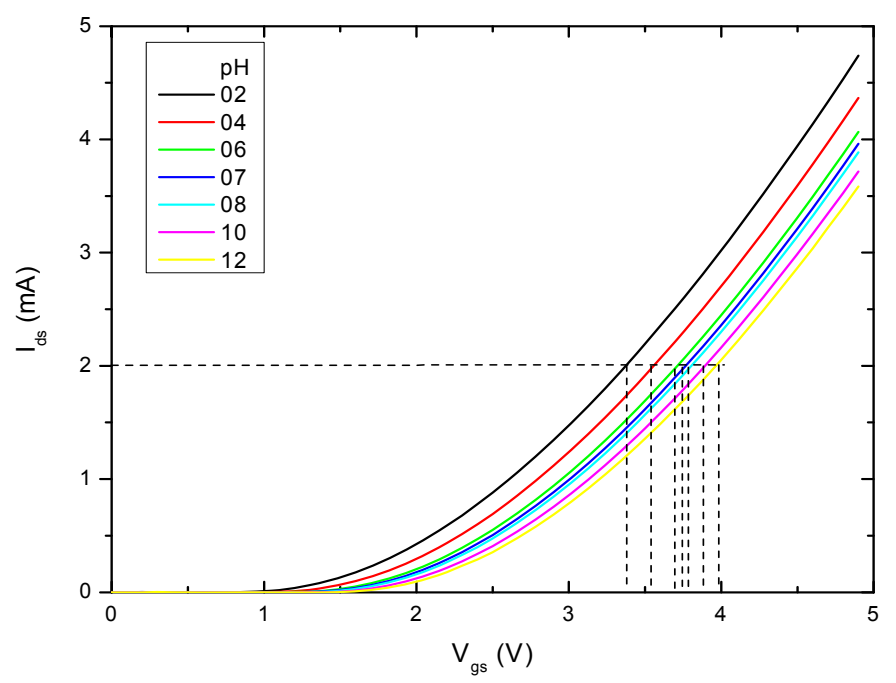

Figura 3.9: Valor lido de $\mathrm{V}_{\mathrm{gs}}$ quando $\mathrm{I}_{\mathrm{ds}}$ possui valor de $2 \mathrm{~mA}$

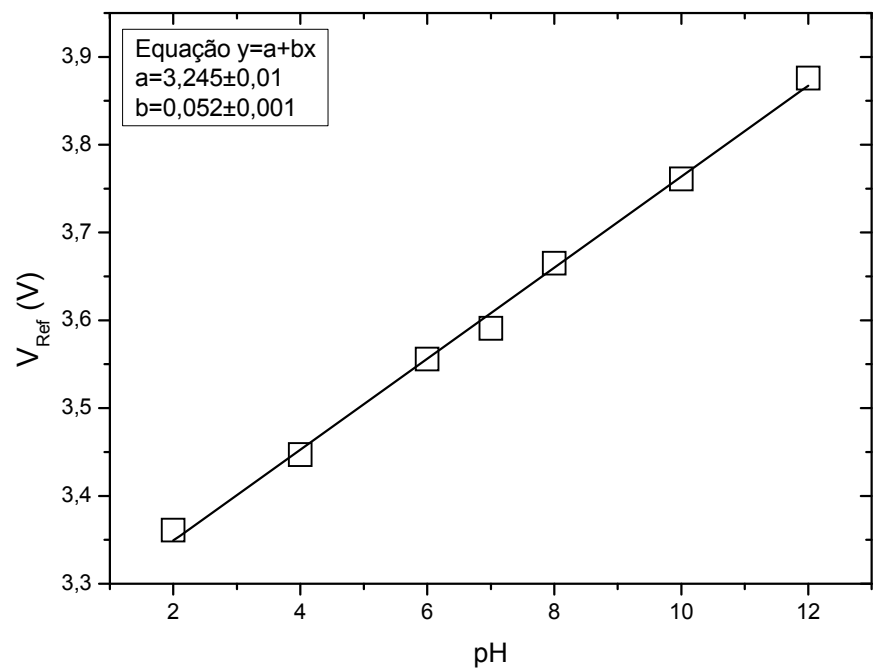

Figura 3.10: Dependência linear da tensão $V_{\text {ref }}$ em função do $p H$ quando $I_{d s}$ fixa 


\section{Capítulo 4 - Resultados e Discussões}

\subsection{Influência do sistema de limpeza}

As limpezas das amostras, para retirada de íons residuais da superfície do filme, foram testadas de duas formas diferentes. A primeira, lavando-se em $\mathrm{pH}$ alcalino, nesse caso no $\mathrm{pH} 12$, chamada de LA (referente à Limpeza Alcalina) e a segunda lavando-se em água corrente e deionizada, cujo $\mathrm{pH}$ utilizado foi 7, chamada de LN (referente à Limpeza Neutra). Para o teste da influência da limpeza sobre a resposta do sensor foi utilizada somente a amostra Al4.

No caso da limpeza LA a amostra era mergulhada em um béquer contendo a solução tampão com pH 12 por um determinado período de tempo, depois a amostra foi secada e então feita a medição em outra solução tampão, que neste caso foram às soluções com pHs 4,7 e 10. Já no caso da limpeza LN a amostra ficava presa para não haver contato com os recipientes e então a amostra foi limpa com água deionizada corrente por um determinado período de tempo, depois a amostra foi secada e então feita a medição em uma solução tampão com pH 04. Em ambos os casos a medição realizada foi a medição chamada VDS. Os períodos de tempo utilizados foram de 30 segundos de limpeza até 10 minutos. Os resultados se encontram na figura 4.1: 


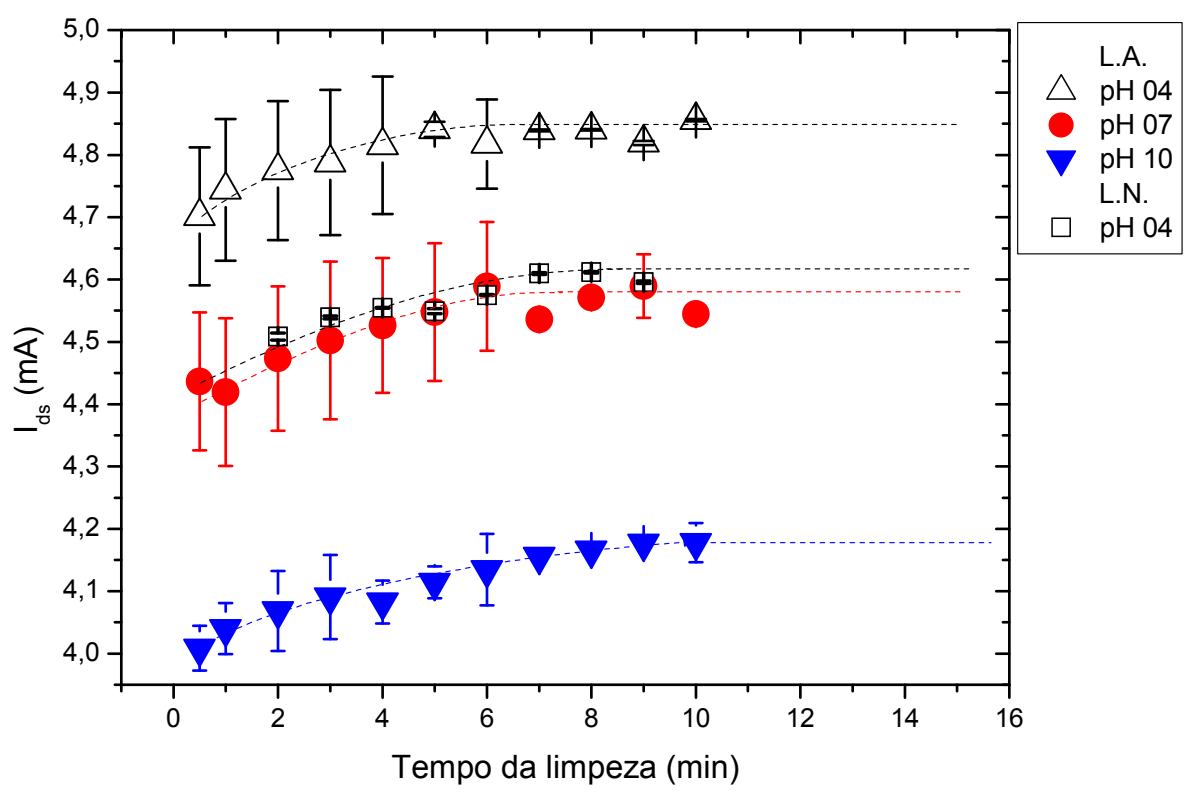

Figura 4.1: Valor da corrente $I_{d s}$ devido à limpeza utilizada. Os pontos da figura 4.1 correspondem ao valor da corrente $\mathrm{I}_{\mathrm{ds}}$ quando $\mathrm{V}_{\mathrm{ds}}$ e $\mathrm{V}_{\mathrm{gs}}$ possuem valor de voltagem igual a $5 \mathrm{~V}$. As siglas LA e LN referem-se respectivamente a limpeza em solução alcalina e limpeza em solução neutra

Pela figura 4.1, pode-se perceber que tanto a limpeza LA quanto a $L N$ tendem a estabilizar o valor final da corrente $I_{d s}$ com o aumento do tempo de limpeza, como sugerido pelas linhas pontilhadas. No entanto, o erro medido parece ser maior quando a limpeza é feita na forma LA, principalmente abaixo de 6 minutos de limpeza. Quando a limpeza da amostra é feita em um $\mathrm{pH}$ alcalino, isto é, com uma grande oferta de íons $\mathrm{OH}^{-}$, essas hidroxilas se ligam quimicamente com os íons $\mathrm{H}^{+}$que estão na superfície da amostra. Essa reação gera moléculas de água neutralizadas. A solução tampão com pH 12 possui uma grande oferta desses íons $\mathrm{OH}^{-}$possibilitando que essa limpeza de caráter químico retire uma grande quantidade de íons $\mathrm{H}^{+}$da superfície. Porém quando esse tipo de limpeza é realizado, a solução está em repouso, isto é, a amostra é colocada dentro de um béquer contendo a solução tampão por um determinado período de tempo e depois é retirada, secada e então feita a medição. Com isso, os íons da solução que estão "longe" da superfície da amostra não entram em contato com os íons da superfície da amostra. Quando a limpeza é feita por um tempo relativamente baixo (pela figura 4.1 podemos 
considerar tempo baixo como um tempo abaixo de 6 minutos) os íons $\mathrm{H}^{+}{\mathrm{e} \mathrm{OH}^{-}}^{-}$ não possuem tempo suficiente para que a reação entre eles ocorra de forma a se obter uma limpeza satisfatória na superfície da amostra. Além do mais, como essa reação ocorre de forma aleatória esse tipo de limpeza não se mostra muito satisfatória possuindo um valor muito grande de erro e demonstrando assim que as medições não são reprodutíveis.

Quando lavamos a amostra com $\mathrm{pH}$ neutro com água corrente, a água corrente consegue retirar os íons que estão mais fortemente ligados a superfície da amostra, mas para que isso ocorra de forma satisfatória a amostra deve ser lavada por no mínimo 8 minutos, como pode ser verificado na figura 4.1. Devido à água utilizada na limpeza ser deionizada, o processo de remoção dos íons não é feito principalmente por reação química como na LA. Esse processo de remoção dos íons devido a água corrente é muito mais eficaz do que o processo de remoção utilizando a solução de $\mathrm{pH}$ alcalina, isso pode ser verificado pelo baixo valor do erro em relação a limpeza anterior. Outro fator responsável pela melhor limpeza em pH 07 é que o ponto isoelétrico do FTO está próximo desse valor de $\mathrm{pH}$. As medições L.N para pHs 07 e 10 possuem o mesmo comportamento que L.N para o pH 04. Com isso os resultados referentes a esses $\mathrm{pHs}$ não estão inclusos na figura 4.1 para melhor visualização dos resultados. A partir de 8 minutos de limpeza, para ambas as formas, o valor da corrente $I_{d s}$ já tende a se estabilizar. A tabela 4.1, retirada da referência (12), mostra o comportamento das amostras em relação ao $\mathrm{pH}$ utilizado na limpeza. 


\begin{tabular}{|c|c|c|}
\hline pH limpeza & $\begin{array}{c}\text { Velocidade de } \\
\text { carregamento das cargas } \\
\text { na superfície da amostra }\end{array}$ & $\begin{array}{c}\text { Resultado com relação ao percentual de cargas dQ para } \\
\text { as configurações de medições crescente e decrescente }\end{array}$ \\
\hline 12 & $\uparrow$ & Dados distintos \\
\hline 07 & $\downarrow$ & Dados distintos \\
\hline 12 & $\downarrow$ & Invariável \\
\hline 07 & $\uparrow$ & Invariável \\
\hline
\end{tabular}

Tabela 4.1 - Resumo comportamental das amostras em relação aos processos de limpeza utilizados. " " representa um valor alto e " $\downarrow$ " representa um valor baixo da grandeza em questão

O autor utilizou duas amostras de FTO com resistividades de folha diferentes, sendo uma de baixa resistividade (5-10 $\Omega / \square)$ e portanto com alta velocidade de carregamento e descarregamento de cargas e outra com alta resistividade (80-100 $\Omega / \square$ ) e portanto com baixa velocidade de carregamento e descarregamento de cargas, como indicado pelas setas na tabela 4.1. Foram realizadas duas formas diferentes de medições, sendo a primeira chamada de medição crescente, onde a ordem das medições foi do menor valor de $\mathrm{pH}$ da solução tampão utilizada para o maior valor de $\mathrm{pH}$ (as soluções de $\mathrm{pH}$ utilizadas possuíam valores de pHs 02, 04, 06, 07, 08, 10 e 12) e a segunda forma chamada de medição decrescente, onde a ordem das medições foi realizada do maior valor de $\mathrm{pH}(\mathrm{pH} 12)$ para o menor valor $(\mathrm{pH} \mathrm{02})$. Os $\mathrm{pHs}$ utilizados para a limpeza das amostras foram os pHs 12 e 07 , como indicado na tabela 4.1.

Considerando uma amostra de baixa resistividade de folha $(5-10 \Omega / \square)$ podemos verificar pela tabela 4.1 (indicado por $\uparrow$ ) que quando a limpeza é feita em um $\mathrm{pH}$ alto há diferença nos resultados obtidos do percentual de cargas $\mathrm{dQ}$ adsorvidos na superfície da amostra em relação ao pH medido, em função do tipo de medição adotado, crescente ou decrescente. Mas quando a limpeza é feita em um pH neutro, os resultados do porcentual de cargas adsorvidos na superfície da amostra não é alterado em função do tipo de medição adotada. 
Quando a amostra utilizada é uma amostra com alta resistividade (80$100 \Omega / \square)$ esse quadro é invertido. Utilizando-se uma limpeza em pH alto os resultados obtidos são invariáveis enquanto que em uma limpeza em pH neutro os resultados obtidos possuem dados distintos.

As figuras com os resultados do porcentual de cargas adsorvidos em função do $\mathrm{pH}$ para as duas amostras utilizadas nos dois sistemas de medições adotados podem ser verificados na referência (12).

A amostra utilizada neste trabalho possui resistividade de folha de 23 $\Omega / \square$ e pode ser considerada de baixa resistividade quando comparada com as amostras utilizadas na referência Rapha, quando a faixa utilizada é de 5 a 100 $\Omega / \square$. Isso corrobora com a proposta de melhor limpeza da amostra em $\mathrm{pH}$ neutro do que alcalino. Com a baixa resistividade e com isso maior velocidade de carregamento e descarregamento das cargas na superfície da amostra, a limpeza em pH neutro não altera a quantidade de cargas que serão adsorvidas na superfície da amostra com a alteração na forma adotada de medição. Alterando-se a ordem de medição dos pHs não deve ocorrer alteração do valor das cargas adsorvidas na superfície da amostra quando essa superfície se encontra limpa. Para que esses valores apresentem alteração no resultados, provavelmente a superfície da amostra possui íons residuais, indicando que a limpeza adotada não é eficaz.

Com isso, foi calculada a sensibilidade da amostra Al4, como pode ser verificado pela figura 4.2 . 


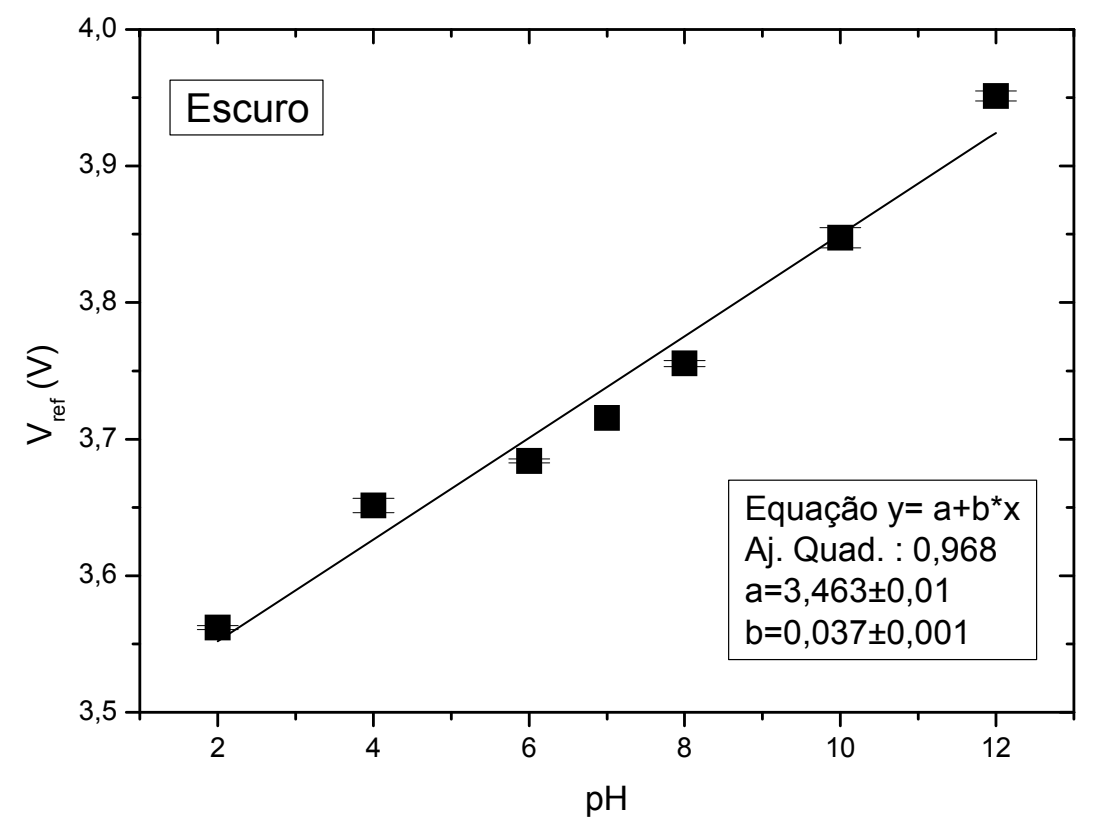

Figura 4.2: Sensibilidade da amostra Al4 no escuro. Os tracejados que aparecem nos pontos são os respectivos erros

O valor encontrado fazendo-se a medição totalmente no escuro foi de 37 $\mathrm{mV} / \mathrm{pH}$, valor dentro do valor vigente esperado pela literatura.

\subsection{Influência do tempo}

Como explicado anteriormente, a medição do tempo é feita fixando-se as tensões $V_{d s}$ e $V_{g s}$ em $5 V$ e então medindo-se a corrente $I_{d s}$ copiosamente por um determinado período de tempo. Neste caso foram utilizados 600 pontos sendo um ponto a cada segundo, totalizando um tempo de 10 minutos. A figura 4.3 mostra o resultado da medição no tempo para a amostra Al4 feita de duas formas, a primeira utilizando o primeiro sistema de limpeza, a LA por 15 minutos e a segunda utilizando o segundo sistema de limpeza, a LN por 15 minutos. Para efeito de comparação a medição foi refeita para três diferentes valores de $\mathrm{pH}$, sendo um $\mathrm{pH}$ ácido $(\mathrm{pH} 04)$, um $\mathrm{pH}$ neutro $(\mathrm{pH} 07)$ e um $\mathrm{pH}$ alcalino ( $\mathrm{pH} 10)$. 


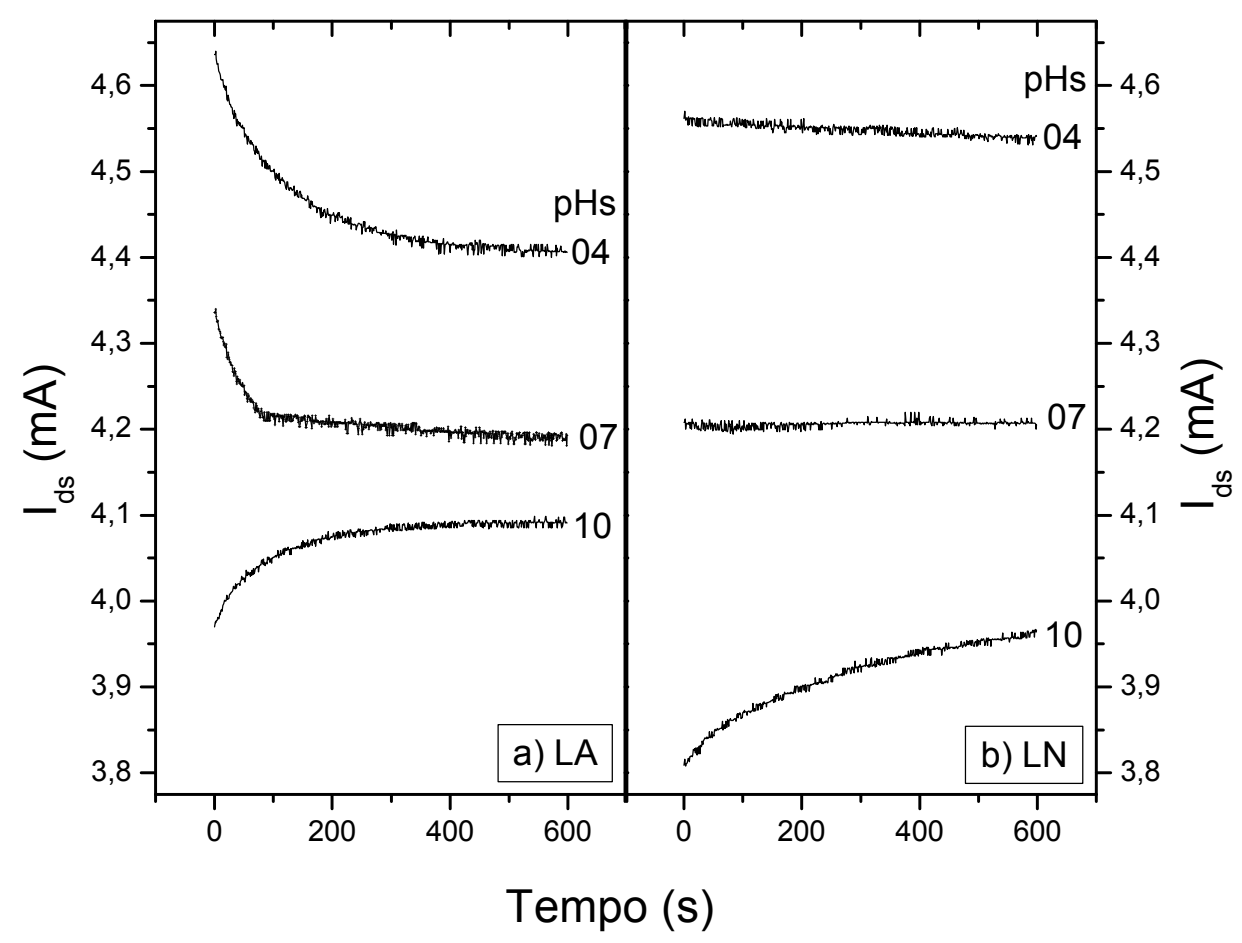

Figura 4.3: Medição no tempo para a amostra Al4 utilizando a) LA e b) LN

Quando a limpeza é feita na forma LA o valor da corrente $I_{d s}$ possui uma maior variação absoluta em função do tempo. Quando a limpeza é feita na forma LN essa variação do valor da corrente em função do tempo é minimizada. Quando a medição é feita no $\mathrm{pH} 07$ não deve ocorrer uma variação do valor da corrente devido ao ponto isoelétrico do FTO. Isso não ocorre quando a limpeza utilizada é a LA evidenciando que a superfície possuía íons residuais.

Esse comportamento exponencial mais evidenciado na resposta do transistor com relação ao tempo quando a amostra é limpa na forma LA demonstra que os íons que estão dentro da solução de $\mathrm{pH}$ e na superfície da amostra estão interagindo mais, e isso pode ser atribuído ao tipo de limpeza. Considerando a curva referente à medição com solução tampão com pH 04 , pode-se perceber que ocorre um decaimento exponencial do valor da corrente $I_{d s}$ até que esse valor se estabiliza. Quando a amostra foi limpa na forma LA, os íons da superfície da amostra foram retirados por interação química como já discutido anteriormente, mas não temos como assegurar que todos os íons 
foram retirados da superfície. Considerando que existam alguns íons residuais na superfície da amostra, quando aplicamos as tensões $V_{d s}$ e $V_{g s}$, devido à grande concentração de íons $\mathrm{H}^{+}$na solução em que a amostra esta mergulhada, iremos obter um valor alto de $\mathrm{dV}$ e consequentemente um valor alto da corrente $I_{d s}$, pois como a oferta de íons $\mathrm{H}^{+}$na solução é alta, mais facilmente os íons irão se deslocar para perto da superfície da amostra e consequentemente mais íons $\mathrm{OH}^{-}$irão se deslocar para perto do eletrodo de referência aumentando então o valor de dV, como discutido na seção 3.3. Porém, quando a limpeza da amostra é feita na forma $L N$, mais rapidamente esses íons $\mathrm{H}^{+}$são adsorvidos na superfície da amostra. Quando os íons $\mathrm{H}^{+}$se ligam aos sítios ligantes livres da superfície da amostra e os íons negativos livres na solução formam essa tensão que chamamos de $\mathrm{dV}$, podemos considerar esse sistema como um capacitor. Lembrando que a capacitância é a variação da carga pela variação da tensão, quando o valor de dV estabiliza consequentemente não há mais variação de carga. Portanto, quando a limpeza da amostra é feita na forma LA, os íons possuem uma maior variação na adsorção da superfície da amostra, fazendo com que haja uma variação maior das cargas $d Q$, e consequentemente, fazendo com que a estabilidade das cargas demore a ocorrer. Já quando a limpeza da amostra é feita na forma LN, os íons $\mathrm{H}^{+}$da solução são adsorvidos muito mais rapidamente na superfície da amostra, estabilizando mais rapidamente dV. Isso evidencia que essa adsorção dos íons mais rapidamente na superfície da amostra é devido a uma melhor limpeza que deixa mais sítios ligantes livres.

Quando olhamos para a curva referente à medição feita em solução tampão com pH 07, esperamos que a resposta seja parecida com a curva do lado direito da figura 4.3 , que é a medição referente a $L N$, pois o ponto isoelétrico do FTO é igual a 7, e portanto não deveria ocorrer uma variação na resposta da corrente $I_{d s}$. Porém quando examinamos a resposta do sensor em relação ao tempo quando a limpeza da amostra é feita na forma LA podemos verificar que ocorre uma variação na resposta da corrente $I_{d s}$, que só se estabiliza em torno de 100 segundos. Essa variação na curva é explicada da mesma forma que a variação na curva referente é medição feita em pH 04, pois como houve uma variação na resposta da corrente $I_{d s}$ provavelmente a 
superfície não estava totalmente limpa e possuía então íons residuais na sua superfície, fazendo com que esses íons residuais interagissem com os íons da solução alterando então o valor de $\mathrm{dV}$ e consequentemente o valor de $I_{d s}$. Quando a limpeza da amostra é feita na forma LN, não há variação no valor de $\mathrm{dV}$, como esperado, evidenciando novamente que a superfície da amostra se encontra mais limpa.

Utilizando agora uma solução tampão com pH 10 para fazer a medição, percebe-se que ocorre um aumento do valor da corrente $I_{d s}$ até que ocorra a estabilização. Quando os íons $\mathrm{H}^{+}$são adsorvidos na superfície da amostra pelas moléculas de $\mathrm{H}_{2} \mathrm{O}$ formam íons hidrônios $\left(\mathrm{H}_{3} \mathrm{O}^{+}\right)$, como explicado na seção 3.3. Esses íons reagem com os íons $\mathrm{OH}^{-}$formando duas moléculas de água, como mostrado na equação (4.1).

$$
\mathrm{H}_{3} \mathrm{O}_{(a q)}^{+}+\mathrm{OH}_{(a q)}^{-} \rightleftharpoons 2 \mathrm{H}_{2} \mathrm{O}
$$

Como o pH 10 possui uma grande oferta de íons $\mathrm{OH}^{-}$e pouca oferta de íons $\mathrm{H}^{+}$, esses íons hidroxilas vão reagir com os íons hidrônios liberando então um sítio ligante na superfície da amostra. Esse sítio livre vai se ligar a uma molécula de água da solução que vai se ligar novamente a outro íon $\mathrm{H}^{+}$e com isso vai aumentar o valor de $\mathrm{dV}$, pois está aumentando a variação de carga $d Q$, até que esse valor se estabilize, pois como a solução é uma solução tampão, e essas reações alteram o valor do $\mathrm{pH}$, essas reações tendem a se estabilizar mesmo se ainda houver oferta de íons na solução para reagir.

Quando a amostra é limpa utilizando a limpeza LA, a corrente $I_{d s}$ possui um valor inicial mais alto do que quando a amostra é limpa na forma LN. Isso é devido a um maior valor de $\mathrm{dQ}$ e consequentemente de $\mathrm{dV}$ e por isso um valor maior de $I_{d s}$, evidenciando que a amostra possui íons residuais na superfície e por isso a limpeza na forma LN é mais eficaz.

Tomando como base toda a discussão anterior, todas as principais medições a partir daqui foram feitas utilizando a limpeza LN por 15 minutos antes de cada experimento. Apenas quando consideramos importante foi também utilizado LA para fins de comparação. 
Para dar continuidade ao estudo do efeito temporal foram feitas as medições para todas as soluções de $\mathrm{pH}$ utilizadas neste trabalho. Os resultados podem ser verificados na figura 4.4.

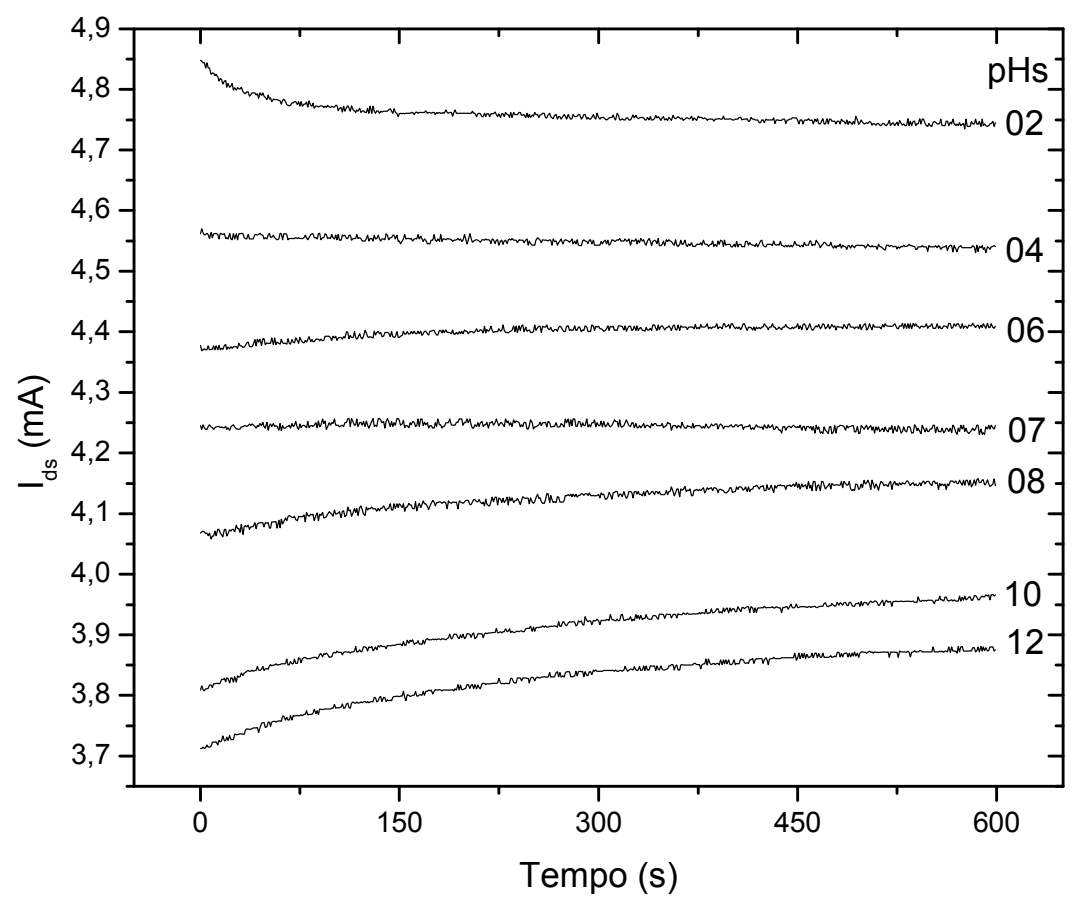

Figura 4.4: Medição no tempo no escuro da amostra Al4 para todos os valores de $\mathrm{pH}$ utilizados

Pela figura 4.4 pode-se verificar que as curvas para $\mathrm{pHs}$ ácidos e alcalinos possuem o mesmo comportamento, exceto pela curva referente ao $\mathrm{pH} 06$ que deveria ter um decaimento do valor da corrente $I_{d s}$, porém a curva possui um leve aumento do valor dessa corrente por um curto período de tempo até que o valor da corrente se torne estável. Isso pode ser atribuído ao valor do $\mathrm{pH} 06$ ser muito parecido com o ponto isoelétrico do FTO e apesar da solução tampão de $\mathrm{pH} 06$ possuir uma maior oferta de íons $\mathrm{H}^{+}$do que de íons $\mathrm{OH}^{-}$, e assim os íons $\mathrm{OH}^{-}$reagiram mais do que os íons $\mathrm{H}^{+}$com os íons da superfície da amostra, dando um caráter mais básico a curva de resposta da medição.

Para que a figura 4.4 possa ser melhor estudada, foi construída a figura 4.5 a partir dos valores obtidos na figura 4.4. Cada ponto da figura é referente 
ao módulo da subtração do último valor medido da corrente $I_{d s}$ para cada valor de $\mathrm{pH}\left(\mathrm{I}_{\mathrm{ds} f}\right)$ e do valor do primeiro ponto medido de $I_{d s}\left(I_{d s} i\right)$, obtendo-se assim um valor $\Delta_{\text {Ids }}=\left|I_{\mathrm{dsf}}-I_{\mathrm{dsi}}\right|$ e então esse valor $\Delta_{\text {Ids }}$ foi dividido pelo valor de corrente inicial $\left(I_{d s}\right.$ i) para podermos avaliar o quanto que essa corrente $I_{d s}$ variou no total para cada valor de $\mathrm{pH}$. Já vimos pela figura 4.4 que o comportamento da corrente difere em relação a característica alcalina ou ácida da solução de pH utilizada na medição, mas para efeito de comparação na figura 4.5 esses valores da variação da corrente foram utilizados em módulo.

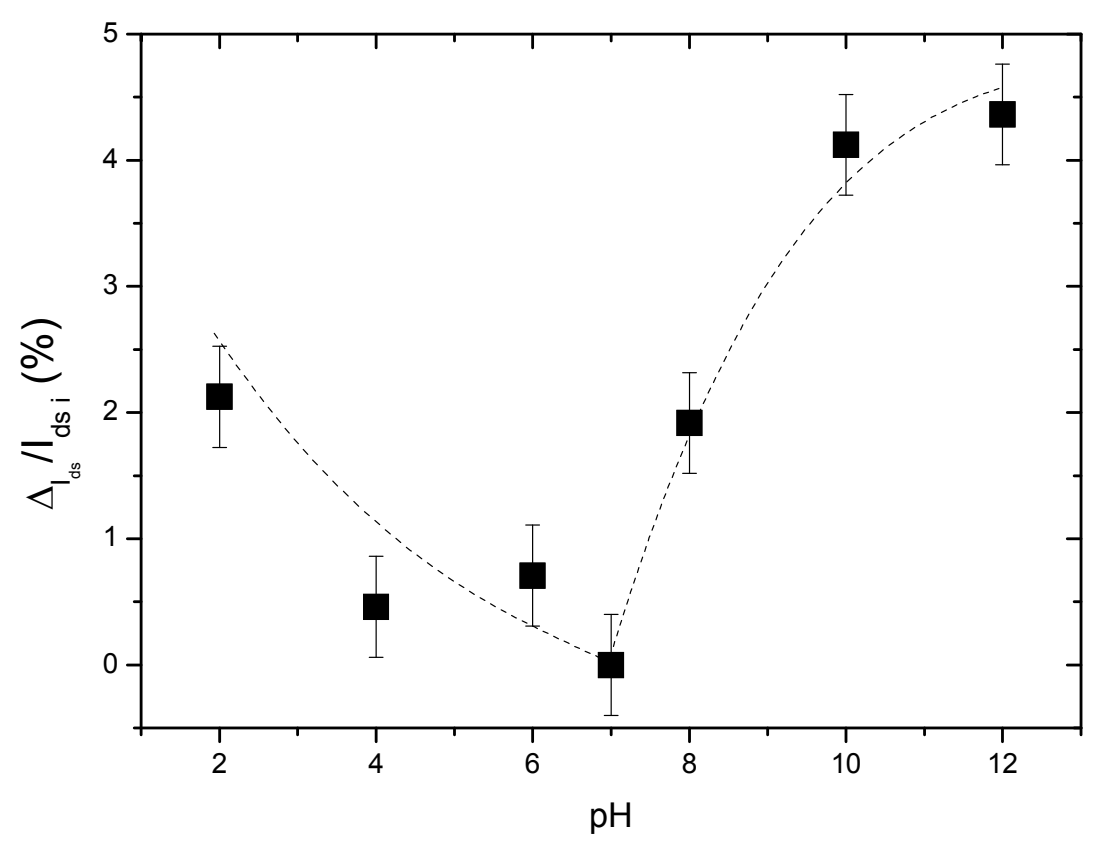

Figura 4.5: Variação total da corrente em relação a corrente inicial. A linha tracejada é apenas um guia para os olhos. As barras de erro foram maximizadas

Como esperado, a variação da corrente quando utilizamos como solução tampão a solução com pH 07 é nula. Já a variação da corrente para pHs ácidos é menor do que para pHs alcalinos. Isso ocorre devido a estabilização do valor da corrente demorar mais para ocorrer em pHs alcalinos do que para pHs ácidos, como já era de se esperar devido a toda discussão anterior da variação das cargas em função da quantidade de íons $\mathrm{H}^{+}$e $\mathrm{OH}^{-}$disponíveis na solução. As soluções ácidas possuem uma oferta muito maior de íons $\mathrm{H}^{+}$do que de íons $\mathrm{OH}^{-}$e devido à dupla camada formada na superfície da amostra onde as 
moléculas de água se ligam aos íons $\mathrm{H}^{+}$, os íons $\mathrm{H}^{+}$são adsorvidos na superfície da amostra mais rapidamente estabilizando o valor de $d Q$ e consequentemente estabilizando o valor de $\mathrm{dV}$ e assim estabilizando também $\mathrm{o}$ valor de $I_{d s}$. Quanto mais alcalina a solução, menor a oferta de íons $\mathrm{H}^{+}$e maior a oferta de íons $\mathrm{OH}^{-}$. Com isso mais reações químicas entre os íons ocorrerão demorando mais tempo para a total estabilização do valor da corrente $I_{d s}$, fazendo então com que o valor total da variação da corrente seja bem maior do que quando a corrente se estabiliza mais rapidamente, como verificado na figura 4.5 .

A variação máxima de corrente que ocorre para cada valor de $\mathrm{pH}$ é menor do que $5 \%$. Mas considerando a variação em corrente que ocorre do $\mathrm{pH}$ 02 ao pH 12 essa variação é em torno de $30 \%$.

\subsection{Influência da luz}

Para o estudo da influência da luz que incide sobre a amostra as mesmas medições feitas nas figuras $4.3,4.4$ e 4.5 foram refeitas para efeito de comparação, mas agora utilizando uma fonte de iluminação.

Quando uma interface semicondutor/eletrólito é irradiada com luz com energia maior do que a banda-gap, fótons são absorvidos, permitindo que elétrons saltem da banda de valência para a banda de condução do semicondutor $^{(50)}$.

O fluxo de corrente e buracos em direções opostas é chamado de fotocorrente. A fotocorrente atingível sob uma intensidade luminosa depende da profundidade da penetração da luz no semicondutor, do comprimento de difusão dos carreadores minoritários e da largura da camada de cargas na interface semicondutor/eletrólito. No caso de uma forte absorção de luz pelo filme da amostra a região de geração do buraco é dentro da camada de depleção, no entanto, se a luz absorvida tiver baixa energia, a fotocorrente depende do potencial devido a largura da camada de cargas na interface semicondutor/eletrólito ${ }^{(50)}$. A fotocorrente geralmente consiste em duas partes, sendo a primeira devido a camada de depleção e a segunda gerada no "bulk" do semicondutor. 
O fotopotencial ou fotovoltagem é a alteração de potencial na camada de cargas na interface semicondutor/eletrólito resultante da separação de cargas dos carreadores em excesso fotogerados. Quando o semicondutor é iluminado o potencial se torna $V_{\text {luz }}=V_{\text {escuro }}+\Delta V$, onde $\Delta V$ é o potencial alterado pelo efeito da iluminação. A corrente medida em $V_{\text {luz }}$ é a soma das correntes dos elétrons e buracos $\left(i=i_{\text {elétrons }}+i_{\text {buracos }}\right){ }^{(50)}$. Estados de superfície, como níveis de impureza no "bulk" do semicondutor, influenciam na recombinação de elétrons e buracos, que afeta significantemente o processo fotoeletroquímico (50)

A figura 4.6 mostra a curva no tempo com a luz visível incidindo sobre a superfície da amostra para três valores de pHs $(4,7$ e 10) tanto para a limpeza LA quanto para a limpeza LN.

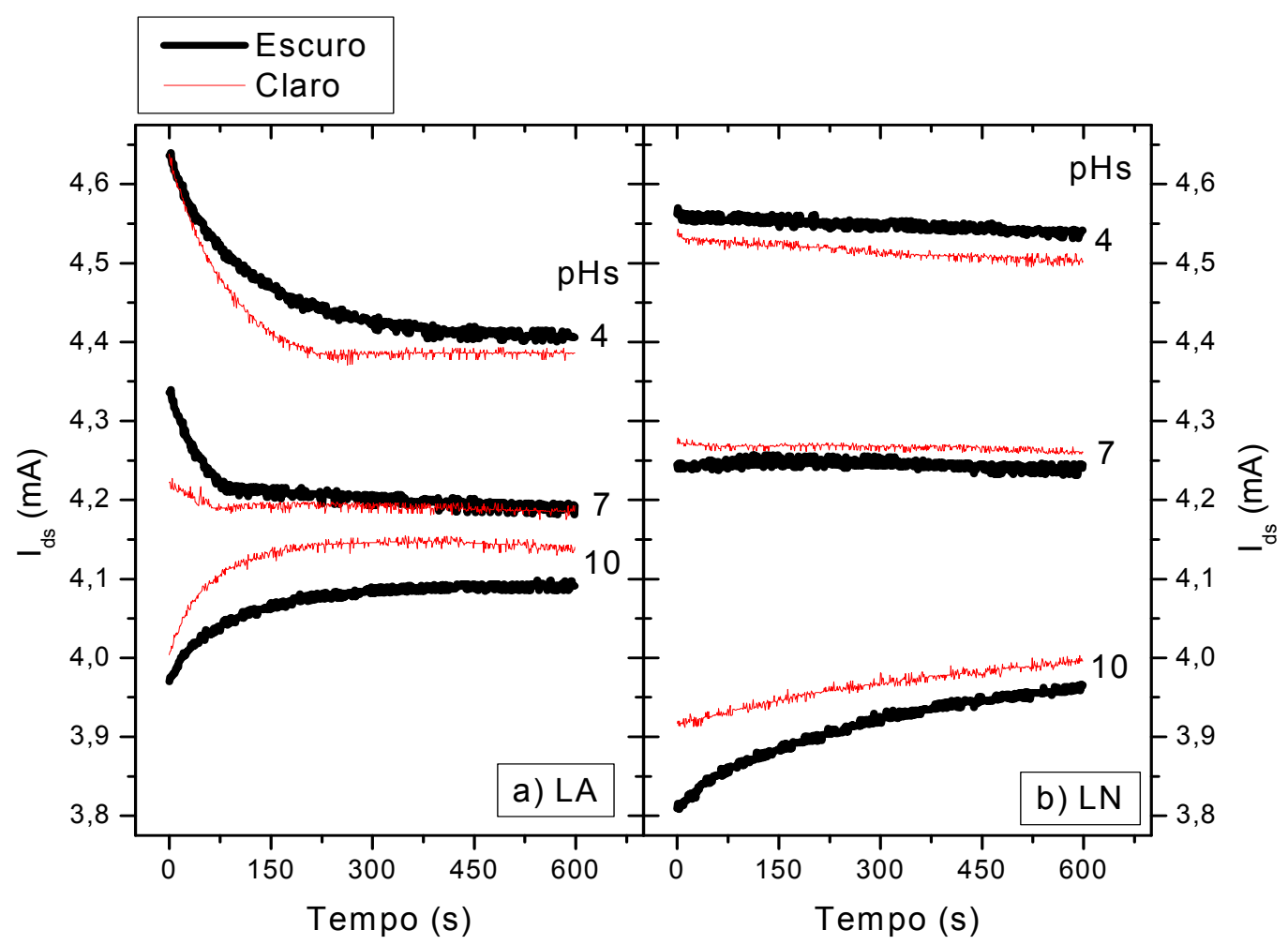

Figura 4.6: Corrente $I_{d s}$ em função do tempo: a) Referente à medição utilizando LA e b) referente à medição utilizando $L N$ 
A luz altera o valor da corrente $I_{d s}$ para todos os valores de $\mathrm{pHs}$. Para a medição utilizando solução tampão com pH 04, tanto para a limpeza LA quanto para a limpeza LN a incidência da luz diminui o valor da corrente $I_{\text {ds }}$ medido. Para a limpeza LA o decaimento exponencial da curva quando considerado o efeito da luz está mais acentuado do que a curva medida no escuro enquanto que para a limpeza LN, tanto as curvas no escuro quanto no claro se mostram com menor variação total da corrente $I_{d s}$. A diminuição do valor da corrente quando o sistema possui influência da iluminação se deve a diminuição do potencial $d V$. Para diminuir $d V$ a variação das cargas adsorvidas $d Q$ na superfície da amostra tem que ter sido menor do que ocorre no escuro.

Quando a amostra entra em contato com a solução tampão com pH 04, que possui uma grande oferta de íons $\mathrm{H}^{+}$, a dupla camada é formada rapidamente formando então íons hidrônios na superfície da amostra. Os íons hidrônios possuem carga positiva, enquanto os elétrons possuem cargas negativas. Se a luz incidente possuir energia o suficiente para que os elétrons saltem da banda de valência para a banda de condução do semicondutor o filem vai possuir mais cargas negativas na banda de condução que irão atrair mais fortemente os íons hidrônios.

O fato de o filme ser dopado com flúor faz com que as ligações entre o flúor e o estanho sejam mais fracas do que quando o estanho é ligado com o oxigênio, devido a carga do íon flúor $\left(\mathrm{F}^{-}\right)$ser metade da carga do íon oxigênio $\left(\mathrm{O}^{2-}\right)$ e por isso o filme possui mais elétrons livres ${ }^{(47)}$.

As cargas vão se atrair mais fortemente na superfície da amostra, mas esse aumento de cargas negativas dentro da rede vai também repelir mais fortemente as cargas negativas dentro da solução. Mas a quantidade de cargas negativas presentes na solução é muito menor do que a quantidade de cargas positivas. Com isso, a variação de dV vai ser menor.

Como já discutido anteriormente, estados de superfície, como níveis de impureza no "bulk" do semicondutor, influenciam na recombinação de elétrons e buracos, que afeta significantemente o processo fotoeletroquímico. A maior variação que ocorre na corrente quando a limpeza utilizada é a LA, indica que 
há uma maior variação de cargas $d Q$ e consequentemente maior dV. Portanto, quando a superfície da amostra possui íons residuais ocorre uma maior variação de cargas $d Q$ demorando mais para $I_{d s}$ se estabilizar, evidenciando então que a limpeza LA não é a mais adequada.

Agora considerando as curvas referentes ao $\mathrm{pH} 07$, quando a medição é feita utilizando a limpeza LA, o valor inicial da corrente $I_{d s}$ no escuro é maior do que o valor inicial da corrente $I_{d s}$ quando a medição é feita no claro. Mas os valores das correntes finais são os mesmos. Já quando a medição é feita utilizando a limpeza LN, os valores de $I_{d s}$ no claro são sempre maiores do que os valores de $I_{d s}$ no escuro. Essa diferença também pode ser justificada pela limpeza. Quando a limpeza é feita na forma $L N$, os valores da corrente $I_{d s}$ tanto no claro quanto no escuro estão estabilizados, como esperado. Para que o valor de $I_{d s}$ seja maior no claro do que no escuro o valor de $\mathrm{dV}$ no claro tem que ser maior. Para o valor de dV ser maior, como discutido anteriormente, o valor de $d Q$ tem que ser maior. A solução tampão com pH 07 é uma solução neutra, e portanto possui a mesma quantidade de íons $\mathrm{H}^{+}$e íons $\mathrm{OH}^{-}$. Portanto a única alteração que deve ser relevante para a alteração de $d V$ deve ser a influência da luz.

Com os elétrons agora na banda de condução devido a incidência da luz, esse aumento de cargas negativas dentro da rede do filme atrai mais fortemente os íons com cargas positivas que estão dentro da solução. Esses íons com cargas positivas vão fazer com os íons hidroxilas dentro da solução se afastem da superfície da amostra aumentando o valor de $\mathrm{dV}$ entre o eletrodo de referência e a superfície da amostra. Isso faz com que aumente o valor de $I_{d s}$. Mas se a superfície da amostra contiver íons residuais, o valor inicial da corrente $I_{d s}$ será menor do que se a amostra estivesse com sua superfície totalmente limpa com todos os sítios livres. Além do mais, como já discutido anteriormente, a curva referente a medição utilizando $\mathrm{pH} 07$ deve ser estável ao invés de possuir um decaimento do valor da corrente $I_{d s}$ até que ocorra a estabilização desse valor, como ocorre quando a limpeza da amostra é feita na forma LA. 
A solução tampão com $\mathrm{pH} 10$ possui uma oferta muito maior de íons hidroxila do que íons $\mathrm{H}^{+}$. O valor da corrente $I_{d s}$ é maior no claro do que no escuro, em ambas as limpezas LA e LN. Para isso ocorrer, o valor de dV tem que ser maior no claro do que no escuro. $O$ aumento de elétrons na banda de condução do filme irá atrair mais fortemente os íons com cargas positivas da solução como já descrito anteriormente. Mas a solução utilizada possui uma oferta muito maior de íons com carga negativa do que com carga positiva, fazendo com que as cargas sejam adsorvidas na superfície da amostra de uma forma mais lenta, e por isso, a variação total da corrente é maior para soluções alcalinas do que quando as soluções utilizadas são ácidas. Essa adsorção mais lenta faz com que a dupla camada se forme mais lentamente e com isso, como já discutido anteriormente, a largura da camada de cargas na interface semicondutor/eletrólito influência diretamente na fotocorrente. Como a dupla camada demora mais para ocorrer, o filme absorve mais luz pois a camada é mais fina por um intervalo de tempo maior até que ocorra a total adsorção das cargas na superfície. Esse aumento de absorção da luz pelo filme faz com que mais elétrons saltem da banda de valência para a banda de condução, aumentando a atração pelos íons positivos na superfície da amostra e repelindo mais fortemente os íons hidroxilas da superfície da amostra aumentando consequentemente o valor de $\mathrm{dV}$ e com isso aumentando também o valor da corrente $I_{d s}$.

Novamente, o aumento de uma forma exponencial do valor da corrente $I_{d s}$ quando é feita a limpeza na forma LA sugere que a superfície da amostra possui íons residuais.

A figura 4.7 é a repetição da figura 4.4 com a inclusão das medições feitas no claro. 


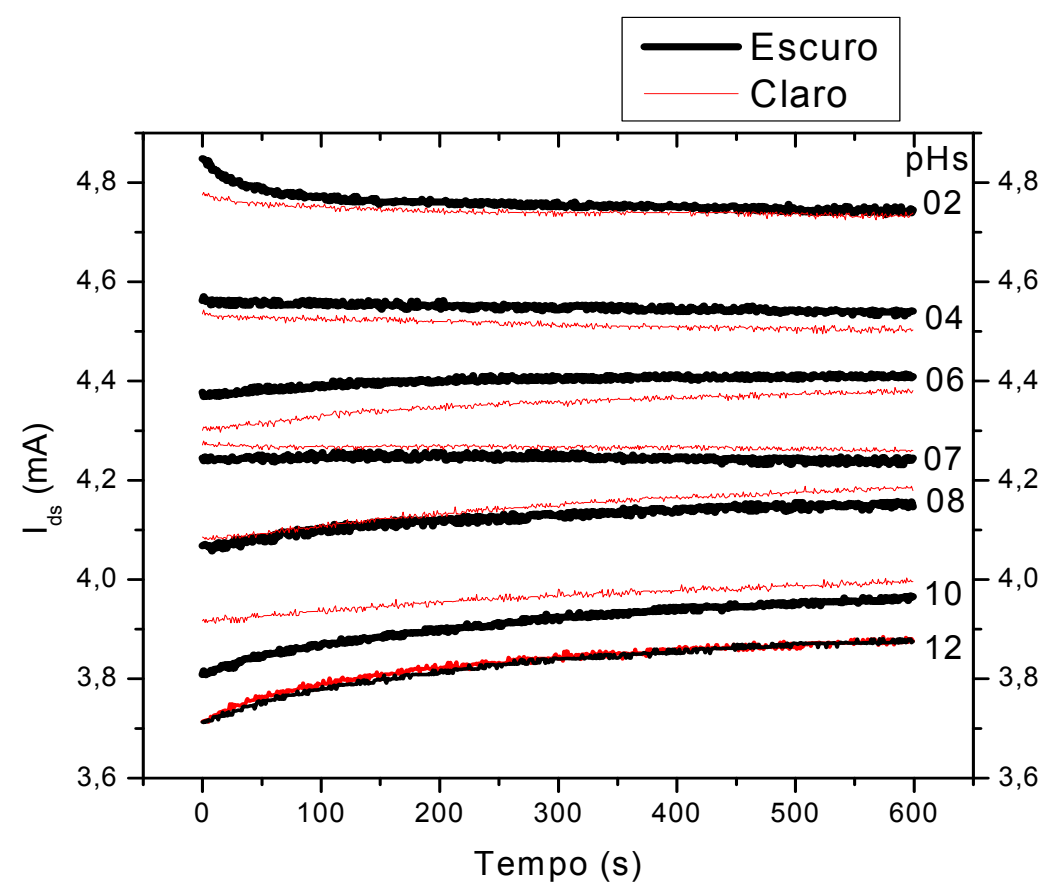

Figura 4.7: Medição no tempo para todos os valores de pHs utilizados, comparando a medição feita no claro com a medição no escuro

Pela figura 4.7 podemos perceber que para pHs ácidos, quando a medição é feita no claro o valor da corrente $I_{d s}$ é sempre menor do que quando a medição é feita no escuro e para pHs alcalinos, o valor da corrente $I_{d s}$ é sempre maior quando a medição é feita no claro do que quando a medição é feita no escuro.

A figura 4.8 mostra os valores da variação da corrente pelo valor inicial da corrente $I_{d s}$, tanto para a medição feita no claro quanto para a medição feita no escuro, já apresentados na figura 4.5. Os últimos são aqui reproduzidos para melhor comparação. 


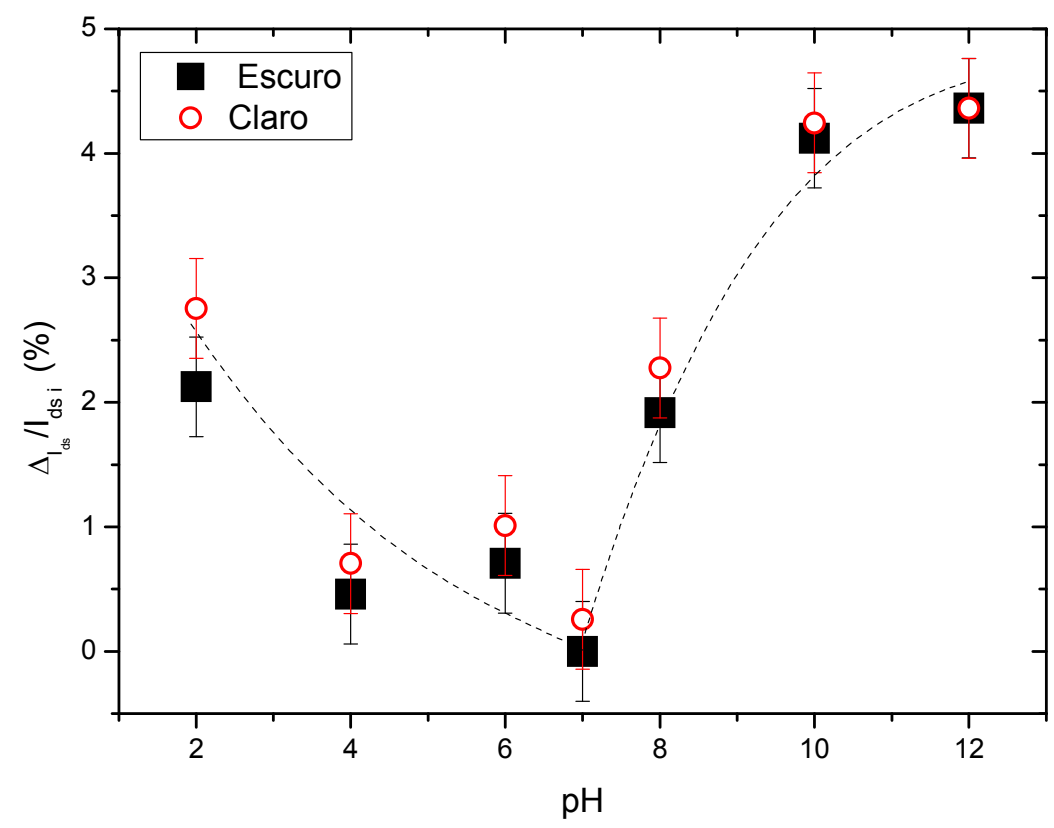

Figura 4.8: Valores em módulo da variação da corrente dividido pelo valor inicial para as medições no claro e no escuro. A linha tracejada é apenas um guia para os olhos. As barras de erro foram maximizadas

Considerando o pH 07, podemos verificar que a influência da luz fez com que houvesse um variação no valor da corrente $I_{d s}$ diferente de zero, fazendo então que houvesse uma pequena variação no valor da corrente até sua total estabilização. Isso evidencia que a luz altera a dinâmica dos íons na superfície da amostra. Para pHs ácidos, mesmo em módulo, a variação entre as medições feitas no claro e escuro foi maior do que para pHs alcalinos. Para um $\mathrm{pH}$ muito alcalino, como o pH 12, a variação da corrente possui exatamente o mesmo valor, o que significa que mesmo o valor da corrente $I_{d s}$ ser levemente maior no claro do que no escuro, como pode ser verificado na figura 4.7, a variação foi exatamente a mesma, evidenciando que para um $\mathrm{pH}$ muito alcalino como o pH 12, a influência da luz altera somente o valor da corrente $I_{d s}$ e não o comportamento da curva. Pela figura 4.8 podemos perceber que aumentando a oferta de íons hidroxilas na solução utilizada diminuímos a variação do valor da corrente $I_{d s}$ em relação ao valor inicial da corrente, quando comparadas as medições feitas no claro ou no escuro. Para pHs com baixa oferta de íons hidroxilas essa variação é muito maior. Para o $\mathrm{pH} 02$, a variação da corrente $I_{\mathrm{ds}}$ 
quando feita a medição no escuro é menor do que quando feita no claro. E essa variação total entre o claro e o escuro, é maior no pH 02 do que no pH 04 , que apesar do $\mathrm{pH} 04$ possuir uma grande oferta de íons $\mathrm{H}^{+}$na solução, ainda possui mais íons $\mathrm{OH}^{-}$do que o $\mathrm{pH} 02$, o que mostra que mesmo considerando pHs ácidos, a maior oferta de íons $\mathrm{OH}^{-}$diminui a variação da corrente $\mathrm{I}_{\mathrm{ds}}$ quando comparadas as medições no claro e no escuro.

O valor da sensibilidade da amostra também altera quando feita a medição no claro ou no escuro, como pode ser verificado na figura 4.9.

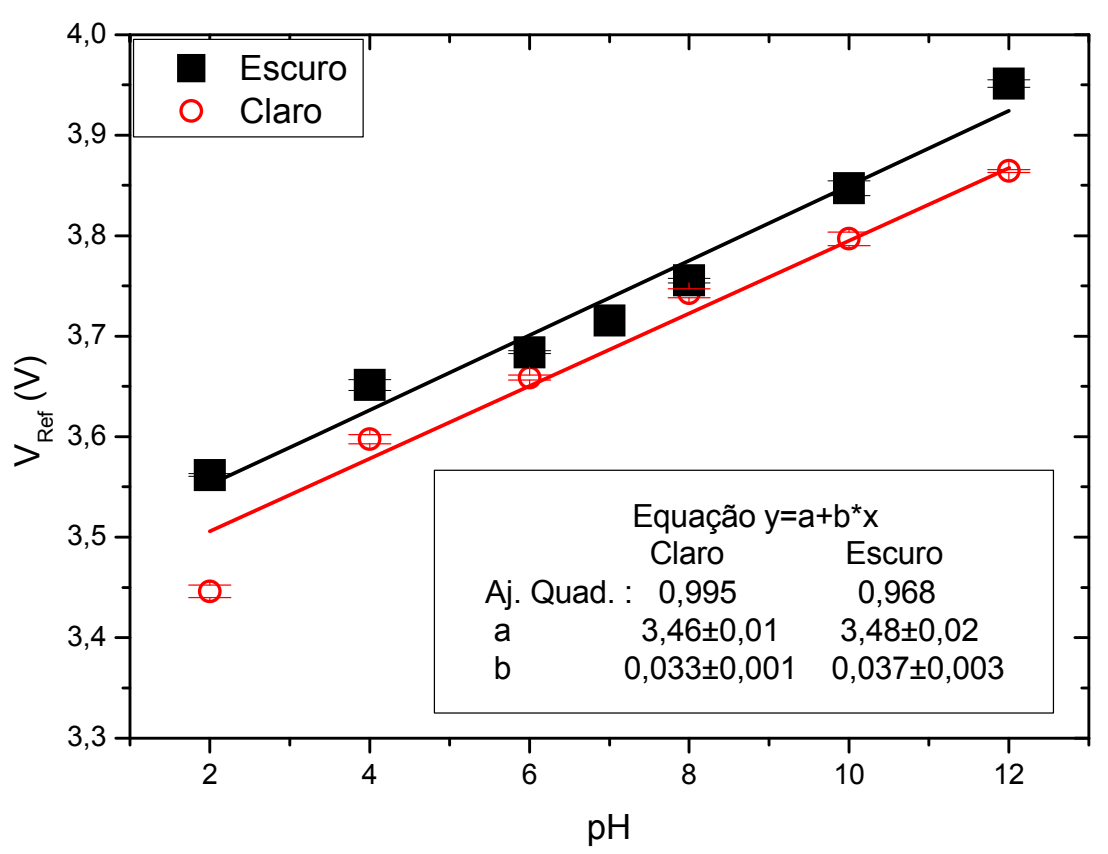

Figura 4.9: Sensibilidade da amostra Al4 quando feita a medição no claro e no escuro

A sensibilidade média da amostra Al4 quando as medições são feitas no escuro é de $37 \mathrm{mV} / \mathrm{pH}$ enquanto que a sensibilidade da mesma amostra, nas mesmas condições, mas agora com a presença da luz diminui para $33 \mathrm{mV} / \mathrm{pH}$, representando uma variação de aproximadamente $10 \%$.

O valor da sensibilidade no claro é menor do que o valor da sensibilidade no escuro, como já era esperado pois, pela figura 4.7 podemos verificar que as medições feitas na presença da luz estão mais próximas da curva referente ao $\mathrm{pH}$ 07. Já as medições feitas sem a presença da luz, as 
curvas possuem uma amplitude maior do valor de $I_{d s}$ em relação as medições feitas no claro.

Devido a toda discussão anterior, todas as medições a partir desse ponto serão realizadas no escuro e a limpeza adotada para todas as medições deste trabalho foi à limpeza em água corrente deionizada por 15 minutos.

\subsection{Influência da ordem de medição}

Vimos na seção 4.2 que há uma grande influência temporal durante o processo de medição. No entanto, todo o objetivo do trabalho é futuramente a construção de um biossensor de pH de resposta rápida. Para isso, foi estudada então a influência da ordem da medição com relação à questão temporal. Foram utilizadas quatro amostras diferentes (Al1, Al2, Al3 e Al4), e todas as medições foram feitas somente na solução tampão de $\mathrm{pH} 02$. Primeiro foi feita a medição VDS, chamada somente nessa seção de $M 1$, em seguida foi feita a medição no tempo, chamada somente nessa seção de MT e depois foi feita uma segunda medição VDS, também chamada somente nessa seção de M2. Com os resultados foi montada a figura 4.10, onde os valores do eixo y são os valores equivalentes a $I_{d s}$ quando as tensões $V_{d s}$ e $V_{g s}$ são iguais a $5 \mathrm{~V}$. 


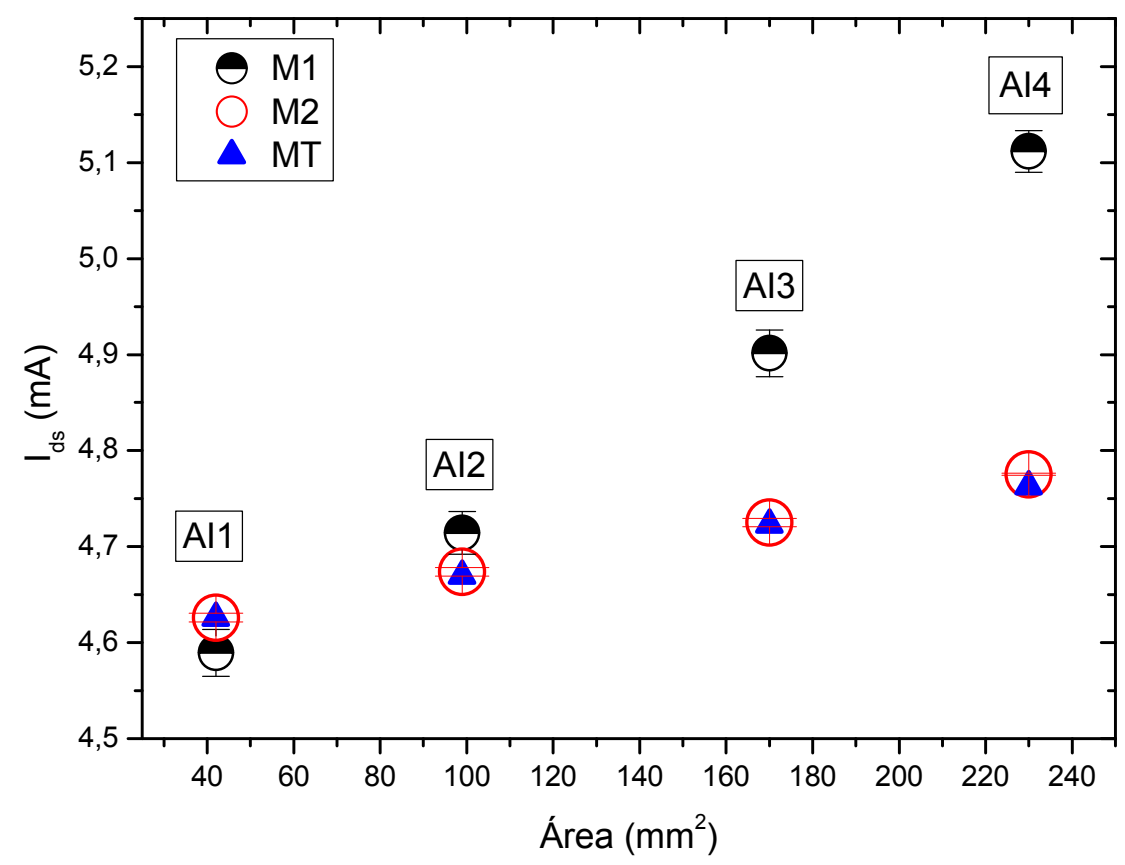

Figura 4.10: Influência da ordem de medição VDS para as quatro diferentes amostras AI1, Al2, Al3 e Al4. As siglas M1, M2 e MT significam respectivamente primeira medição VDS, segunda medição VDS e medição no tempo

Pode-se perceber pela figura 4.10, que quanto maior a área da amostra maior é a diferença entre a primeira medição VDS (M1) e a segunda medição VDS (M2). Para todas as amostras as medições MT e M2 possuem o mesmo valor de $I_{d s}$. Quando fazemos a primeira medição (M1), estamos mantendo fixa a voltagem $V_{g s}$ em $5 \mathrm{~V}$ e variando a voltagem $V_{\text {ds }}$ de 0 a $5 \mathrm{~V}$, portanto com $V_{g s}$ fixa em $5 \mathrm{~V}$ o canal entre o dreno e a fonte já está com sua capacidade máxima de passar corrente e quando variamos a voltagem $V_{d s}$ estamos variando a quantidade de corrente que vai passar entre o dreno e a fonte. Como essa é a primeira medição realizada, a superfície da amostra se encontra limpa e portanto, sem íons residuais, o valor de $I_{d s}$ quando $V_{g s}$ e $V_{d s}$ são iguais a $5 \mathrm{~V}$ é alto.

Em seguida, foi realizada a medição no tempo (MT), mantendo então as tensões $V_{d s}$ e $V_{g s}$ fixas em $5 \mathrm{~V}$ e medindo o valor da corrente $I_{d s}$ por um determinado período de tempo. Como já verificado na figura 4.4 após um determinado período de tempo o valor da corrente $I_{d s}$ se estabiliza em um valor 
abaixo do primeiro valor medido da corrente $I_{d s}$ para o $\mathrm{pH} \mathrm{02,} \mathrm{logo} \mathrm{em} \mathrm{seguida,}$ foi realizada a segunda medição, a chamada $M 2$, onde foi mantido o valor da tensão $V_{g s}$ em $5 \mathrm{~V}$, mas o valor da tensão $V_{d s}$ foi novamente variada entre $0 \mathrm{e}$ $5 \mathrm{~V}$. Nesse tipo de medição a tensão $\mathrm{V}_{\mathrm{gs}}$ sempre manteve o valor fixo em $5 \mathrm{~V}$ e com isso o canal entre o dreno e a fonte sempre esteve aberto, mas após a $M T$, quando fazemos a medição $M 2$, o valor da tensão $V_{d s}$ começa novamente do zero e vai aumentando até seu valor máximo de $5 \mathrm{~V}$, fazendo com que a corrente entre o dreno e a fonte $\left(l_{d s}\right)$ comece bem baixa até atingir o valor máximo de corrente que vai passar entre o dreno e a fonte. Mas quando isso acontece, a amostra não está mais com a superfície limpa, pois entre a M1 e a M2 não foi realizada nenhuma limpeza, as medições M1, MT e M2 foram realizadas em sequência, e portanto, quando a corrente $I_{d s}$ atinge seu valor máximo em M2 esse valor tem que ser o mesmo valor da corrente $I_{d s}$ da medição $\mathrm{MT}$, pois novamente o sistema se encontra com $\mathrm{V}_{\mathrm{ds}}$ e $\mathrm{V}_{\mathrm{gs}}$ igual a $5 \mathrm{~V}$, e com isso o valor de $I_{d s}$ não deve ser diferente.

Quanto maior a superfície de contato da amostra maior a variação de $I_{d s}$ entre a medição M1 e as medições MT e M2. Isso ocorre pois quanto maior a superfície de contato maior o número de sítios ligantes disponíveis e com isso, teremos um maior valor de $\mathrm{dV}$, como pode ser verificado pela equação (2.14), e consequentemente o valor da corrente $I_{d s}$ também será maior. Somente com a amostra Al1, os valores médios finais de $I_{d s}$ medidos após as medições MT e M2 são maiores do que o valor médio de $I_{d s}$ após a medição M1. No entanto, esses valores estão dentro do erro, evidenciando que o comportamento da resposta do sensor em função do tamanho da área se mantém (diminuição da diferença das correntes entre as medições M1 e M2), e que com a diminuição da área diminui a variação do valor da corrente em função do tempo, sendo portanto o valor da corrente mais estável. A amostra Al1 possui uma área pequena, com isso há uma menor probabilidade de ocorrer situações fora do equilíbrio em relação a áreas maiores. Mesmo após a limpeza a superfície da amostra pode ainda conter algumas impurezas e com um aumento da área, maior a probabilidade da superfície conter impurezas.

Quando alteramos o tipo de medição para o que chamamos de medição VGS, os resultados são diferentes, como podemos verificar na figura 4.11. 


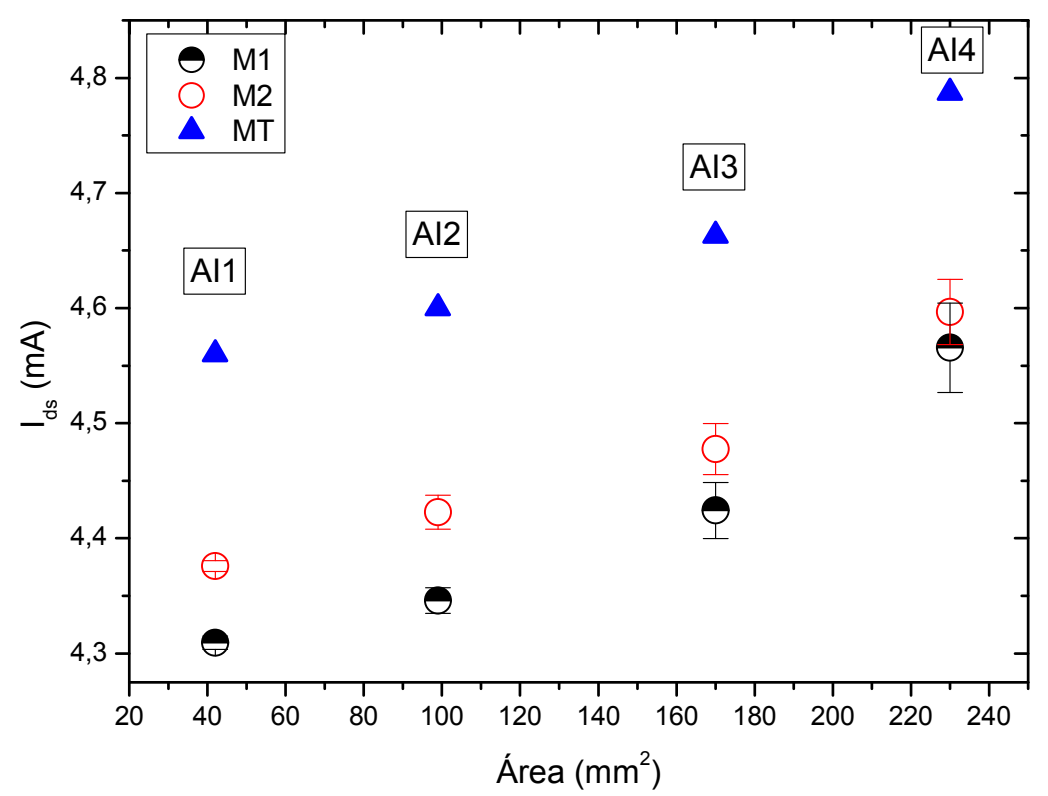

Figura 4.11: Influência da ordem de medição para VGS para as quatro diferentes amostras

Quando fazemos a medição chamada VGS, mantemos fixo o valor da tensão $V_{\mathrm{ds}}$ em $5 \mathrm{~V}$ e variamos o valor da tensão $\mathrm{V}_{\mathrm{gs}}$ de 0 a $5 \mathrm{~V}$, como explicado na seção 3.3. Então, quando fazemos a primeira medição $M 1$, variamos a tensão $V_{g s}$ até que o canal fique totalmente aberto e por isso, mesmo mantendo a tensão $V_{d s}$ fixa em $5 \mathrm{~V}$ a corrente $I_{d s}$ começa com seu valor igual a $O A$ e vai aumentando gradativamente de acordo com a abertura do canal. Quanto maior a superfície de contato da amostra maior o valor final de $I_{d s}$ após a medição $M 1$. Em seguida, fazemos a medição $M T$, onde tanto a tensão $V_{d s}$ quanto a tensão $\mathrm{V}_{\mathrm{gs}}$ possuem valores fixos e iguais a $5 \mathrm{~V}$. $\mathrm{O}$ valor final da corrente $I_{d s}$ medido é muito superior ao valor final de $I_{d s}$ após a medição M1.

Quando fazemos a medição VDS, mantendo $V_{g s}$ fixo, não alteramos a quantidade de cargas no metal do MOSFET. O capacitor que é formado entre $o$ metal e o substrato no interior do MOSFET não é alterado. Com isso, todo o estudo feito quando consideramos somente a medição VDS altera somente o valor da corrente $I_{\mathrm{ds}}$, sem alterar drasticamente a dinâmica dos íons dentro da solução e na superfície da amostra, pois a voltagem aplicada ao eletrodo de referência não é alterada, sendo alterado somente o valor de $d V$, que é dependente da quantidade de íons livres das soluções utilizadas. Mas quando 
alteramos o valor de $\mathrm{V}_{\mathrm{gs}}$, não só alteramos a tensão aplicada ao eletrodo de referência como ainda temos que considerar o valor de dV. Alterando a tensão aplicada ao eletrodo de referência estamos alterando toda a dinâmica dos íons dentro da solução. Portanto, quando fazemos a medição M1 estamos aumentando gradativamente o valor da tensão aplicada ao eletrodo de referência e com isso conseguimos um determinado valor de $I_{d s}$. Continuamos então aplicando uma tensão de $5 \mathrm{~V}$ ao eletrodo de referência mantendo a tensão $V_{\mathrm{ds}}$ em $5 \mathrm{~V}$ também, que é a medição $\mathrm{MT}$. $O$ valor da corrente $I_{\mathrm{ds}}$ ainda não foi estabilizado, portanto ele continua aumentando de valor. Pode-se perceber pelas figuras 4.10 e 4.11 que após um determinado período de tempo o valor de $I_{d s}$ independente do tipo de medição é praticamente o mesmo, como seria esperado pois após um determinado período de tempo o valor de $I_{d s}$ está estabilizado, já que as tensões $V_{d s}$ e $V_{g s}$ possuem o mesmo valor de $5 \mathrm{~V}$.

No entanto, quando iniciamos novamente a tensão $V_{g s}$ com $0 \mathrm{~V} e$ aumentamos gradativamente até $5 \mathrm{~V}$, estamos alterando diretamente a dinâmica dos íons dentro da solução. Quando iniciamos a medição M2 não havia nenhuma tensão aplicada ao eletrodo de referência e o canal dentro do MOSFET estava fechado novamente não passando nenhuma corrente entre $o$ dreno e a fonte. Aumentando o valor da tensão aplicada ao eletrodo de referência aumentamos então o potencial entre o eletrodo de referência e os íons da solução aumentando o valor de dV. O valor final de $I_{d s}$ após M2 é maior do que o valor final de $I_{d s}$ após M1. Para isso acontecer, o valor de $d V$ tem que ter sido maior em M2 do que em M1 e portanto o valor de dQ também tem que ter sido maior em M2 do que em M1. Isso ocorre pois quando terminamos a medição MT e de repente não aplicamos mais voltagem alguma ao eletrodo de referência, os íons da solução vão se rearranjar dentro da solução. Quando a voltagem começa a aumentar e os íons começam a sentir essa voltagem 0 valor de $\mathrm{dV}$ vai aumentar e com isso o valor de $\mathrm{I}_{\mathrm{ds}}$ também.

\subsection{Influência da área de superfície da amostra}

Pelas figuras 4.10 e 4.11 podemos perceber que o valor final da corrente $I_{d s}$ altera com a área de superfície da amostra. Com base nisso, essa seção é 
dedicada ao estudo da influência da área de superfície da amostra na resposta do sensor.

A figura 4.12 mostra o valor final da corrente $I_{d s}$ quando feita a medição VDS no pH 02 em função da área das amostras Al1, Al2, Al3 e Al4.

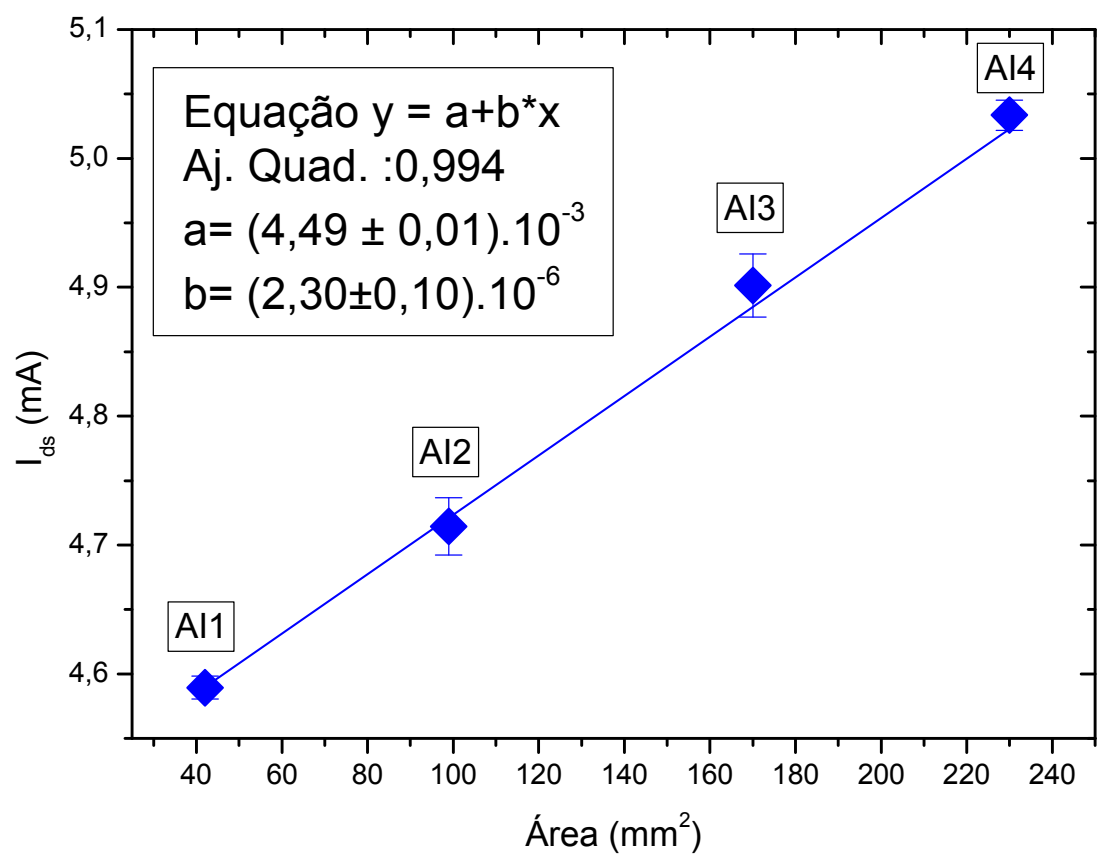

Figura 4.12: Valor final da corrente $I_{d s}$ para as amostras Al1, Al2, Al3 e Al4 em função da área na medição VDS para a solução tampão com pH 02

Podemos perceber claramente que o valor final da corrente $I_{d s}$ é menor quanto menor for a área de superfície da amostra utilizada na medição. Foi traçado um ajuste linear na figura 4.12 para melhor visualização da dependência da corrente $I_{d s}$ com a área da amostra.

A área Al4 é em torno de cinco vezes maior a área Al1, no entanto a corrente aumenta em torno de somente $10 \%$.

Quanto menor a área da amostra, menor a superfície de contato com a solução e, portanto, menor a quantidade de sítios ligantes disponíveis diminuindo assim o valor de $\mathrm{dV}$ e consequentemente o valor da corrente $\mathrm{I}_{\mathrm{ds}}$. 
Isso ocorre quando utilizamos amostras que possuem áreas diferentes e portanto, quando feita a medição as amostras se encontram totalmente mergulhadas na solução tampão utilizada. Mas quando utilizamos somente uma amostra, nesse caso a amostra Al4, e ao invés de mergulhar totalmente a amostra na solução para realizar a medição mergulhamos somente uma parte da superfície da amostra a resposta do sensor é alterada, como podemos verificar na figura 4.13. Como já explicado na seção 3.2.2.3.1, o sistema de medições SM1-D se refere ao sistema de medições decrescente, isto é, a primeira medição é feita com a amostra totalmente submersa (AM4), a segunda medição é feita com somente $3 / 4$ da amostra submersa (AM3), a terceira medição é feita com $1 / 2$ da amostra submersa (AM2) e a quarta e última medição é feita com somente $1 / 4$ da amostra submersa (AM1). Já o sistema de medições SM1-C se refere ao sistema de medições crescente, onde a primeira medição é realizada com somente $1 / 4$ da amostra submersa (AM1), a segunda medição é realizada com $1 / 2$ da amostra submersa (AM2), a terceira medição com $3 / 4$ da amostra submersa (AM3) e a quarta e última medição é realizada com toda a amostra submersa (AM4).

Nessa seção, para efeito de comparação, quando realizadas as medições com as amostras individuais (Al1, Al2, Al3 e Al4) esse sistema de medições foi nomeado de SM2. 


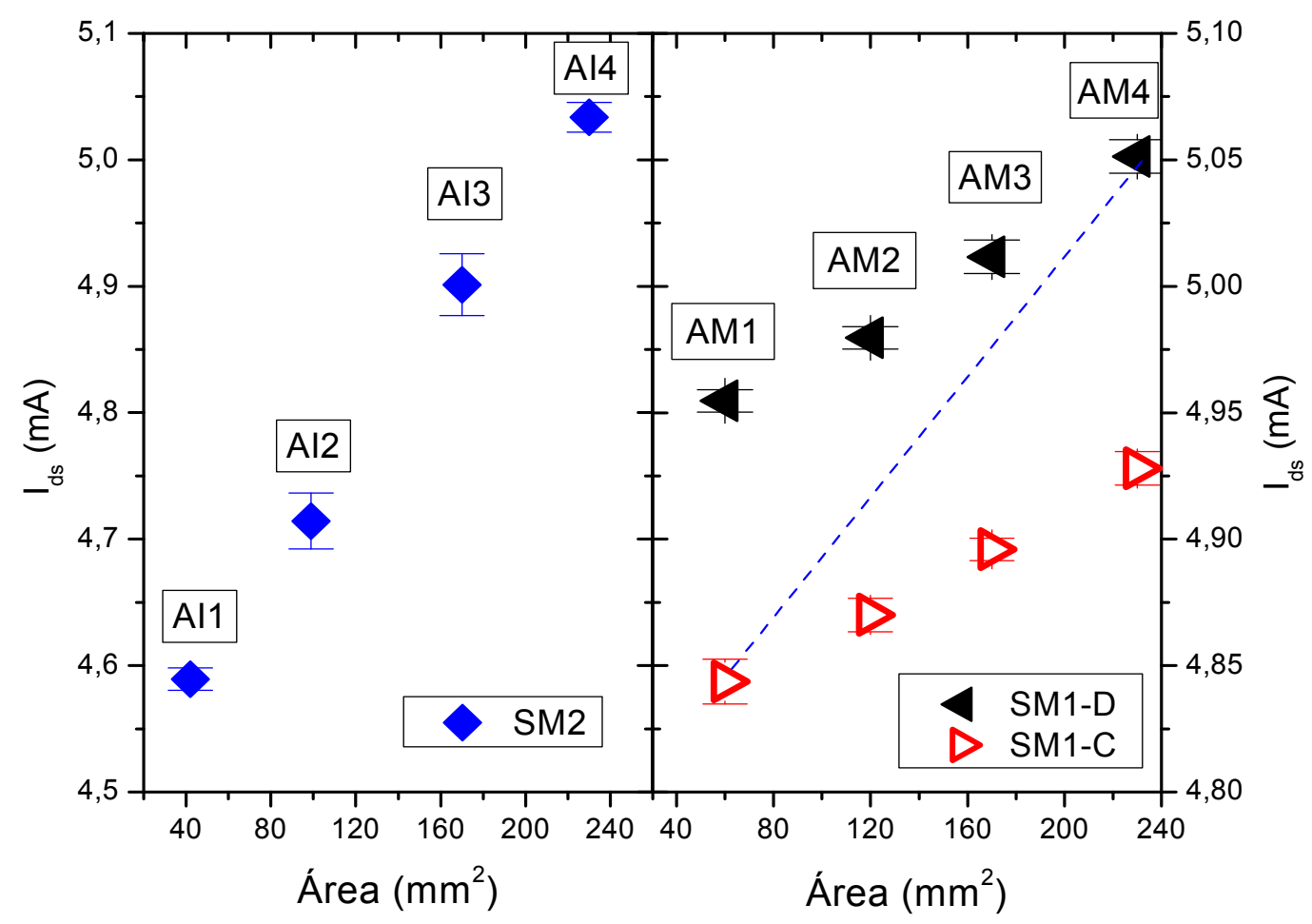

Figura 4.13: Valor final da corrente $I_{d s}$ quando feita a medição VDS para os sistemas de medição SM2 (lado esquerdo) e SM1-D e SM1-C (lado direito)

Do lado esquerdo foi mantida a figura 4.12 e do lado direito foi adicionada a resposta do sensor quando feitas as medições nas formas SM1-D e SM1-C. Cada uma mantém a sua escala, sendo a escala da ordenada da figura da esquerda diferente da escala da ordenada da figura da direita. A figura 4.13 foi montada dessa forma para efeito de comparação entre os tipos de medições em função da área da superfície das amostras e facilitar o entendimento da discussão sobre a figura.

Durante todo o sistema de medições SM1-D e SM1-C a amostra não foi limpa entre uma medição e outra propositalmente, pois o objetivo do estudo é verificar a influência da área quando totalmente submersa (SM2) e a influência da área quando não utilizada totalmente (SM1-D e SM1-C), para efeito de comparação.

Quando o sistema de medições realizado é o SM1-D, os valores finais das correntes $I_{d s}$ estão deslocados para cima em relação aos valores finais das correntes quando a medição realizada é a SM1-C. Isso ocorre pois, quando a 
primeira medição realizada é feita com a amostra totalmente submersa (AM4), toda a superfície da amostra está em contato com a solução e com isso possui um número maior de sítios livres para interagir com os íons livres da solução. Logo em seguida foi feita a medição com a área AM3. O valor final da corrente $I_{d s}$ diminuiu em relação ao medido utilizando AM4. O mesmo ocorre com AM2 e AM1 respectivamente. Isso se deve a dois fatores, sendo o primeiro fator a questão da área de contato disponível ser maior na primeira medição e diminuir nas próximas medições, sem ignorar o fato que quando feita a primeira medição a superfície da amostra se encontra limpa, e já a partir da segunda até a última medição a amostra já possui um determinado nível de saturação dos sítios livres da superfície da amostra diminuindo então o valor da corrente $I_{d s}$. $O$ segundo fator é o fator temporal já demonstrado na figura 4.4. Pois quando retiramos um pedaço da superfície e fazemos a medição, a superfície que continua submersa na solução está em contato com a solução por um tempo maior e com isso o fator temporal influencia na resposta final da corrente.

Ao realizarmos as medições utilizando o sistema de medições SM1-C, a resposta do sensor é alterada. A primeira medição realizada foi utilizando somente um pequeno pedaço da área da amostra. Quando medimos AM1 utilizando SM1-D mesmo que $3 / 4$ da superfície da amostra esteja fora da solução, ainda tem cargas armazenadas nessa superfície, e quando medimos a mesma área AM1 utilizando o sistema SM1-C, toda a superfície da amostra que está fora da solução ainda não entrou em contato com a solução então somente o pedaço da superfície que esta dentro da solução é que vai realmente contribuir com o valor de $\mathrm{dV}$ gerado. Por isso o valor da corrente $I_{\mathrm{ds}}$ encontrado quando feita a medição na forma SM1-C não é o mesmo valor encontrado quando feita a medição na forma SM1-D considerando a mesma área. A próxima medição é realizada inserindo mais um pedaço da amostra dentro da solução. Essa nova área ainda não havia entrado em contato com a solução e com isso, todos os sítios que existem nessa área ainda estavam livres, o que contribui com o aumento de $\mathrm{dV}$ e consequentemente com o aumento de $I_{d s}$. No entanto, a área AM1 que já estava em contato com a solução encontra-se em um estado temporal mais evoluído, que vai contribuir para que o valor da corrente $I_{d s}$ total seja abaixo do que a mesma área AM2 
quando feita a medição no sistema SM1-D. Portanto, a corrente $I_{d s}$ aumenta devido aos sítios da nova área entrarem em contato com a solução, mas esse aumento não é tão efetivo devido ao fator temporal da amostra AM1 estar atuando de forma a diminuir o valor da corrente. O mesmo ocorre quando inserimos as áreas AM3 e AM4. Por isso a resposta do sensor ocorre na forma demonstrada na figura 4.13 (lado direito).

A linha tracejada entre o valor de $I_{d s}$ da área AM4 no sistema SM1-D e o valor de $I_{d s}$ da área AM1 no sistema SM1-C foi feita para demonstrar onde estariam os valores esperados da corrente $I_{d s}$ se utilizadas amostras com áreas totais entre as áreas AM1 e AM4. Entretanto quando utilizamos o sistema SM2, o valor final da corrente $I_{d s}$ é menor do que o esperado para as amostras Al1 e Al2 (que pode ser verificado comparando o lado esquerdo da figura $4.13 \mathrm{com}$ o lado direito considerando a diferença nas escalas das ordenadas). A amostra AI2 possui um valor de área entre os valores das áreas das amostras AM1 e AM2. Com isso, o valor final esperado da corrente $I_{d s}$ deveria estar na mesma faixa dos valores de correntes $I_{d s}$ encontrados para as outras duas amostras (na linha tracejada), independente do sistema de medição utilizado (SM1-D ou SM1-C). Mas o valor encontrado da corrente foi muito menor, mesmo com toda a área da amostra submersa na solução. Mesmo que a amostra Al1 possui a menor área, pela figura 4.13 podemos verificar que o valor final da corrente $I_{d s}$ encontrado também é menor do que o valor esperado. Apesar das amostras Al1, Al2, Al3 e Al4 terem sido fabricadas no mesmo processo acredita-se que pode ter ocorrido algum problema de não homogeneidade do material durante sua fabricação, como também pode ter ocorrido algum estrago no filme durante a manipulação da lâmina para a fabricação das amostras individuais, mesmo que este trabalho tenha sido feito com extremo cuidado. Com isso, o número de sítios na superfície da amostra pode ser bem menor do que o esperado, resultando em uma área efetiva muito menor do que a área geométrica. Assim, as áreas efetivas das superfícies dessas amostras podem ser estimadas pelo valor da corrente $I_{d s}$ encontrado.

Utilizando os sistemas de medições SM1-D e SM1-C agora para três diferentes valores de pHs, foram realizadas as medições VDS e VGS para efeito de comparação e com isso montou-se a figura 4.14 . 


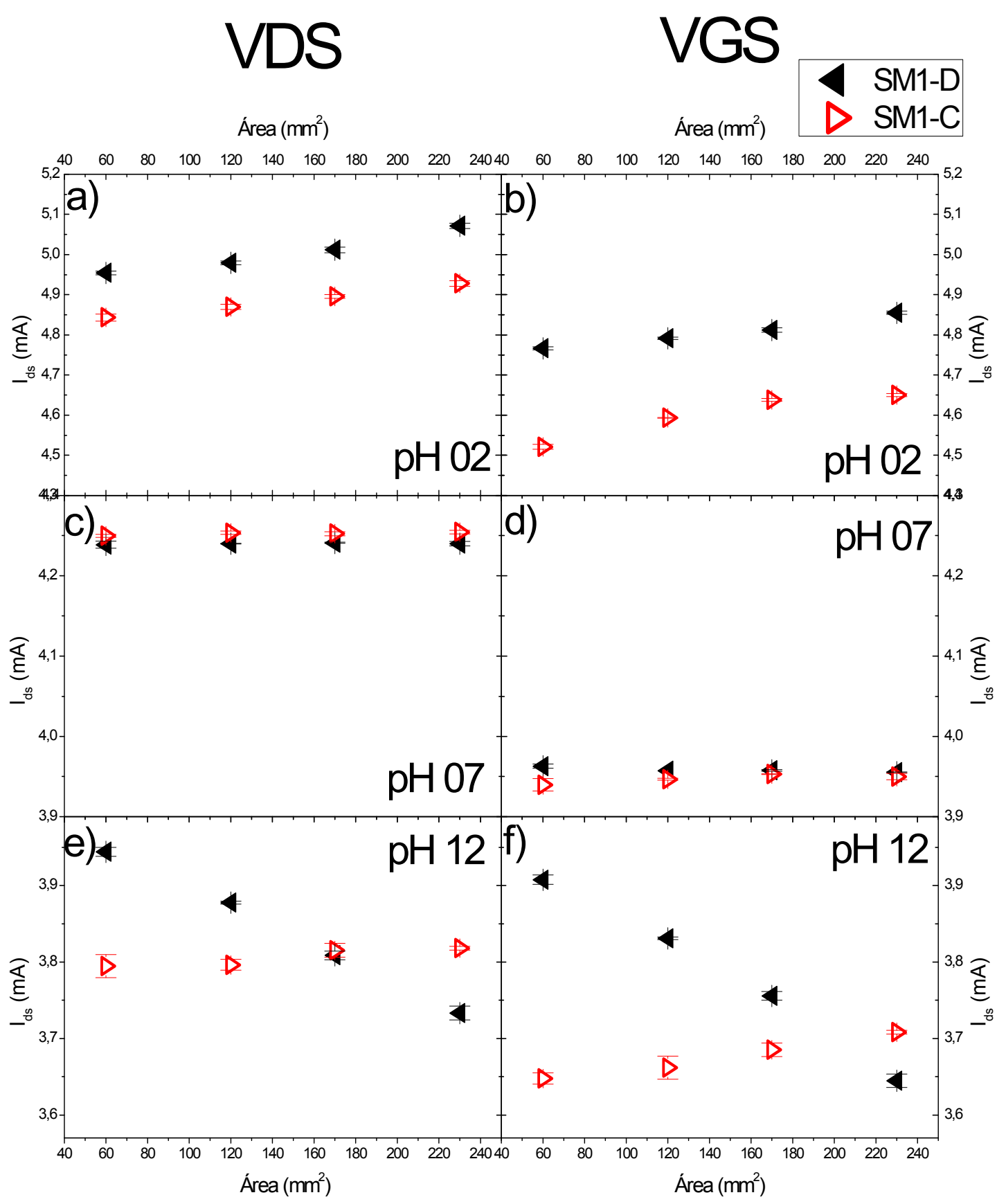

Figura 4.14: Medições VDS e VGS para os pHs 02, 07 e 12 feitas nas formas SM1-D e SM1-C. As figuras (a) e (b) se referem respectivamente as medições VDS e VGS para a solução tampão com $\mathrm{pH}$ 02, as figuras (c) e (d) se referem respectivamente as medições VDS e VGS para a solução tampão com pH 07 e as figuras (e) e (f) se referem respectivamente as medições VDS e VGS para a solução tampão com pH 12

É importante observar que as abscissas das três figuras do lado esquerdo (figuras (a), (c) e (e)) possuem a mesma escala, assim como as três figuras do lado direito (figuras (b), (d) e (f)). Já as ordenadas estão somente em mesma escala para os gráficos referentes ao mesmo valor de $\mathrm{pH}$. 
A figura 4.14 (a) é exatamente a mesma figura do lado direito da figura 4.13. Portanto deve ser considerada toda a discussão anterior. A figura 4.14 (b) é referente aos sistemas de medição SM1-D e SM1-C quando feita a medição VGS utilizando a solução tampão com pH 02. Os valores das correntes encontrados seguem o mesmo comportamento quando a medição é feita na forma VDS, porém com um deslocamento para baixo. Quando a medição é feita na forma VDS, como já discutido anteriormente, não há uma alteração no canal do MOSFET que possibilitará a passagem de corrente entre o dreno e a fonte. Mas quando a medição é feita na forma VGS, essa alteração no canal ocorre alterando assim a dinâmica dos íons dentro da solução e com isso diminuindo o valor final de $I_{d s}$, como pode ser verificado comparando as figuras 4.14 (a) e 4.14 (b).

As figuras 4.14 (c) e (d) são referentes às medições VDS e VGS respectivamente utilizando solução tampão com pH 07. Pode-se perceber que a alteração do valor da corrente $I_{d s}$ em relação a área é mínimo para ambas as medições. O comportamento dos valores das correntes encontrados é o mesmo independente da medição utilizada ocorrendo somente um deslocamento da corrente entre a medição VDS e a medição VGS, como ocorre quando utilizado a solução tampão com pH 02. Essa resposta da corrente mais estabilizada está de acordo com o esperado, já que quando a medição é feita utilizando a solução tampão com pH 07 não é esperado uma variação da corrente devido ao ponto isoelétrico do FTO, então mesmo considerando uma oferta maior ou menor de sítios devido a solução tampão utilizada o valor da corrente não deve alterar de forma significativa.

As figuras 4.14 (e) e (f) são referentes às medições VDS e VGS respectivamente utilizando solução tampão com pH 12. Quando a medição é feita na forma SM1-C, o comportamento da resposta do sensor para ambas as medições VDS e VGS é o mesmo, sendo que o valor da corrente quando feita a medição VGS é menor que o valor da corrente quando feita a medição VDS. Mas quando a medição é feita na forma SM1-D, o comportamento da resposta do sensor ocorre de forma inversa ao comportamento da resposta do sensor quando a solução utilizada é a com pH 02 , isto é, quando a solução tampão utilizada é a com pH 02 a resposta do sensor quando a medição utilizada é a 
SM1-D ocorre de forma crescente em relação a área, mas quando a solução tampão utilizada é a com pH 12 a resposta do sensor quando a medição utilizada é a SM1-D ocorre de forma decrescente em relação a área. Isso ocorre pois quando inserimos toda a superfície da amostra (área AM4) todos os sítios da superfície entram em contato com a solução e com isso obtemos o primeiro valor de $I_{d s}$. Quando retiramos uma parte da área da superfície da amostra (área AM3) e realizamos a medição novamente, a área retirada ainda possui cargas na superfície influenciando no valor final de dV. Com a diminuição da área da superfície imersa deveria diminuir o valor da corrente como ocorre com o $\mathrm{pH} 02$, mas quando utilizamos o pH 12 o fator temporal se torna mais evidente. Como demonstrado na figura 4.4, quando a solução utilizada é uma solução alcalina o valor da corrente aumenta até que ocorra a estabilização devido à maior oferta de íons $\mathrm{OH}^{-}$, na solução que irão reagir com os íons hidrônios da superfície da amostra aumentando o valor de dQ e consequentemente aumentando o valor de dV. Pelas figuras 4.14 (e) e (f) podemos perceber que o fator temporal quando realizada a medição SM1-D é mais influente na resposta do sensor do que a influência da área.

Quando a medição é feita na forma SM1-C, inicialmente colocamos somente uma pequena área de toda a superfície da amostra em contato com a solução tampão. Essa pequena área (AM1) possui um número bem menor de sítios ligantes e com isso o valor de $d V$ será menor e consequentemente o valor da corrente $I_{d s}$ também diminuirá. Quando inserimos uma nova área (AM2), essa nova área possui novos sítios que ainda não haviam entrado em contato com a solução. A área AM1 que já se encontrava submersa e com isso em uma fase temporal mais avançada vai fazer com que o valor da corrente aumente. Com isso o valor final da corrente $I_{d s}$ para a segunda medição (AM2) vai ser maior do que o valor final da corrente $I_{d s}$ encontrado quando feita a primeira medição (AM1). O mesmo ocorre para AM3 e AM4.

A sensibilidade para cada área considerando cada sistema de medição é mostrada na figura 4.15 . 


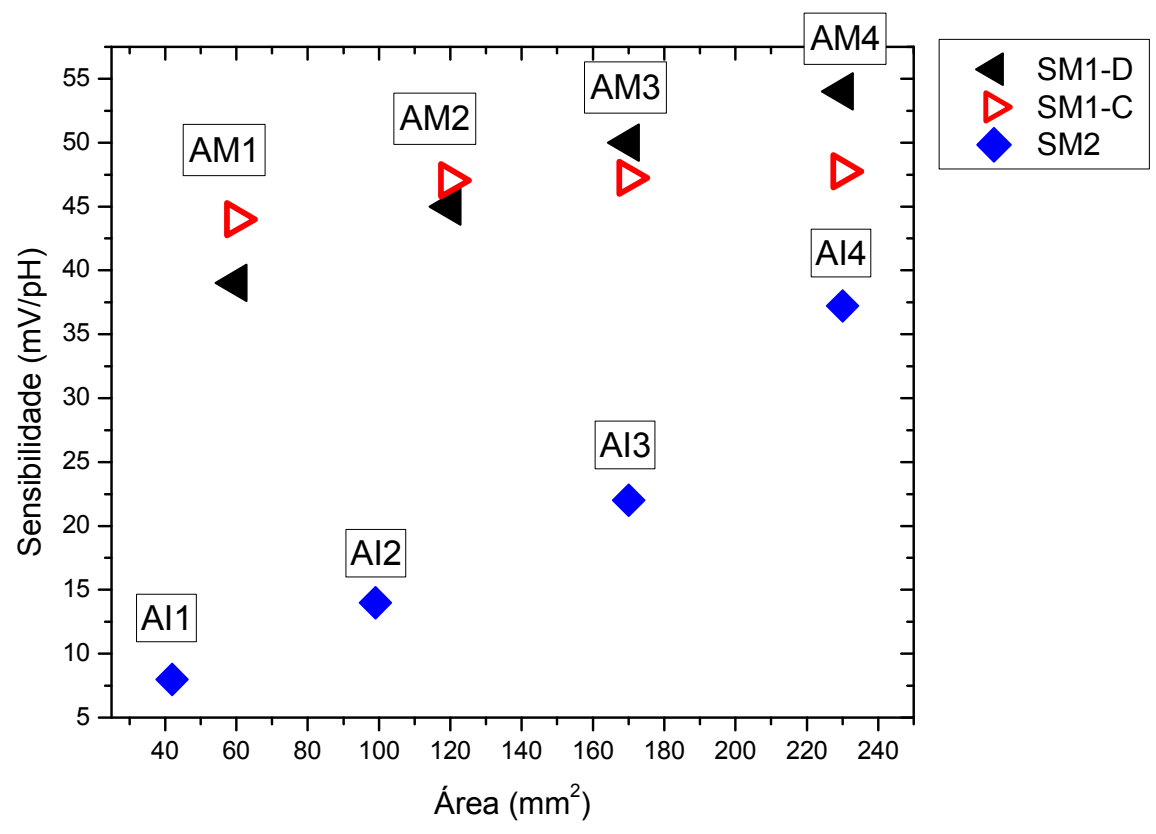

Figura 4.15: Sensibilidade encontrada para cada área para cada sistema de medição

Considerando o sistema de medição SM1-D, podemos perceber pela figura 4.15 que quanto maior a área da amostra maior o valor da sensibilidade. Já quando o sistema de medição utilizado é o SM1-C, o valor da sensibilidade aumenta com o aumento da área, mas esse aumento não é muito significativo. Quando fazemos a medição no sistema SM1-D e a primeira medição é feita com toda a superfície da amostra em contato com a solução tampão utilizada, todos os sítios da superfície da amostra entram em contato com os íons da solução. Na segunda medição, a área efetiva da superfície da amostra é menor, porém ainda possui cargas acopladas nessa superfície que irão influenciar no valor de dV. O mesmo ocorre para as terceira e quarta medições.

A sensibilidade é calculada pela medição VGS como demonstrado na seção 3.3, figura 3.10. Já vimos pela figura 4.14 que para pHs ácidos o valor da corrente $I_{d s}$ diminui com a diminuição da área e para pHs alcalinos o valor da corrente aumenta. Isso faz com que a faixa total dos valores das correntes encontrados diminua, diminuindo assim o valor da sensibilidade. Mas quando consideramos o sistema SM1-C, vimos pela figura 4.14 que o aumento da área da superfície da amostra que esta em contato com a solução aumenta o valor 
da corrente $I_{d s}$. Essa variação para $\mathrm{pHs}$ ácidos é maior do que para $\mathrm{pHs}$ alcalinos, fazendo com que a amplitude dos valores encontrados diminua mas não de forma muito significativa quando a medição SM1-D é realizada. Isso faz com que a sensibilidade aumente com o aumento da área mas esse aumento não é significativo, como pode-se perceber pela figura 4.15.

Com as amostras individuais Al1 a Al4 (sistema de medição SM2), podemos perceber que a sensibilidade diminui com a diminuição da área. Essa sensibilidade pequena pode ser devido à discussão anterior sobre a possível diferença na qualidade da fabricação dessas amostras. Durante a fabricação das amostras, pode ter ocorrido algum problema de não homogeneização na deposição do material no substrato, por exemplo.

Para podermos entender como o tamanho da área pode afetar a sensibilidade da amostra foi feita uma revisão bibliográfica para diversos materiais utilizados como membranas sensíveis do EGFET, onde foi considerado o material da membrana sensível, a sensibilidade desse material, a área do material utilizada e com esses dados foi calculada a sensibilidade/área como pode ser verificado na tabela 4.1. 


\begin{tabular}{|c|c|c|c|c|}
\hline Material & Sensibilidade $(\mathrm{mV} / \mathrm{pH})$ & Área $\left(\mathrm{mm}^{2}\right)$ & $\begin{array}{c}\text { Sensibilidade/Área } \\
\left(\mathrm{mV} / \mathrm{pH} \cdot \mathrm{mm}^{2}\right)\end{array}$ & Referência \\
\hline $\mathrm{ZnO}$ & 17,73 & 4,0 & 04,43 & $(51)$ \\
\hline $\mathrm{ZnO}$ & 38 & 100 & 00,38 & (31) \\
\hline $\mathrm{ITO} / \mathrm{Si}$ & 41,43 & 4,0 & 10,36 & (52) \\
\hline $\mathrm{ITO} / \mathrm{SiO}_{2} / \mathrm{Si}$ & 43,04 & 4,0 & 10,76 & $(52)$ \\
\hline ITO & 58 & 4,0 & 14,50 & (4) \\
\hline $\mathrm{SnO}_{2}$ & 23 & 0,5 & 46,00 & (4) \\
\hline $\mathrm{SnO}_{2}$ & 42 & 1,0 & 42,00 & (4) \\
\hline $\mathrm{SnO}_{2}$ & 42 & 1,8 & 23,33 & (4) \\
\hline $\mathrm{SnO}_{2}$ & 51 & 2,3 & 22,17 & (4) \\
\hline $\mathrm{SnO}_{2}$ & 52 & 3,5 & 14,86 & (4) \\
\hline $\mathrm{SnO}_{2}$ & 57 & 4,0 & 14,25 & (4) \\
\hline $\mathrm{SnO}_{2}$ & 56 & 6,0 & 09,33 & (4) \\
\hline $\mathrm{SnO}_{2}$ & 54 & 6,3 & 08,57 & (4) \\
\hline $\mathrm{SnO}_{2}$ & 51 & 8,8 & 05,79 & (4) \\
\hline $\mathrm{SnO}_{2}$ & 56 & 13,6 & 04,12 & (4) \\
\hline $\mathrm{SnO}_{2}$ & 63 & 14,0 & 04,50 & (4) \\
\hline $\mathrm{SnO}_{2} / \mathrm{ITO}$ & 14 & 0,18 & 77,78 & (4) \\
\hline $\mathrm{SnO}_{2} / \mathrm{ITO}$ & 37 & 0,2 & 185,0 & (4) \\
\hline $\mathrm{SnO}_{2} / \mathrm{ITO}$ & 49 & 0,25 & 196,0 & (4) \\
\hline $\mathrm{SnO}_{2} / \mathrm{ITO}$ & 57 & 0,8 & 71,25 & (4) \\
\hline $\mathrm{SnO}_{2} / \mathrm{ITO}$ & 55 & 1,1 & 50,00 & (4) \\
\hline $\mathrm{SnO}_{2} / \mathrm{ITO}$ & 56 & 2,0 & 28,00 & (4) \\
\hline $\mathrm{SnO}_{2} / \mathrm{ITO}$ & 51 & 2,3 & 22,17 & (4) \\
\hline $\mathrm{SnO}_{2} / \mathrm{ITO}$ & 55 & 2,6 & 21,15 & (4) \\
\hline $\mathrm{SnO}_{2} / \mathrm{ITO}$ & 54 & 7,5 & 07,20 & (4) \\
\hline $\mathrm{SnO}_{2} / \mathrm{ITO}$ & 57,1 & $4.10^{6}$ & $1,43.10^{-5}$ & (53) \\
\hline Polipirrol/SnO ${ }_{2} / \mathrm{ITO}$ & 27,8 & $4.10^{6}$ & $6,95.10^{-6}$ & (53) \\
\hline FTO & 50 & 100 & 00,50 & (54) \\
\hline $\mathrm{Si}_{3} \mathrm{~N}_{4}$ & 41 & $1,376.10^{2}$ & $2,98.10^{4}$ & (55) \\
\hline
\end{tabular}

Tabela 4.2: Revisão bibliográfica para comparação da sensibilidade/área para diferentes materiais utilizados como membranas sensíveis a íons no EGFET 
Pelos valores obtidos na tabela 4.1 foi construída a figura 4.16.

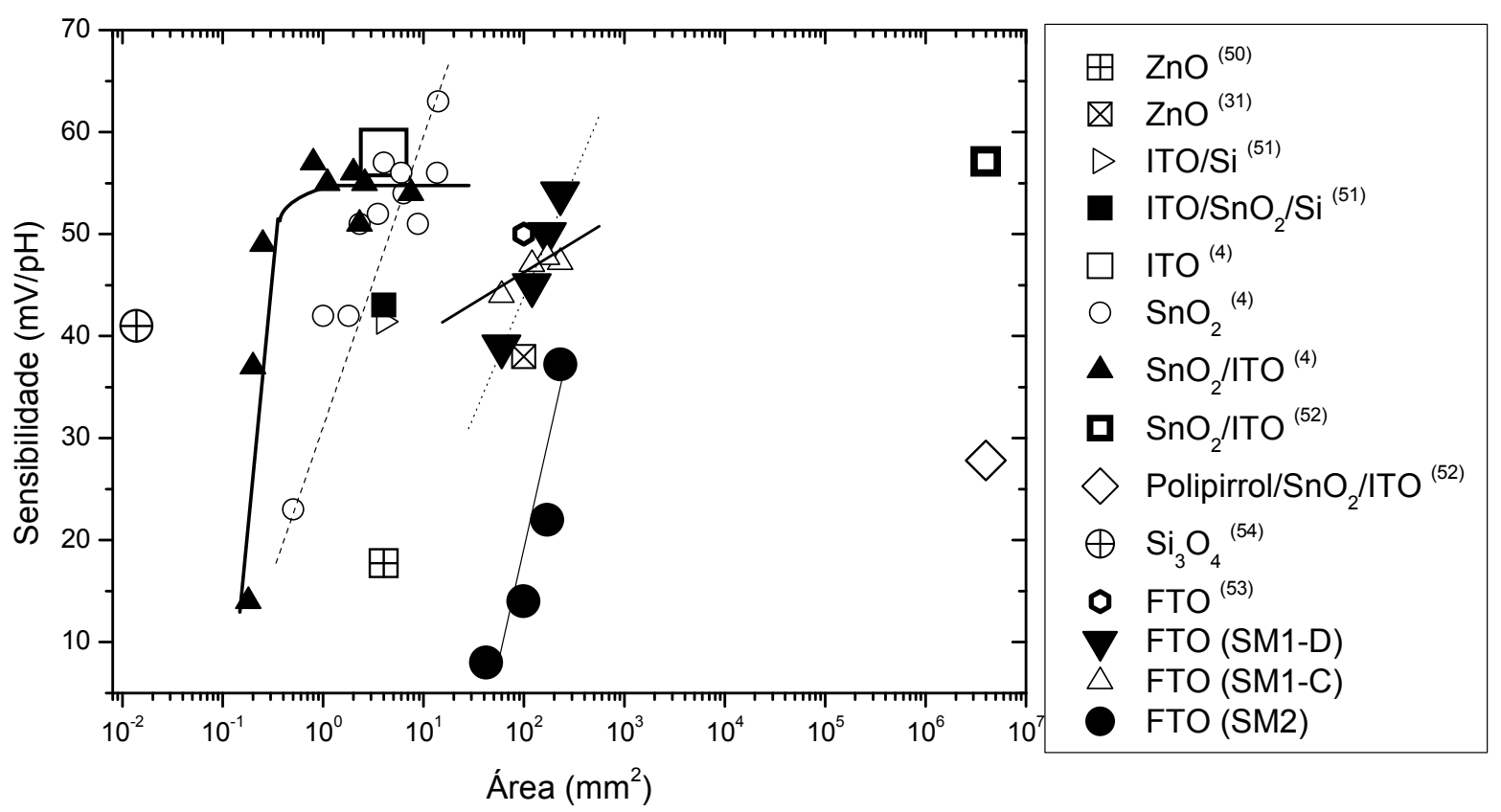

Figura 4.16: Sensibilidade pela área para diversos materiais utilizados como membranas sensíveis do EGFET

A figura 4.16 se encontra em escala monolog para facilitar a visualização. Diferentes áreas para o mesmo material estão demonstradas pelos mesmos símbolos. Quando isso ocorre foi traçado uma linha para facilitar a comparação. A figura 4.17 resume apenas os materiais que possuem diferentes áreas em um mesmo trabalho. 


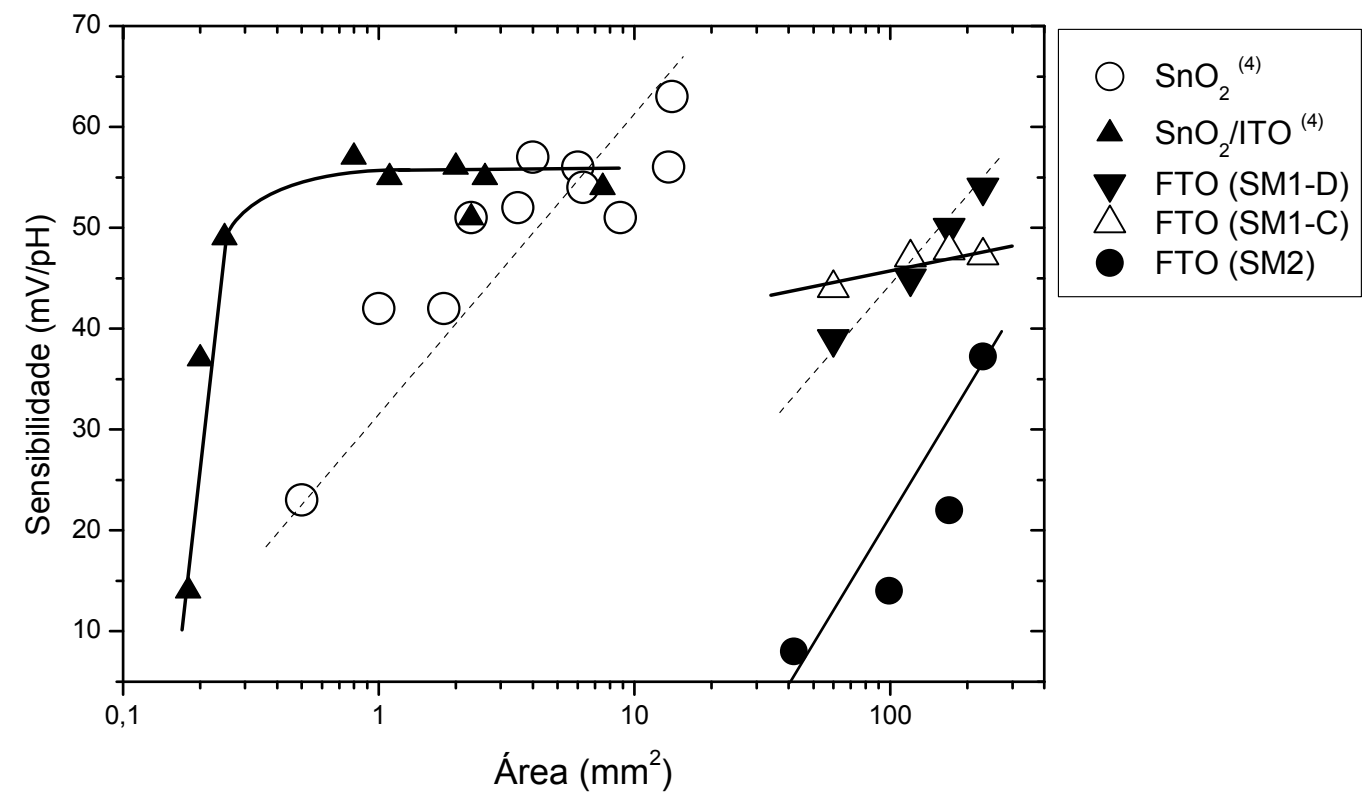

Figura 4.17: Sensibilidade pela área para os materiais $\mathrm{SnO}_{2}, \mathrm{SnO}_{2} / \mathrm{ITO}$ e FTO

Para todos os materiais considerados, de uma forma geral quanto maior a área maior a sensibilidade.

Considerando o material utilizado $\mathrm{SnO}_{2} / \mathrm{ITO}(\boldsymbol{\Delta})$ a sensibilidade do material aumenta com o aumento da área, mas a partir de uma determinada área essa sensibilidade se mantém estável como sugerido pela linha desenhada para facilitar a visualização.

Quando o material utilizado é somente $\circ \mathrm{SnO}_{2}(\mathrm{O})$ a sensibilidade aumenta com o aumento da área do material. $\mathrm{O}$ mesmo ocorre quando $\mathrm{o}$ material utilizado é o FTO, pois a sensibilidade também aumenta com o aumento da área. Na figura 4.16 a referência (54) também utilizou o material FTO $(\boldsymbol{O})$ e a sensibilidade encontrada em função da área está semelhante a sensibilidade encontrada quando as medições consideradas são as SM1-D e SM1-C. Quando a medição utilizada é a SM2 a sensibilidade em função da área das amostras está abaixo do esperado como pode ser verificado na figura 4.17. Como já comentado isso pode ocorrer devido a possíveis falhas no filme diminuindo assim a área efetiva das amostras individuais ou a própria diferença de qualidade durante o processo de fabricação da amostra. 
A figura 4.18 refere-se à sensibilidade/área pela área. Quando verificamos a sensibilidade/área pela área podemos comparar a qualidade da amostra pois uma amostra muito grande com pequena sensibilidade não deve ser considerada tão eficaz quanto uma amostra pequena com a mesma sensibilidade da amostra maior, pois se a amostra menor possui a mesma sensibilidade então possui a mesma quantidade de sítios ligantes na superfície mesmo com menor área, como demonstrado na equação (2.11).

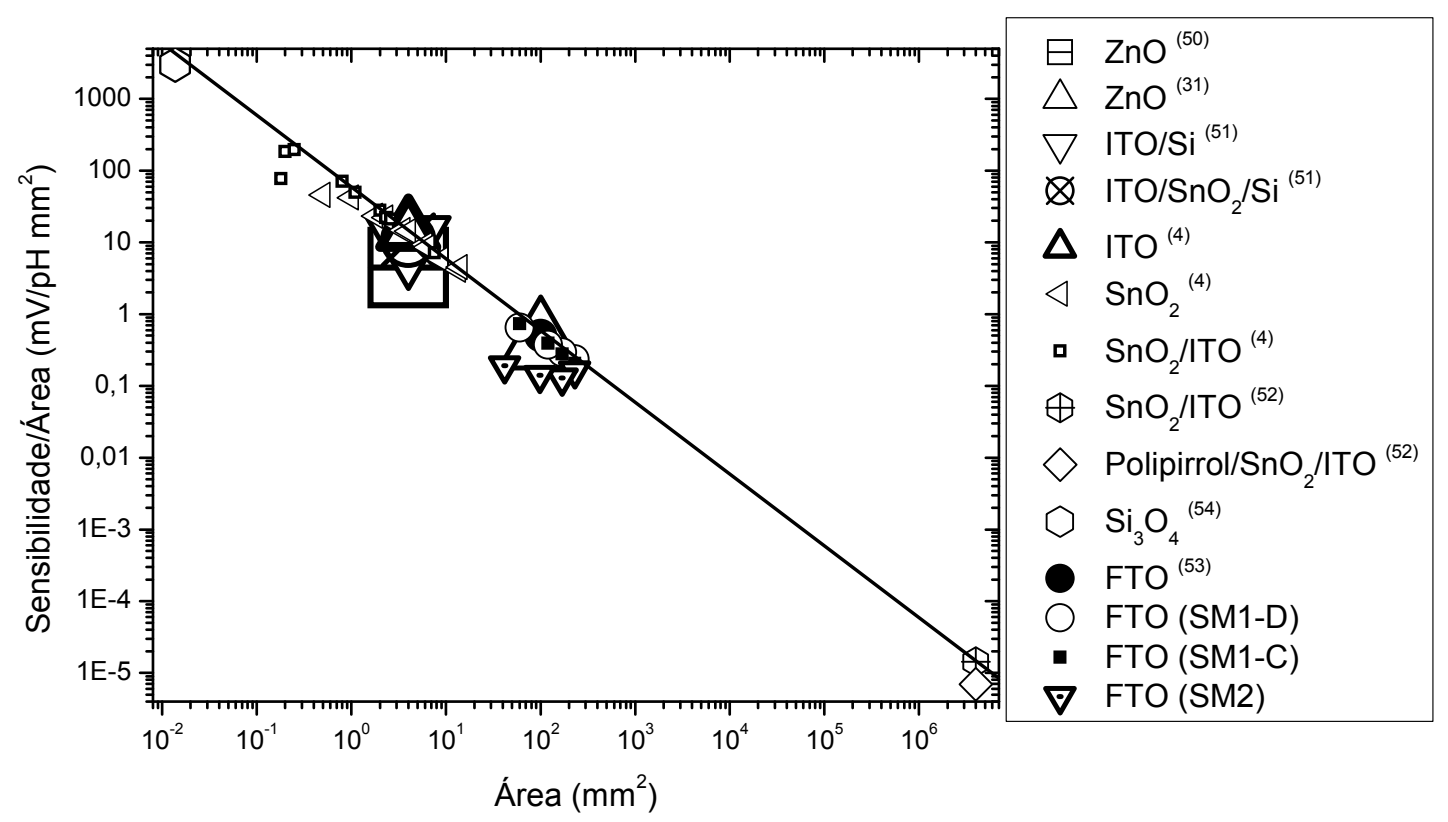

Figura 4.18: Sensibilidade/área pela área para diferentes materiais utilizados como membrana sensível a íons do EGFET. A linha é referente ao valor máximo teórico da sensibilidade

Os eixos estão em escala logarítmica. A linha na figura 4.18 é a linha referente à sensibilidade igual a $59.2 \mathrm{mV} / \mathrm{pH}$, referente a sensibilidade Nernstiana a temperatura ambiente ${ }^{(56)}$. Esse valor segundo a teoria de Nernst é o maior valor de sensibilidade que a membrana sensível a íons pode apresentar. Para melhor visualização da figura 4.18, as duas áreas com maior concentração de pontos foram ampliadas, como pode ser verificado nas figuras 4.19 e 4.20. A melhor membrana sensível a íons pode ser considerada a membrana formada por $\mathrm{Si}_{3} \mathrm{O}_{4}$, pois ela possui a menor área com maior sensibilidade/área e ainda essa sensibilidade/área está muito perto da sensibilidade Nernstiana. Já as piores membranas podem ser consideradas as 
com materiais $\mathrm{SnO}_{2} / \mathrm{ITO}$ da referência (53) e polipirrol/ $\mathrm{SnO}_{2} / \mathrm{ITO}$, pois possuem a maior área de membrana com menor sensibilidade/área.

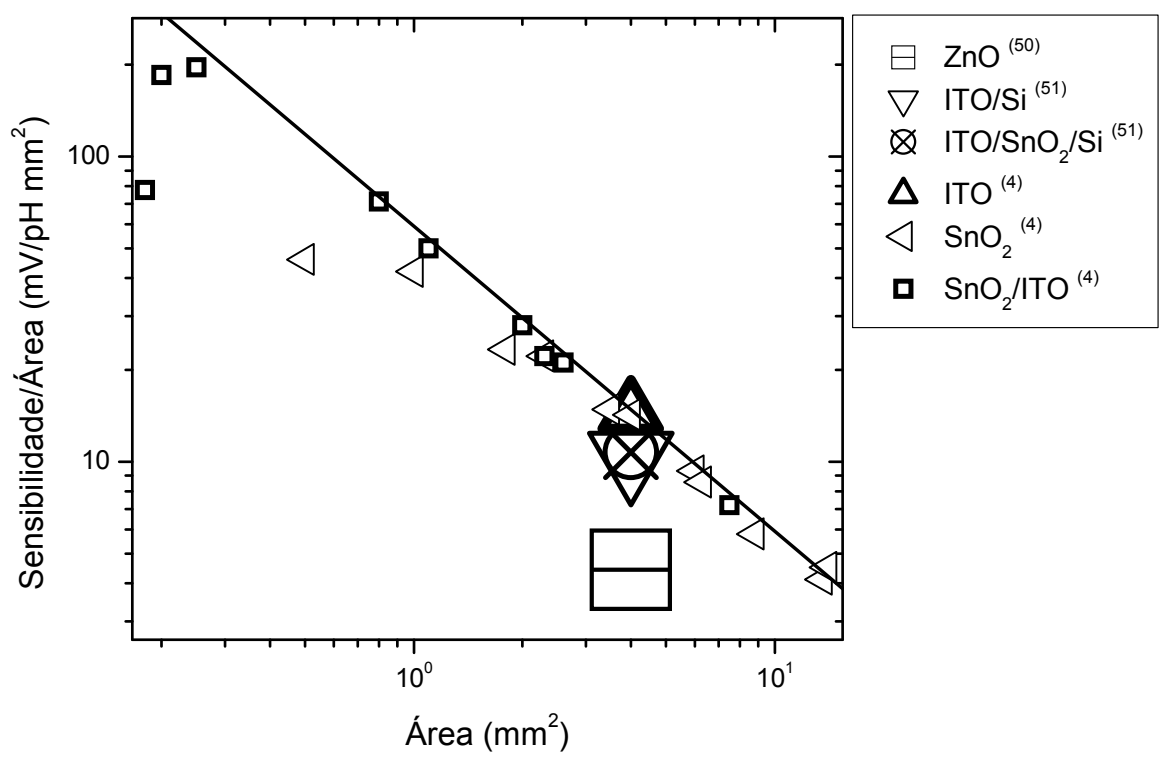

Figura 4.19: Ampliação da figura 4.18

A maioria das amostras feitas com $\mathrm{SnO}_{2} / \mathrm{ITO}$ ( $\square$ ) possuem uma sensibilidade/área próximas a sensibilidade de $59,2 \mathrm{mV} / \mathrm{pH}$, sendo assim consideradas boas membranas. Para áreas menores essa sensibilidade/área diminui significantemente. Considerando as amostras feitas somente de $\mathrm{SnO}_{2}$ $(\triangleleft)$ pode-se perceber pela figura 4.19 que com o aumento da área melhor a sensibilidade/área das amostras. A amostra produzida somente com ITO $(\Delta)$ possui praticamente a mesma sensibilidade/área da amostra produzida com $\mathrm{SnO}_{2}$ para a mesma área. 


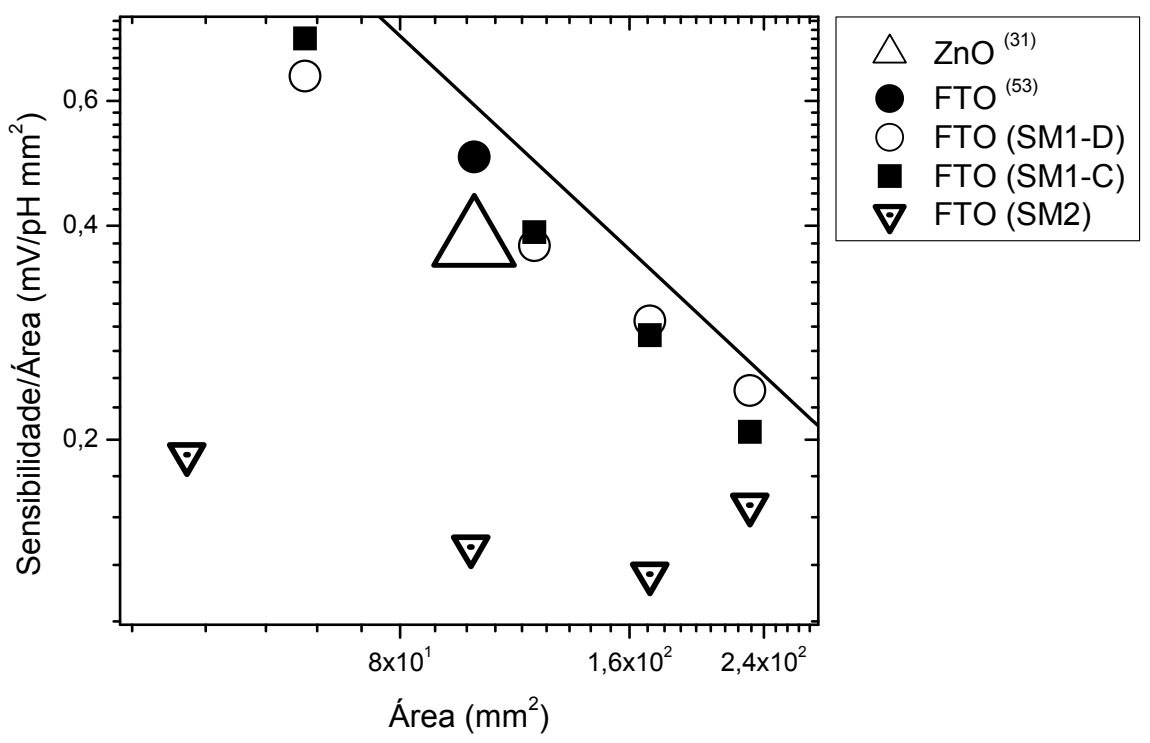

Figura 4.20: Ampliação da figura 4.18

Na figura 4.20 a maioria dos pontos pertence ao material FTO utilizado como membrana sensível a íons. Quando consideramos o FTO utilizando SM1$D$ podemos perceber que quanto maior a área menor é a sensibilidade/área. $O$ mesmo quando considerado SM1-C. Mas quando consideramos SM2, quanto menor a área, maior a sensibilidade/área exceto para a maior área onde a sensibilidade/área aumenta. Mas para estas áreas (SM2) a sensibilidade/área está muito abaixo do esperado e portanto essas membrana sensíveis a íons não são consideradas boas membranas.

Portanto, pelas figuras 4.19 e 4.20 podemos verificar que as melhores membranas sensíveis a íons do EGFET são as fabricadas com $\mathrm{SnO}_{2} / \mathrm{ITO}$ ( $\square$ ) e com $\mathrm{SnO}_{2}(\triangleleft)$. Porém, essas membranas possuem uma boa sensibilidadelárea somente para as áreas maiores, diminuindo essa sensibilidade com a diminuição da área. Mas o desafio maior atualmente é o desenvolvimento de uma membrana sensível a íons que possua boa sensibilidade/área, baixo custo e possível miniaturização. A melhor membrana encontrada nessa revisão bibliográfica foi a de $\mathrm{Si}_{3} \mathrm{O}_{4}(D)$ pois possui a maior sensibilidade/área e a menor área. 
As amostras AM1 a AM4 possuem uma sensibilidade/área considerada boa, mas ainda abaixo do ideal, tanto para os sistemas de medições SM1-D quanto SM1-C. As amostras Al1 a Al4 possuem sensibilidade/área não satisfatórias. No entanto, o estudo do FTO como membrana sensível a íons do EGFET é de extrema importância. Pode-se inferir a alta condutividade desses filmes de FTO como uma propriedade importante para a operação desse dispositivo. Acredita-se que a baixa condutividade pode reduzir a sensibilidade do dispositivo quando conectado ao MOSFET comercial ${ }^{(57 ; 58)}$.

Os artigos da literatura devem ser vistos com muito cuidado quando comparados os diferentes materiais. As áreas dos dispositivos devem ser levadas em consideração para considerar a sensibilidade do material utilizado.

\subsection{Influência da temperatura}

Para verificarmos a influência da variação da temperatura da solução na resposta do sensor, a temperatura da solução foi alterada de $22^{\circ} \mathrm{C}$ até $60^{\circ} \mathrm{C}$ e então feita a medição nas formas VDS e VGS. A figura 4.21 mostra os resultados obtidos quando a solução tampão utilizada foi a com pH 02.

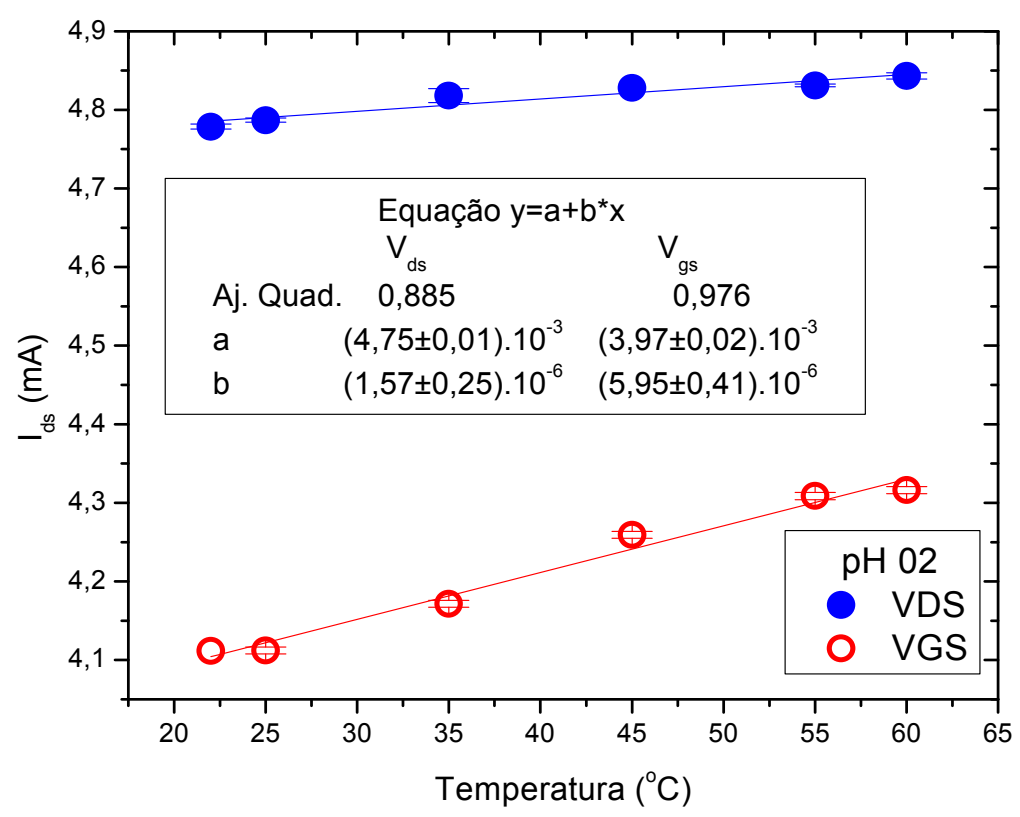

Figura 4.21: Valor final da corrente $I_{d s}$ nas medições VDS e VGS para a solução tampão com $\mathrm{pH} 02$ em função da temperatura 
Pode-se verificar pela figura 4.21 que, tanto para a medição VDS quanto para a medição VGS, o valor final da corrente $I_{d s}$ aumenta com o aumento da temperatura. O aumento da temperatura na solução utilizada aumenta tanto a mobilidade dos íons dentro da solução quanto a velocidade de reação iônica, como explicado na seção 2.3. Com o aumento da temperatura, aumenta-se a energia cinética, a mobilidade dos íons dentro da solução e a taxa de difusão da solução, fazendo com que dV aumente e consequentemente aumenta-se o valor de $I_{d s}$.

Foi traçado um ajuste linear para facilitar a visualização da inclinação da reta e com isso verificar qual medição (VDS ou VGS) obteve a maior variação da corrente em função da alteração da temperatura.

Quando a medição é feita na forma VDS a corrente $I_{d s}$ teve uma variação de $0,06 \mathrm{~mA}$ ou $1,2 \%$ quando a temperatura varia de $22^{\circ} \mathrm{C}$ a $60^{\circ} \mathrm{C}$, enquanto que, quando realizada a medição na forma VGS a variação da corrente $I_{d s}$ quando a temperatura tem essa mesma variação é de 0,21 mA ou $5,11 \%$.

O aumento da temperatura não afeta a resposta do transistor pois o MOSFET se encontra fora do sistema onde ocorre a alteração da temperatura. Por isso, a alteração da corrente em função do aumento da temperatura quando a medição utilizada é a VDS ocorre somente devido ao aumento da mobilidade dos íons dentro da solução. Com o aumento da temperatura e consequentemente aumento da mobilidade dos íons, aumenta-se o valor de dQ resultando em uma corrente mais alta.

Já a medição VGS possui uma maior influência na dinâmica dos íons como já discutido anteriormente e por isso a variação da corrente $I_{d s}$ quando a medição é feita na forma VGS é maior do que quando feita na forma VDS. O aumento da temperatura altera a constante da velocidade da adsorção e com isso desloca a reação ou para esquerda ou para direita. Neste caso, considerando a reação 4.1 que ocorre entre a superfície e os íons da solução o aumento da temperatura vai favorecer a reação da direita para a esquerda aumentando assim o valor de $\mathrm{dV}$ e consequentemente o valor da corrente. 
Com o aumento da tensão no eletrodo de referência de 0 a $5 \mathrm{~V}$ o valor final da corrente é menor quando a medição realizada é a VGS do que quando a medição realizada é a VDS. Mas com o aumento da temperatura aumenta-se cada vez mais a mobilidade dos íons dentro da solução e com o aumento da tensão no eletrodo de referência a influência da mobilidade dos íons é mais forte fazendo com que o dV aumente mais drasticamente com o aumento da temperatura e consequentemente aumentando-se o valor da corrente $I_{d s}$.

Quando a solução tampão utilizada é a com pH 07 a resposta do sensor é mostrada na figura 4.22 .

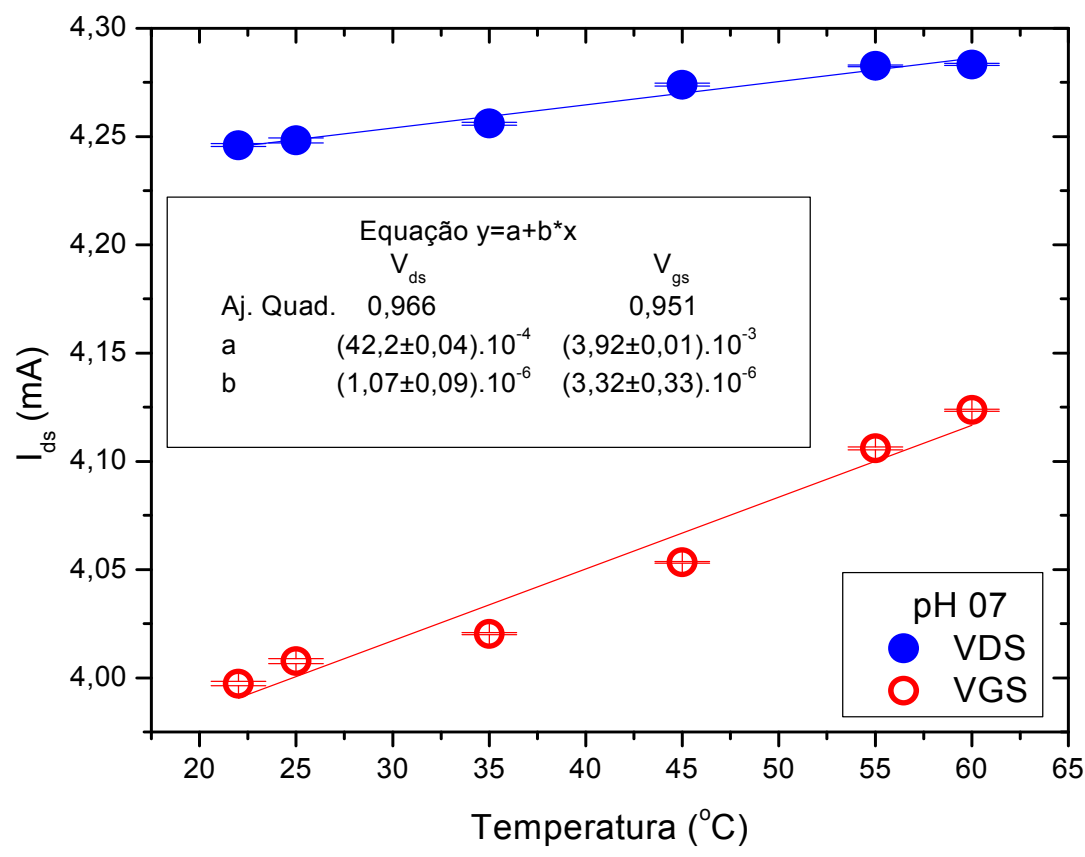

Figura 4.22: Valor final da corrente $I_{d s}$ nas medições VDS e VGS para a solução tampão com pH 07 em função da temperatura

A variação total da corrente $I_{d s}$ quando a medição é feita na forma VDS é de $0,03 \mathrm{~mA}$ ou $0,94 \%$ enquanto que a variação da corrente quando a medição é feita na forma VGS é de $0,12 \mathrm{~mA}$ ou 2,91\%. Essa variação também ocorre pela maior mobilidade dos íons dentro da solução em função do aumento da temperatura, bem como pelo aumento da velocidade da reação dos íons dentro da solução com os íons da superfície da amostra. 
As variações das correntes tanto para as medições VDS e VGS possuem em torno da metade do valor das variações das correntes para as respectivas medições utilizando solução tampão com pH 02. A solução tampão com $\mathrm{pH} 02$ possui uma grande quantidade de íons $\mathrm{H}^{+}$e em pouca oferta de íons $\mathrm{OH}^{-}$. Com o aumento da temperatura e o deslocamento da reação 4.1 para a esquerda a formação de íons hidrônios e hidroxilas se torna mais favorável do que a formação de moléculas de água. Com a grande oferta de íons $\mathrm{H}^{+}$que se liga as moléculas de água formando íons hidrônios e a formação de hidrônio sendo favorecida com o aumento da temperatura, a variação de $d Q$ e consequentemente de $d V$ quando a solução utilizada é a com $\mathrm{pH} 02$ deve ser maior do que quando a solução utilizada é a de $\mathrm{pH} 07$, pois esta é uma solução de pH neutro e além do mais, por ser o ponto isoelétrico do FTO a quantidade de íons $\mathrm{OH}^{-}$e $\mathrm{H}^{+}$na superfície deve ser igual.

Agora quando a solução tampão utilizada é a de pH 12, os valores encontrados das correntes $I_{d s}$ em função da temperatura estão mostrados na figura 4.23 .

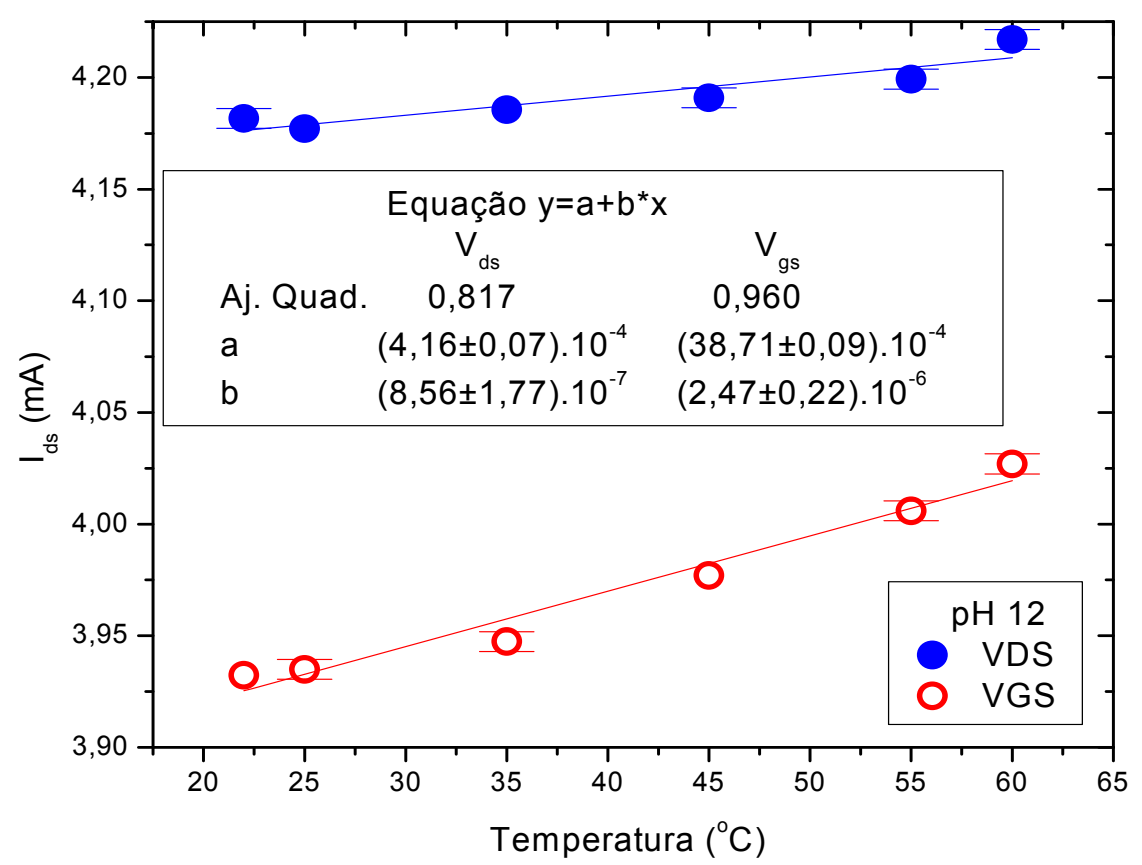

Figura 4.23: Valor final da corrente $I_{d s}$ nas medições VDS e VGS para a solução tampão de pH 12 em função da temperatura 
O comportamento das respostas do sensor é o mesmo das soluções anteriores, sendo que a variação do valor da corrente quando a medição é feita na forma VDS é de $0,04 \mathrm{~mA}$ ou $0,95 \%$ e na forma VGS é de $0,10 \mathrm{~mA}$ ou $2,54 \%$. Esses valores estão bem próximos dos valores encontrados para a solução de $\mathrm{pH} 07$.

Isso ocorre pois a solução com pH 12 possui uma grande oferta de íons hidroxilas e com o aumento da temperatura e então o deslocamento da reação 4.1 para a esquerda favorecendo a formação de íons hidrônios e hidroxilas haverá mais hidroxilas ainda na solução. Mas como a solução com pH 12 já possui esses íons em excesso a formação de mais íons hidroxilas na solução não será sentida de forma abrupta na superfície da amostra, fazendo com que os valores relativos a alteração da corrente em função da temperatura para a solução com pH 12 seja bem menor do que esses valores para a solução com $\mathrm{pH} 02$.

Além do mais, com o aumento da temperatura, os possíveis íons residuais na superfície da amostra serão retirados mantendo assim a superfície da amostra mais limpa e aumentando assim o valor final da corrente $I_{d s}$, além do aumento da temperatura interferir na velocidade das reações que ocorrem entre os íons da solução e os da superfície da amostra, aumentando assim dQ e consequentemente aumentando o valor de $I_{d s}$.

O valor da sensibilidade quando a amostra está em um sistema com a temperatura em $60^{\circ} \mathrm{C}$ aumentou em $60 \%$ do valor da sensibilidade quando a amostra está em um sistema com a temperatura em $22^{\circ} \mathrm{C}$.

Isso ocorre pois, como verificado nas figuras 4.21 e 4.23, quando a medição é feita a $60^{\circ} \mathrm{C}$ o aumento do valor final da corrente para o pH ácido é o dobro do aumento do valor final da corrente para o $\mathrm{pH}$ alcalino. Com isso, a faixa entre os valores finais da corrente para todos os valores de pHs aumenta, aumentando assim a sensibilidade em função do aumento da temperatura.

Outro experimento realizado foi o de cálculo da resistividade da folha da amostra em função do aumento da temperatura, utilizando a técnica de medição de quatro pontas. Essa técnica é largamente utilizada para a medição 
da resistividade e resistência de folhas. Utilizam-se quatro pontas chamadas de eletrodos dispostas linearmente sobre a superfície da amostra, injeta-se corrente através de dois eletrodos e então mede-se a tensão sobre os outros dois ${ }^{(59)}$. A resistividade da folha foi medida para todas as temperaturas utilizadas e não houve alteração significativa, evidenciando que a alteração da temperatura não altera as propriedades da amostra. A variação total da resistividade de folha em função do aumento da temperatura foi em torno de $8 \%$, no entanto o erro em relação ao aumento da temperatura aumenta de forma significativa aumentando em torno de $70 \%$. Esse aumento no erro pode ocorrer devido ao aquecimento da amostra por efeito Joule devido à corrente injetada ${ }^{(14 ; 59)}$. A pequena variação na resistividade de folha do FTO condiz com o esperado, pois o FTO é termicamente estável devido a não dependência de buracos do oxigênio para fornecer carreadores de cargas e com isso, quando exposto a altas temperaturas o FTO não experimenta diminuição característica na condutividade como ocorre, por exemplo, com o ITO ${ }^{(60)}$. 


\section{Capítulo 5 - Conclusões}

Neste trabalho foram feitos diversos estudos a fim de entender a influência da alguns fatores sobre o sistema de medidas EGFET utilizando filme fino de FTO como membrana sensível a íons $\mathrm{H}^{+}$para futuramente ser utilizado como um biossensor de $\mathrm{pH}$. Os fatores estudados foram a influência do tempo de medida na resposta do sensor, a influência da luz sob a membrana, a influência da área da membrana em contato com a solução tampão utilizada e a influência da variação da temperatura na solução tampão utilizada e consequentemente na membrana sensível a íons.

A dinâmica dos íons dentro da solução quando em contato com a superfície da membrana sensível a íons (FTO) é alterada por um determinado período de tempo até que ocorra a sua estabilização. $E$ a alteração também tem como influência o pH da solução utilizada, sendo a resposta do sensor em função do tempo para pHs ácidos diferente da resposta do sensor em função do tempo para pHs alcalinos. A solução de $\mathrm{pH} 02$ é a solução que obtém o maior valor de resposta da corrente $I_{d s}$ devido á sua maior oferta de íons $\mathrm{H}^{+}$. No entanto, a menor variação dos valores da corrente $I_{d s}$ é obtida quando a solução utilizada é a de pH 07 , devido ao ponto isoelétrico do FTO ser nessa faixa de $\mathrm{pH}$. A maior variação dos valores de corrente ocorre para os pHs mais alcalinos. A variação total da corrente para cada valor de $\mathrm{pH}$ ocorrem em torno de $5 \%$ enquanto que a variação do valor de corrente entre os pHs 02 ao 12 é de aproximadamente $30 \%$.

Quando a medição do valor da corrente $I_{d s}$ é feita com a amostra totalmente no escuro a reposta do sensor possui uma alteração em relação à mesma medição feita com a amostra em contato com a luz visível. A luz faz com que os elétrons na banda de valência saltem para a banda de condução no filme fino de FTO alterando então o valor encontrado da corrente para todos os pHs, no tempo de estabilização da corrente e na sensibilidade da amostra. Os resultados obtidos com a presença da luz sugerem que a luz influência na resposta do sensor. A variação do valor encontrado da sensibilidade quando as medições são realizadas no claro ou no escuro é de aproximadamente $10 \%$. 
A área da superfície da amostra influencia na resposta do sensor de duas diferentes formas, se a área das amostras utilizadas possuírem diferentes tamanhos a resposta do sensor é diferente do que se a mesma amostra utilizar quantidades diferentes da sua área. É necessário um cuidado maior quando comparada a sensibilidade encontrada para diversos materiais utilizados como membranas sensíveis do EGFET para sensor de pH na literatura. Deve-se levar em consideração a sensibilidade/área e não somente o valor da sensibilidade encontrada.

Em uma faixa de temperatura de $22^{\circ} \mathrm{C}$ a $60^{\circ} \mathrm{C}$ pode-se perceber que com o aumento da temperatura aumenta-se tanto o valor da corrente como também a sensibilidade da amostra. Para pHs ácidos essa alteração é maior do que para pHs alcalinos devido a temperatura alterar a constante de velocidade de adsorção. As alterações dos valores das correntes em função da temperatura encontrados foram entre $0,94 \%$ até $5,11 \%$. O aumento da sensibilidade em função da temperatura foi de $60 \%$.

Todos os resultados obtidos neste trabalho são de grande importância para a escolha da membrana sensível a íons do EGFET como sensor de $\mathrm{pH}$ para futuramente ser utilizado como biossensor de $\mathrm{pH}$ para aplicações médicas. A área da membrana deve ser sempre levada em consideração quando estudada a sensibilidade que o material apresenta. A luz também possui influência significativa na resposta do sensor. Apesar de o estudo ser voltado para um sensor de resposta rápida, o tempo de resposta não deve ser esquecido, pois altera o valor da corrente e essa alteração é dependente do valor do $\mathrm{pH}$ da solução utilizada. 


\section{Referências Bibliográficas}

1. Bergveld, P. Development of an ion-sensitive solid-state device for neurophysiological measurements. leee Transactions On Biomedical Engineering. 1970, Vol. 17, pp. 70-71.

2. Liao, H. K., et al. Study on $\mathrm{pH}(\mathrm{pzc})$ and surface potential of tin oxide gate ISFET. Materials Chemistry and Physics. 1999, Vol. 59, pp. 6-11.

3. Yin, L. T., et al. Study of indium tin oxide thin film for separative extended gate ISFET. Materials Chemistry and Physics. 2001, Vol. 70, pp. 12-16.

4. Yin, L. T., et al. Separate structure extended gate $\mathrm{H}+$-ion sensitive field effect transistor on a glass substrate. Sensors and Actuators B-chemical. 2000, Vol. 71, pp. 106-111.

5. Yin, L. T., et al. Characteristics of silicon nitride after $\mathrm{O} 2$ plasma surface treatment for pH-ISFET applications. Ieee Transactions On Biomedical Engineering. 2001, Vol. 48, pp. 340-344.

6. Gimmel, P., et al. Ta2O5-gates of pH-sensitive devices - Comparative spectroscopic and electrical studies. Sensors and Actuators. 1989, Vol. 17, pp. 195-202.

7. Liao, H. K., et al. Study of amorphous tin oxide thin films for ISFET applications. Sensors and Actuators B-chemical. 1998, Vol. 50, pp. 104-109.

8. Resende, S. M. A física de materiais e dispositivos eletrônicos. Recife : Editora da Universisdade Federal de Pernambuco, 1996.

9. Sedra, A. S. and Smith, K. C. Microelectronic Circuits. s.l. : Oxford University Press, 2007.

10. Guerra, E. M., et al. Extended gate field effect transistor using V2O5 xerogel sensing membrane by sol-gel method. Solid State Sciences. 2009, Vol. 11, pp. 456-460.

11. Nelson, D. L. and Cox, M. M. Lehninger Princípios de Bioquímica. 3. New York: W. H. Freeman and Company, 2002.

12. Nascimento, R. A. S. Análise de procedimentos de medida de dispositivos EGFET utilizando filmes de FTO. Dissertação de mestrado em Física Aplicada à Medicina e Biologia. s.I. : Universidade de São Paulo - Ribeirão Preto, 2010, p. 119.

13. Chi, L. L., et al. Study on extended gate field effect transistor with tin oxide sensing membrane. Materials Chemistry and Physics. 2000, Vol. 63, pp. 19-23. 
14. Sze, S. M. Physics of semiconductor devices. New Jersey: WileyInterscience, 1981.

15. Sze, S. M. and Ng, K. K. Physics of semiconductor devices. New Jersey : Wiley-Interscience, 2007.

16. Torres, K. Y. C., et al. Recent advances and new perspectives of ionselective electrodes. Quimica Nova. 2006, Vol. 29, pp. 1094-1100.

17. Fernandes, J. C. B., et al. Ion-selective electrodes: Historical, mechanism of response, selectivity and concept review. Quimica Nova. 2001, Vol. 24, pp. 120-130.

18. Batista, P. D. Dispositivos semicondutores a partir de óxidos de estanho e zinco. Tese de Doutorado. Ribeirão Preto : Universidade de São Paulo, 2008, p. 184.

19. Silva, G. R. Materiais micro e nanoestruturados para sensores de íons do tipo EGFET. Tese de doutorado. Ribeirão Preto : Universidade de São Paulo, 2009.

20. Kim, D. S., et al. An extended gate FET-based biosensor integrated with a Si microfluidic channel for detection of protein complexes. 2006, Vol. 117, 2, pp. 488-494.

21. Shinwari, M. W., et al. Study of the electrolyte-insulator-semiconductor field-effect transistor (EISFET) with applications in biosensor design. Microelectronics Reliability. 2007, Vol. 47, pp. 2025-2057.

22. Buck, R. P. Electrochemistry of Ion-selective Electrodes. Sensors and Actuators. s.l. : Kluwer Academic Publishers, 1981, Vol. 1, pp. 197-260.

23. Fung, C. D., et al. A generalized theory of an electrolyte-insulatorsemiconductor field-effect transistor. Ieee Transactions On Electron Devices. 1986, Vol. 33, pp. 8-18.

24. Lowinsohn, D. and Bertotti, M. Sensores eletroquímicos: Considerações sobre mecanismos de funcionamento e aplicações no monitoramento de espécies químicas em ambientes microscópios. Química Nova. 2006, Vol. 29, pp. 1318-1325.

25. Thévenot, D. R., et al. Electrochemical biosensors: recommended definitions and classification. Pure and Applied Chemistry. 1999, Vol. 71, pp. 2333-2348.

26. Bergveld, P. ISFET, Theory and Practice. IEEE SENSOR CONFERENCE TORONTO. University of Twente. 2003, p. 26. 
27. Van Hal, R. E. A general model to describe the eletrostatic potencial at electrolyte oxides interface. Advances in Colloid and Interfaces Science. 1996, Vol. 69, pp. 31-62.

28. Chiang, J. L. and Chou, J. C. Simulation and experimental study of the pHsensing property for AIN thin films. Japanese Journal of Applied Physics. 2011, Vol. 40, pp. 5900-5904.

29. Chiang, J. L. and Chen, Y. C. Study on light and temperature properties of AIN pH-ion-sensitive field-effect transistor devices. Japanese Journal of Applied Physics. n 7A, 2005, Vol. 44, p. 4831.

30. Batista, P. D., et al. SnO2 extended gate field-effect transistor as $\mathrm{pH}$ sensor. Brazilian Journal of Physics. 2006, Vol. 36, pp. 478-481.

31. Batista, P. D. and Mulato, M. ZnO extended-gate field-effect transistors as pH sensors. Applied Physics Letters. 2005, Vol. 87, p. 3.

32. Carpiné, D. Recuperação do aroma álcool feniletílico por adsorção em batelada e em coluna. Dissertação de mestrado. Curitiba: Universidade Federal do Paraná, 2011, p. 115.

33. IUPAC. Reporting physisorption data for gas/solid systems with special reference to the determination of surace area and porosity. Pure and Applied Chemistry. s.I. : n. 4, 1985, Vol. 57, pp. 603-619.

34. Ruthven, D. M. Principles of adsorption and adsorption processes. John Wiley \& Sons. 1984, p. 433.

35. Masel, R. Principles of adsorption and reaction on solid surfaces. Wiley Series in Chemical Engineering. 1996.

36. Scheer, A. P. Desenvolvimento de um sistema para simulação e otimização do processo de adsorção para avaliação da separação de misturas líquidas. Tese de doutorado. s.I. : Universidade Estadual de Campinas - FEQ, 2002, p. 223.

37. Suzuki, M. Adsorption Engineering. Chemical engineering monographs. 1990, Vol. 25.

38. Valencia, C. A. V. Aplicação da adsorção em carvão ativado e outros materiais carbonosos no tratamento de águas contaminadas por pesticidas de usp agrícola. Tese de mestrado. s.I. : Oontifícia Universidade Catóica do Rio de Janeiro, 2007, p. 116.

39. Domingues, V. M. F. Utilização de um produto natural (cortiça) como adsorvente de pesticidas piretróides em águas. Faculdade de Engenharia da Universidade do Porto. 2005, p. 224. 
40. IUPAC. Compendium of Chemical Terminology (the Gold Book). Blackwell Scientific Publications. 1997. ed. 2a.

41. Sekar, M. and Sakti, V., Rengaraj, S. Kinetics and equilibrium adsorption study of lead (II) onto activated carbon prepared from coconut shell. Colloid and Interface Science. 2004, Vol. 279, pp. 307-313.

42. Barros, A. R. B. Remoção de íons metálicos em água utilizando diversos adsorventes. Centro Tecnológico da Universidade Federal de Santa Catarina. 2001. p. 89.

43. Jimenez, R. S., et al. A remoção de metais pesados de efluentes aquosos pela zeólita natural escolecita - influência da temperatura e do $\mathrm{pH}$ na adsorção em sistemas monoelementares. Química Nova. 2004, Vol. 27, n. 5, pp. 734738.

44. Khattri, S. D. and Singh, M. K. Colour removal from synthetic dye wastewater using a bioadsorbent. Water Air and Soil Pollution. 2000, Vol. 120, pp. 283-294.

45. Al-Degs, Y., et al. Effect of carbon surface chemistry on the removal of reactive dyes from textile effluent. Water Research. 2000, Vol. 34, pp. 927-935.

46. Appel, C., et al. Point of zero charge determination in soils and minerals via traditional methods and detection of electroacoustic mobility. Geoderma. 2003, Vol. 113, pp. 77-93.

47. Magalhães, E. C. S. Propriedades ópticas de filmes finos de dióxido de estanho puro e dopado com flúor. Tese de doutorado. s.I. : Instituto de Física da Universidade Estadual da Bahia, 2006.

48. Purushothaman, K. K., Dhanashankar, M. and Muralidharan, G. Preparation and characterization of $\mathrm{F}$ doped $\mathrm{SnO} 2$ films and electrochromic properties of FTO/NiO films. Current Applied Physics. 2009, Vol. 9, pp. 67-72.

49. Banerjee, A. N., et al. Synthesis and characterization of nano-crystalline fluorine-doped tin oxide thin films by sol-gel method. Journal of Sol-gel Science and Technology. 2003, Vol. 28, pp. 105-110.

50. Zhang, G. Electrochemistry of Silicon and its Oxides. [ed.] Kluwer Academic Publishers. 2001, pp. 31-39.

51. Chiang, J. L., et al. Ion sensitivity of the flowerlike $\mathrm{ZnO}$ nanorods synthesized by the hydrothermal process. Journal of Vacuum Science \& Technology B. 2009, Vol. 27, pp. 1462-1465. 
52. Chiang, J. L., et al. Hydrogen ion sensors based on indium tin oxide thin film using radio frequency sputtering system. Thin Solid Films. 2009, Vol. 517, pp. 4805-4809.

53. Pan, C. W., et al. Using polypyrrole as the contrast $\mathrm{pH}$ detector to fabricate a whole solid-state pH sensing device. leee Sensors Journal. 2003, Vol. 3, pp. 164-170.

54. Batista, P. D. and Mulato, M. Polycrystalline fluorine-doped tin oxide as sensoring thin film in EGFET pH sensor. Journal of Materials Science. 2010, Vol. 45, pp. 5478-5481.

55. Kagohashi, Y., et al. Complementary metal-oxide-semiconductor ionsensitive field-effect transistor sensor array with silicon nitride film formed by catalytic chemical vapor deposition as an ion-sensitive membrane. Japanese Journal of Applied Physics. 2010, Vol. 49, pp. 01-06.

56. Chou, J. C., Kwan, P. K. and Chen, Z. J. SnO2 separative structure extended gate $\mathrm{H}+-$ ion sensitive field effect transistor by the sol-gel technology and the readout circuit developed by source follower. Japanese Journal of Applied Physics. 2003, Vol. 42, pp. 6790-6794.

57. Pan, C. W., et al. Development of the real-time $\mathrm{pH}$ sensing system for array sensors. Sensors and Actuators B-chemical. 2005, Vol. 108, pp. 870-876.

58. Pan, C. W. Development of the tin oxide $\mathrm{pH}$ electrode by the sputtering method. Sensors and Actuators B-chemical. 2005, Vol. 108, pp. 863-869.

59. Oka, M. M. Medida de quatro pontas. 2000.

60. Russo, B. and Cao, G. Z. Fabrication and characterization of fluorine doped thin oxide thin films and nanorods arrays via spray pyrolysis. Applied Physics A. 2008, Vol. 90, pp. 311-315. 


\section{tis TeXAS INSTRUMENTS

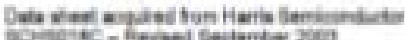 \\ CMOS \\ Dual Complementary Pair Plus Inverter \\ Hiph-Voltape Types 120.Voit Ratingl

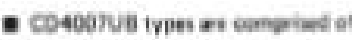

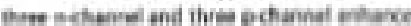 menthyse MOS twenviter. The srassief

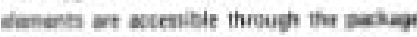 fermingh is provide a cumusiant naks for earatructing the sarious typical corouts themen is fis 2

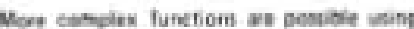

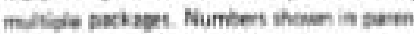

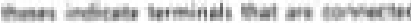 lagritur ta form the varieus eanformiam lintad \\ Nhe CDexrue tyose aresupplad in 14tex: fermetse doubin-lins ceramk package FIA sumn. 14-iead dudthise plast: pacloges (E suffix), 14heod smulkoutline packoges M. MT. MOS. and NSR buflires; and thkad then shrink smulecedine packoges (FW and FWh nolises!}

Aaplicarions:

- Eatromely hiphinput incedance enplifies

- Shaper

- imertars

- Tlumbild desecter

- Linaur amelifier

- Crrval easilietere

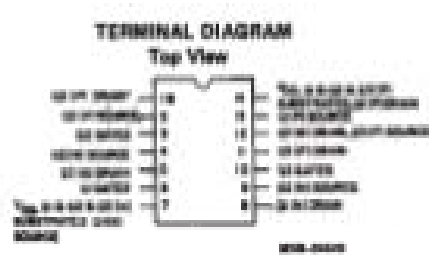

\section{CD4007UB Types}

Fonure:

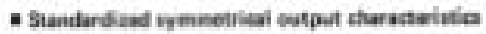

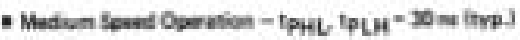
at $10 \mathrm{~V}$

- $100 \mathrm{~s}$ tasted lar geierrest currant at $20 \mathrm{~V}$

- Mesta al novisument of JetC fomtatine

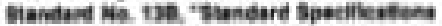

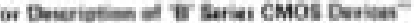

- Mesianen iacel cerrent of 1 ja in ia V

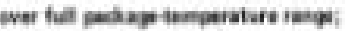

100 nA at $14 \mathrm{~V}$ and $\mathrm{Z}^{2} \mathrm{C}$

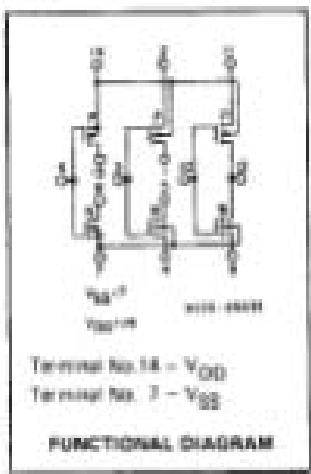

AECOMETRDEO OPERATING CONOITIONS

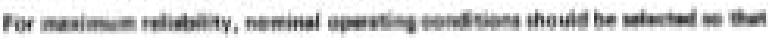
opestios a desw wothe the falleming nesp:

\begin{tabular}{|c|c|c|c|}
\hline \multirow{2}{*}{ CHARACTERISTIC } & \multicolumn{2}{|c|}{ LiMiTs } & \multirow{2}{*}{ UNIT: } \\
\hline & MIN. & MAX. & \\
\hline 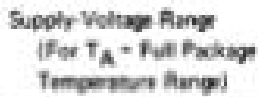 & 3 & 18 & $\mathbf{v}$ \\
\hline
\end{tabular}

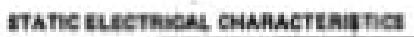

\begin{tabular}{|c|c|c|c|c|c|c|c|c|c|c|c|}
\hline \multirow{3}{*}{$\begin{array}{l}\text { CHARACTEN- } \\
\text { isthe }\end{array}$} & \multicolumn{3}{|c|}{ condincens } & \multicolumn{7}{|c|}{ LWETS AT wDICATED TEUAREATUAES PC) } & \multirow{3}{*}{ UNiTs } \\
\hline & \multirow{2}{*}{$\begin{array}{l}V_{0} \\
\text { (v) }\end{array}$} & \multirow{2}{*}{$\begin{array}{l}V_{1 M} \\
(v i)\end{array}$} & \multirow{2}{*}{$\begin{array}{l}\text { Voo } \\
|\mathrm{V}|\end{array}$} & & & & & & +25 & & \\
\hline & & & & -5 & -40 & an & 18 & Min. & In & Mex. & \\
\hline \multirow{4}{*}{ 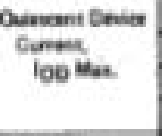 } & - & as & 3 & $a x$ & 0.25 & 15 & 75 & $=$ & 0.04 & 2.25 & \multirow{4}{*}{ in } \\
\hline & $=$ & 6,10 & 18 & si & os & 75 & 15 & $=$ & esi & 05 & \\
\hline & 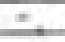 & 0.15 & 10 & 1 & 1 & 30 & 3 & $=$ & 061 & 1 & \\
\hline & $=$ & 0,20 & $x$ & 8 & 1 & 160 & 160 & $=$ & 0.07 & 1 & \\
\hline \multirow{3}{*}{ 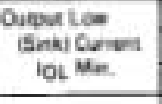 } & 04 & Qs & 5 & d6a & 861 & 642 & 03 & ast & 1 & $=$ & \multirow{7}{*}{$m$} \\
\hline & 0.5 & Q, 10 & 10 & 18 & 15 & 1.1 & 29 & 13 & 26 & - & \\
\hline & 13 & Q15 & 15 & 42 & $i$ & 27 & 2.4 & 34 & 6.8 & - & \\
\hline \multirow{4}{*}{$\begin{array}{l}\text { Onteut Hip } \\
\text { Shural } \\
\text { Oenent. } \\
\text { ion Wie. }\end{array}$} & 46 & as & 5 & -66 & -061 & $-0,2$ & -036 & -251 & -1 & - & \\
\hline & 25 & 05 & 5 & -2 & -13 & -13 & -1.15 & -15 & -32 & $=$ & \\
\hline & os & 010 & 10 & -15 & -15 & -11 & $-d i$ & -13 & -26 & $=$ & \\
\hline & 125 & 0.18 & 15 & -42 & -4 & -28 & -24 & -34 & $-6 \pi$ & $=$ & \\
\hline \multirow{3}{*}{ 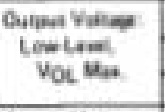 } & 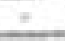 & 00 & 5 & \multicolumn{4}{|c|}{ e.sh } & $=$ & 0 & 6.65 & \multirow{6}{*}{ 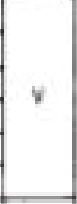 } \\
\hline & $=$ & 0.10 & 101 & \multicolumn{4}{|c|}{60} & $=$ & 0 & 0.05 & \\
\hline & + & 0.15 & 19 & \multirow{2}{*}{\multicolumn{4}{|c|}{$\frac{0.05}{4.95}$}} & 7 & 6 & 0.5 & \\
\hline \multirow{3}{*}{ 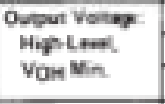 } & $=$ & as & 5 & & & & & An & 5 & - & \\
\hline & - & 0,10 & 10 & \multicolumn{4}{|c|}{2.95} & 996 & 10 & - & \\
\hline & - & 0.15 & 15 & \multicolumn{4}{|c|}{14.86} & 145 & 15 & $=$ & \\
\hline \multirow{3}{*}{$\begin{array}{l}\text { input low } \\
\text { Vuitup. } \\
\text { Vit Wue. }\end{array}$} & 45 & - & 5 & \multicolumn{4}{|c|}{1} & - & - & 1 & \multirow{6}{*}{$v$} \\
\hline & 9 & $=$ & 10 & \multicolumn{4}{|c|}{2} & + & - & 2 & \\
\hline & 126 & $=$ & 15 & \multicolumn{4}{|c|}{26} & $=$ & $=$ & 26 & \\
\hline \multirow{3}{*}{ 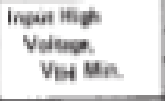 } & 0.5 & $=$ & 5 & \multicolumn{4}{|c|}{4} & 4 & $=$ & $=$ & \\
\hline & 1 & $=$ & 19 & \multirow{2}{*}{\multicolumn{4}{|c|}{$\frac{\text { if }}{12.6}$}} & i & $=$ & $=$ & \\
\hline & 1.5 & $=$ & 15 & & & & & 12.5 & $=$ & - & \\
\hline $\begin{array}{l}\text { Input Clarwiont } \\
\text { IIN Mas. }\end{array}$ & & 0,18 & 19 & $=0.1$ & \pm 0.1 & \pm 1 & 21 & - & $210^{-5}$ & \pm 0.1 & A \\
\hline
\end{tabular}




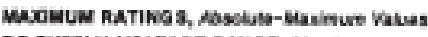

DC SUPPLY-VOLTMAE RAMEE, MoOI

Wotages referenced bo $V_{8 g}$ Terminal)

EPUI VOLTAGE RANOE. MLI INPUTS

DC NAPUT CUAACVT, AWY CNE WEPT

POWEA DISSIPATKON PEA PACKASE FD:

Fo $T_{A}=-550 \mathrm{C}$ is $+1000 \mathrm{C}$

Warda Lireacty at $12 \mathrm{mwpe}$ so $800 \mathrm{~m}$

DEVCE DISBPATION PEA CUTPUT TRAMEISTOA

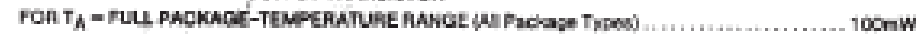

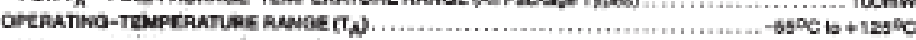

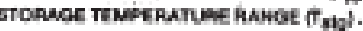

$-62^{\circ} \mathrm{C} b+150^{\circ} \mathrm{C}$

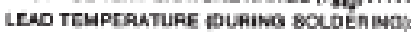

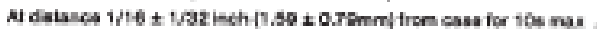

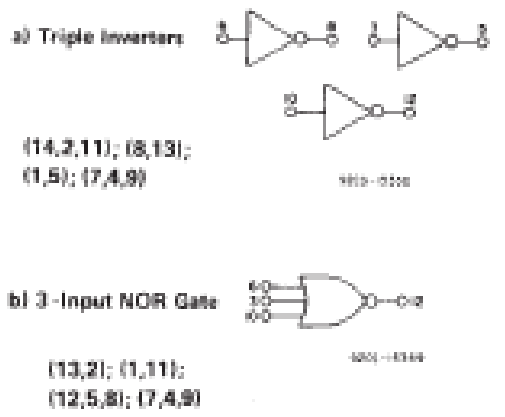

e) 3-Inpet NAND Gate

(1,12.13); $2,14,11):$

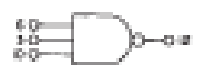

$(4,8) ;(5,9)$

d) Tree (Reluy) Logie

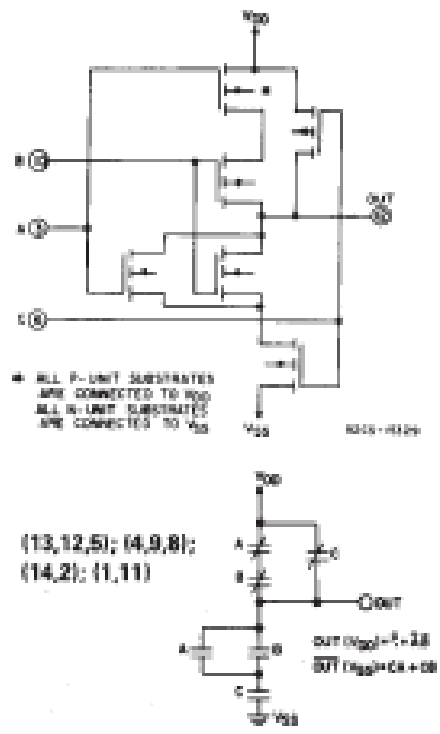

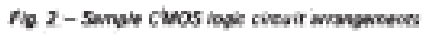
sengy two cosconts 
S) High Sinb Curemt Drise

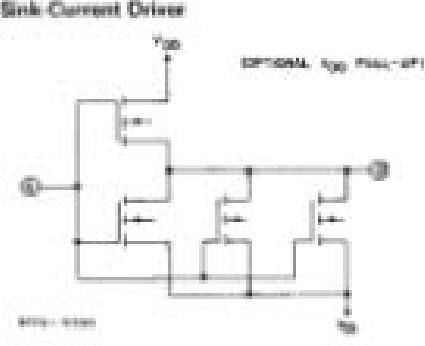

n Migh Souvecumant Driver

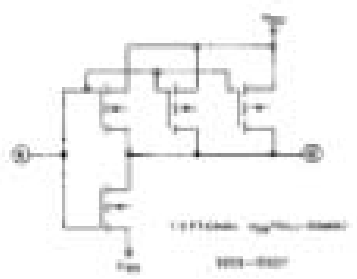

is, $2,100,18.5,127:$

$(11,10 ; 7.4 .9\}$

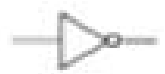

6,3,10t; $(12,1,12$

$(14,2,111 ; 07,9)$

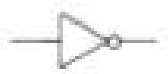

ON High Sink-and Sourco-Cument Driver

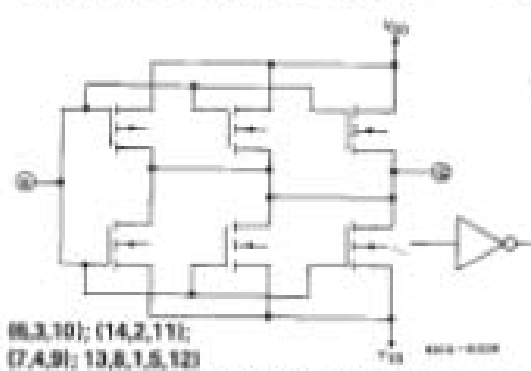

-1) Dual Ei Oirmsenal Tranumiedon Gating
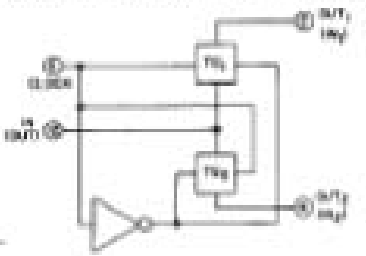

$(1,5,12):(2,2)$;

$(11,4) ; 0,12,10 \%:$

16,31

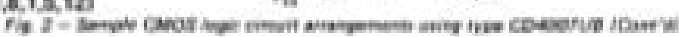

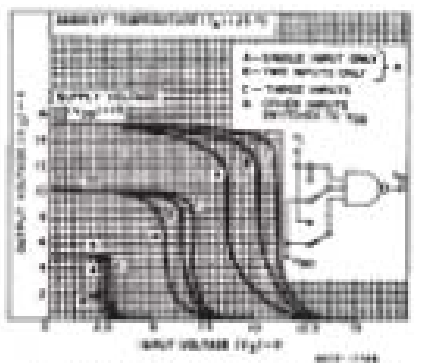

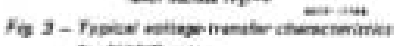
nor NewD pais
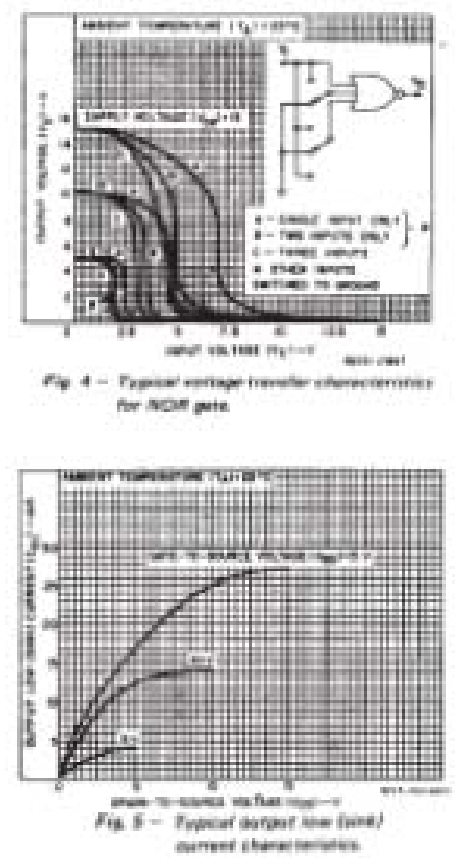

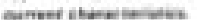

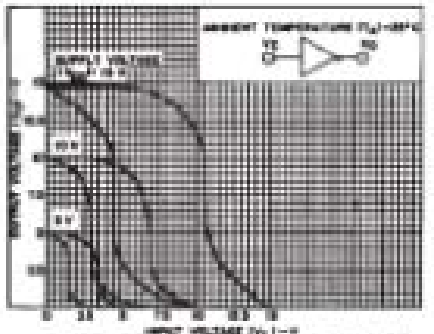

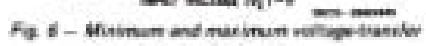

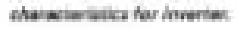

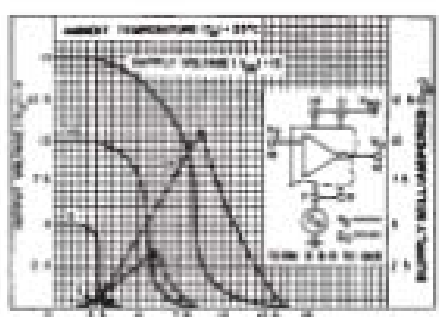

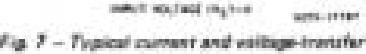

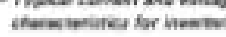

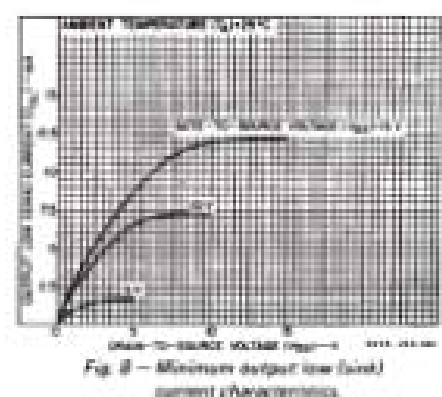




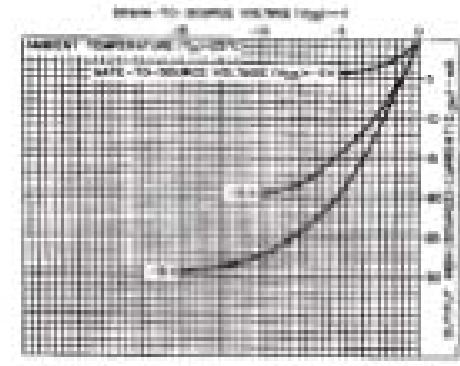

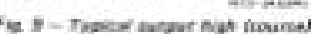
ancer aturestarates

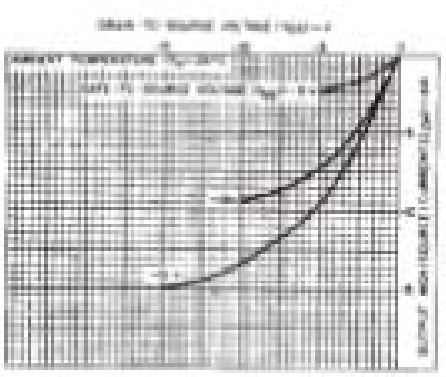

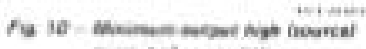

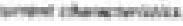

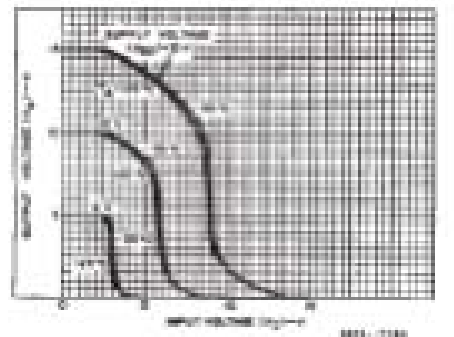

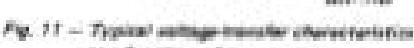

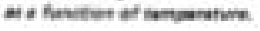

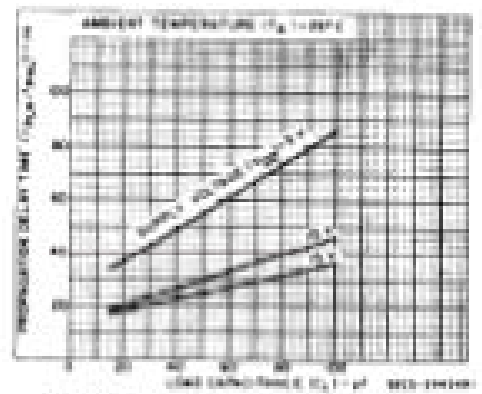

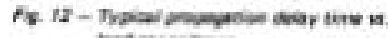
4ed aventors.
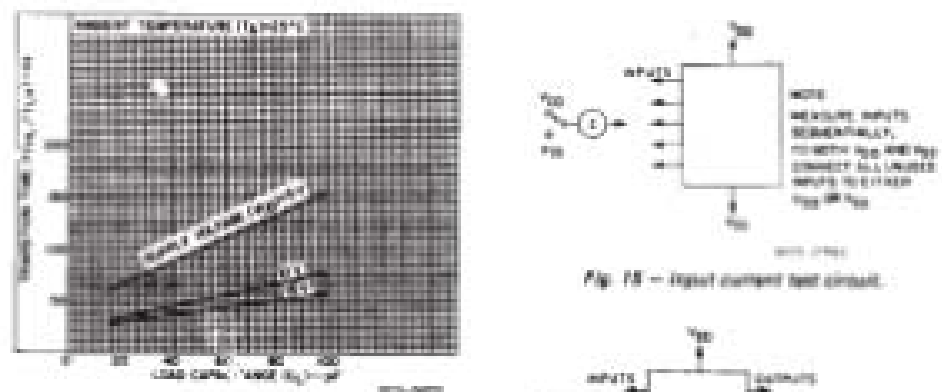

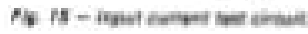

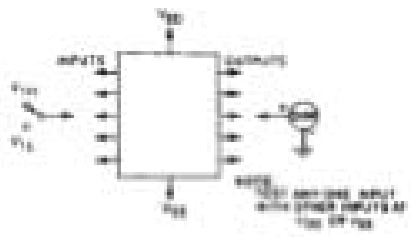

nine

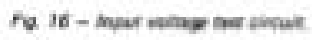

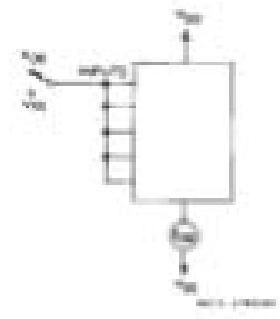

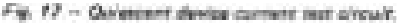

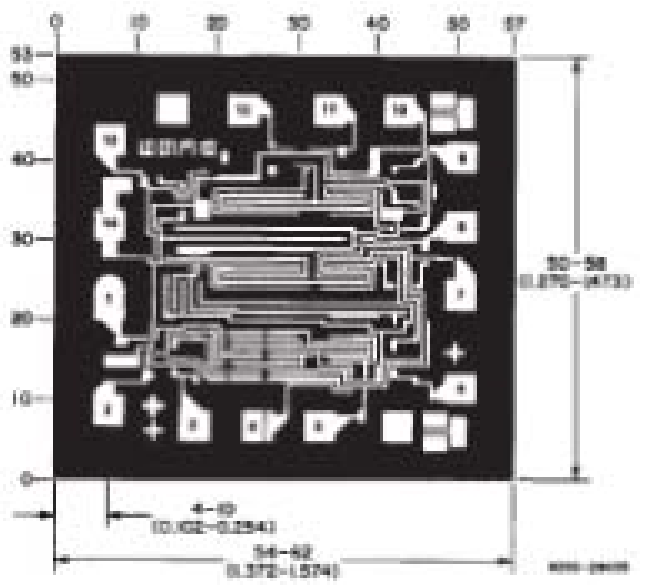

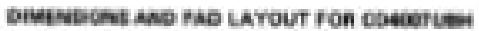


PACKAGING INFORMATION

\begin{tabular}{|c|c|c|c|c|c|c|c|c|}
\hline Orderable Device & statux ${ }^{(0)}$ & $\begin{array}{l}\text { Paoksase } \\
\text { Type }\end{array}$ & $\begin{array}{l}\text { Paoksos } \\
\text { Drawing }\end{array}$ & Pint & $\begin{array}{c}\text { Packago } \\
\text { Chy }\end{array}$ & Eso Plan ${ }^{(2)}$ & Load/Ball Finlch & WaL Pook Temp (a) \\
\hline couscrues & ACTVE & PDIP & N & 14 & 25 & $\begin{array}{l}\text { Pe-Pret } \\
\text { (Roks) }\end{array}$ & CU NIPONU & LtVI-NONONO \\
\hline CDeOOTUBF & ACTIVE & CDIP & $\mathrm{J}$ & 14 & 1 & None & Call $\pi$ & LEVES-NOANC-NGC \\
\hline CO4OCTUEF3A & ACTVEE & COIP & 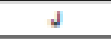 & 14 & 1 & None & Calm & LeVE-ANCANC-AC \\
\hline CD400RUEF3A116 & OESOLETE & COIP & 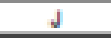 & 14 & & None & $\operatorname{col} \pi$ & $\cos \pi$ \\
\hline CouogruaM & ACTVE & SOIC & D & 14 & 50 & $\begin{array}{l}\text { Po-free } \\
\text { (Rohs) }\end{array}$ & CU NIPDNU & $\begin{array}{l}\text { LeVE-2-260C-1 YEAR, } \\
\text { Leve-1-235C-UNLIM }\end{array}$ \\
\hline CO4007UEM96 & ACTVE & SOIC & D & 14 & 2500 & $\begin{array}{l}\text { Pe-fret } \\
\text { (Aons) }\end{array}$ & CU NIPONU & $\begin{array}{l}\text { Leve-2-260C-1 YEAR } \\
\text { Leve-1-23SC-UNUM }\end{array}$ \\
\hline CDLODTUBMT & ACTIVE & SOIC & D & 14 & 250 & $\begin{array}{l}\text { Po-frese } \\
\text { (Fohs) }\end{array}$ & CU NIPDAU & $\begin{array}{l}\text { LeVE-2-260C-1 YEAR } \\
\text { LeVE-1-235C-UNLIM }\end{array}$ \\
\hline CO4OCTUENSA & ACTIVE & so & NS & 14 & 2000 & $\begin{array}{l}\text { Pe-fret } \\
\text { (Rods) }\end{array}$ & CUNIPONU & $\begin{array}{l}\text { Levi-2-246C-1 YEAR } \\
\text { Leve-1-23SC-UNLIM }\end{array}$ \\
\hline CDAOCTUEPW & ACTIVE & TSSOP & $P W$ & 14 & 90 & $\begin{array}{l}\text { Po-free } \\
\text { (Alohs) }\end{array}$ & CU NIPDNU & LeVE-1-250C-UNLIM \\
\hline CDLOOTUEFWR & ACTVE & TsSOP & $F W$ & 14 & 2000 & $\begin{array}{l}\text { Pe-Pret } \\
\text { (Rots) }\end{array}$ & CUNIPON & Leve-1*2soc-UNLIM \\
\hline
\end{tabular}

The manesing status values are defined as follows:

ACTIVE: Product device recommended for new designs,

IFEBUY: TI has announced fat the device will be discortinut, and g ifetime-buy perod is in et"ect

NFWD: Not recommended for new oesigns. Device is in production to subport exsthe customers, but $\mathrm{Tl}$ does not recommend using ths part in a new dealg.

PREVIEW: Device has been announced but is not in production. Samples may or may not be avallakie

OesOLETE: Ti has dsconthued the producton of the device.

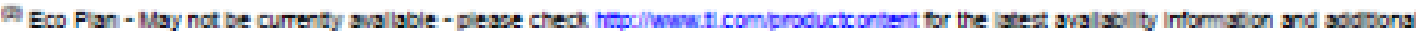

product content detals.

None: Not yet avalabie Lead (Foflet), tor al 6 substances, including the reguirement mat lead not exceed $0.1 \%$ by weght in homogeneous materisis. Where designed to be asidered at high temperatures, T1 Pb-Free products are sultable for use in spectied lead-hee procezces.

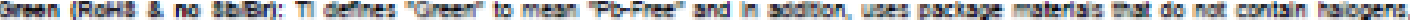
including bromine (Bn) or antemony (Bb) abeve $0.1 \%$ of lista product weight.

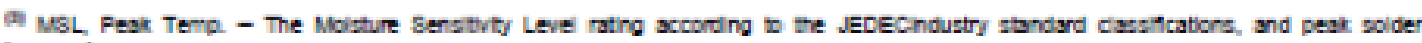
zmotrature.

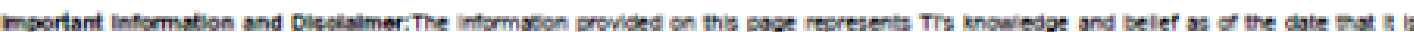
grovided. $\mathrm{T}$ bases it knowiedge and belef on information provided by third parties, and makes no represertation or warranty as to the

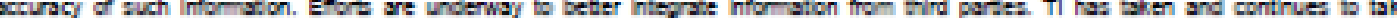
reasonabie altes to provide representative and accurale intormasion but may not have cenducted desiructive fitaing or chemica analysis on

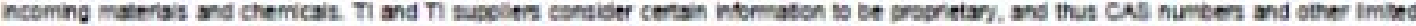
rormason may not be aula

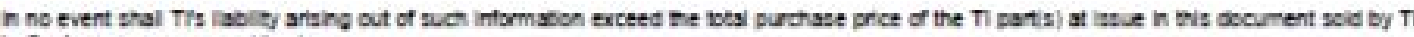
E Custerier on an annua basia 


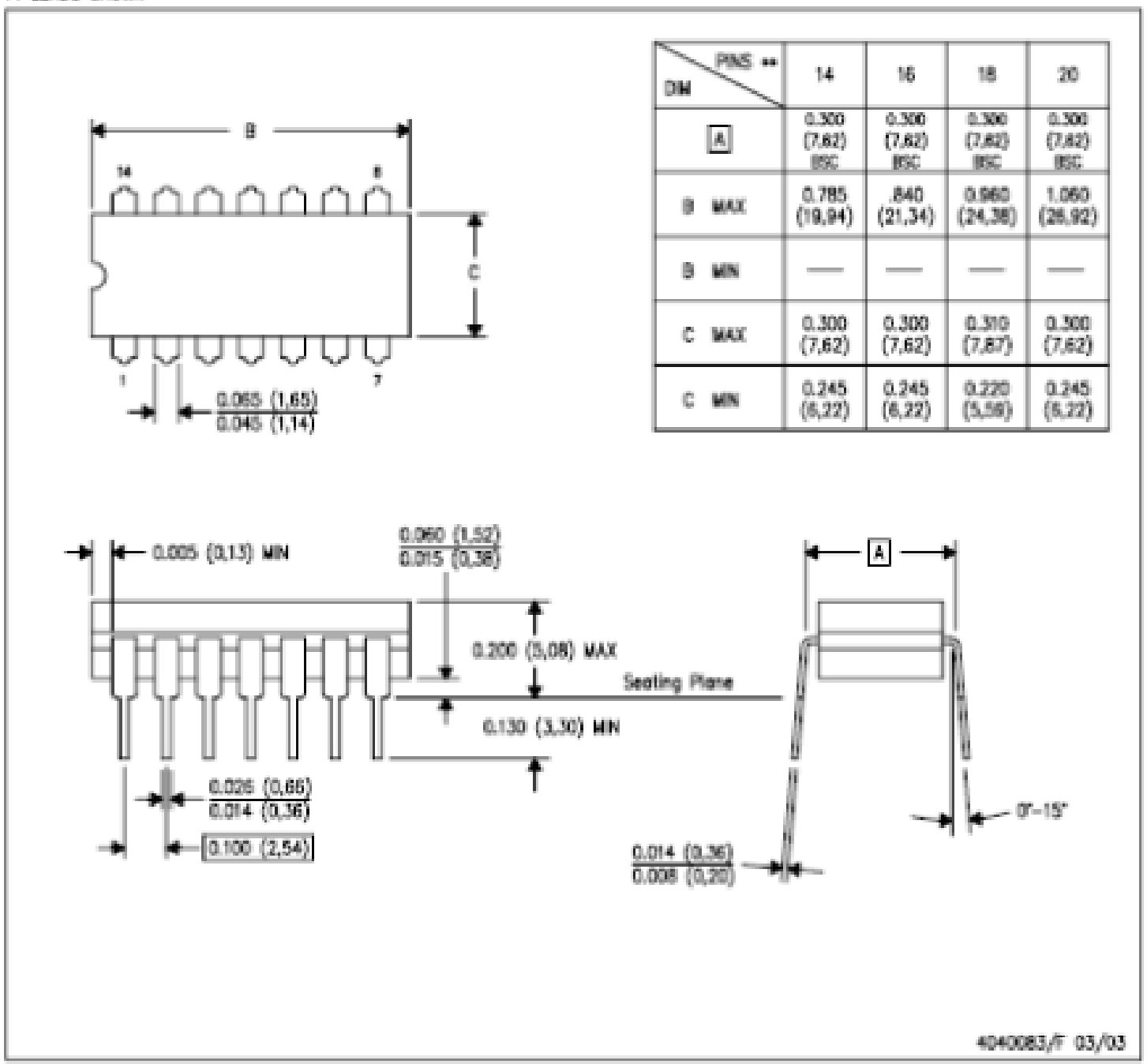

Nots. A. 41 liner dimensicns ore in inches (milimeters).

B. Dit arong is subject to thange nithout retice.

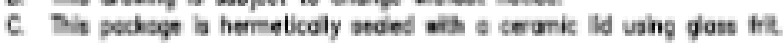

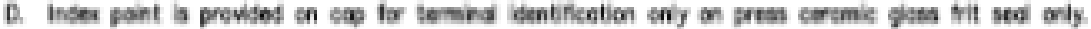

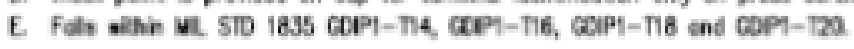




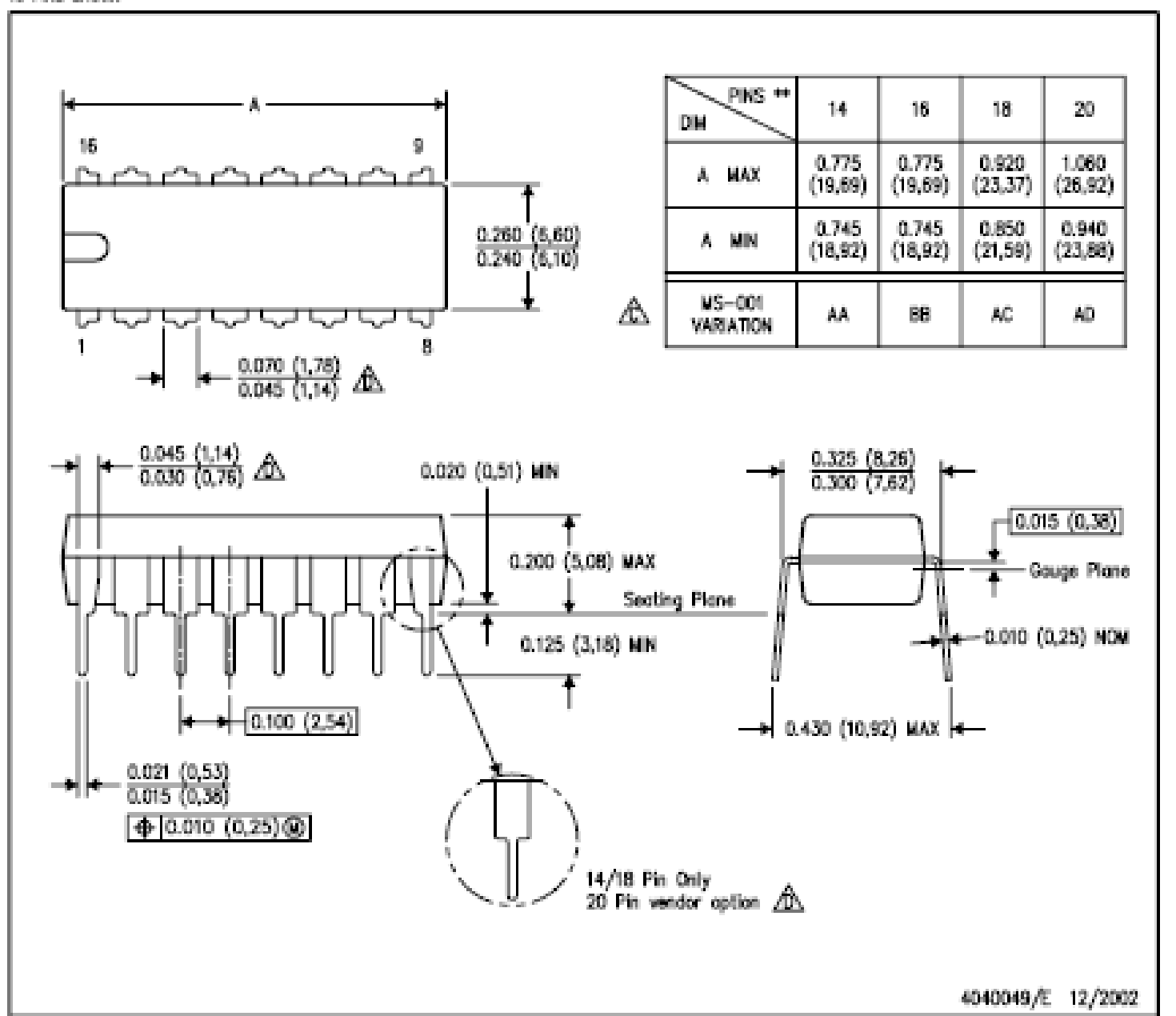

KOTES: A. NI lires dimersions ore in inches (milimeters).

B. This draing is s.bject to chenge without notise.

A Fala within EDEC vS-DO1, excest 18 ard 20 pin minimum bsdy length (Oim A).

A Te 20 pin end lead shoulder width is a vendor option, eiter holf or full wisth 


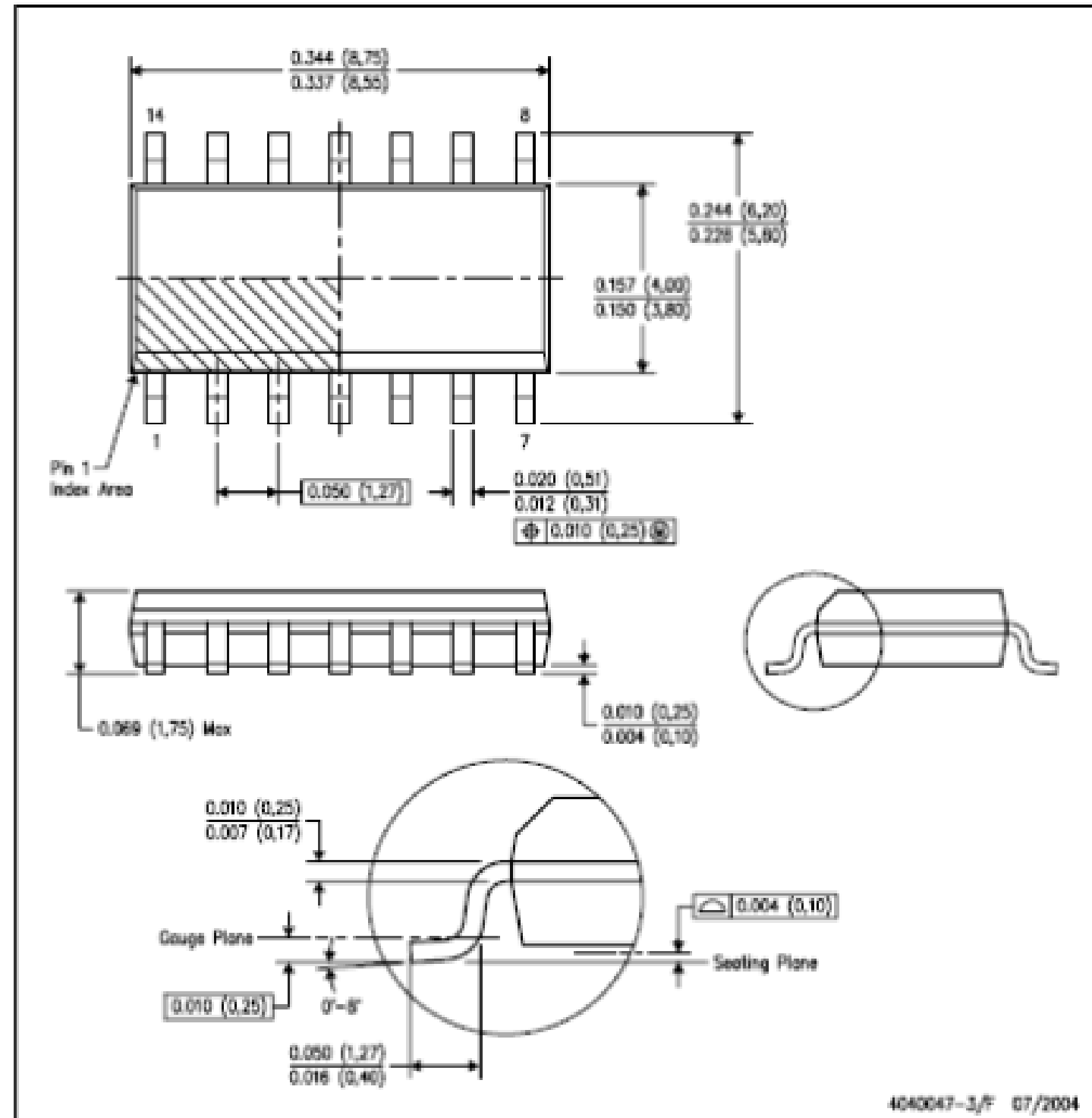

notes
A. Al linear dmersions are in inctes (milimelers).
C. Body dimensions do not include molt fash or protrusion not to eaceed $0.006(0,15)$
D. Fols with FDEC US-012 wriction 13 

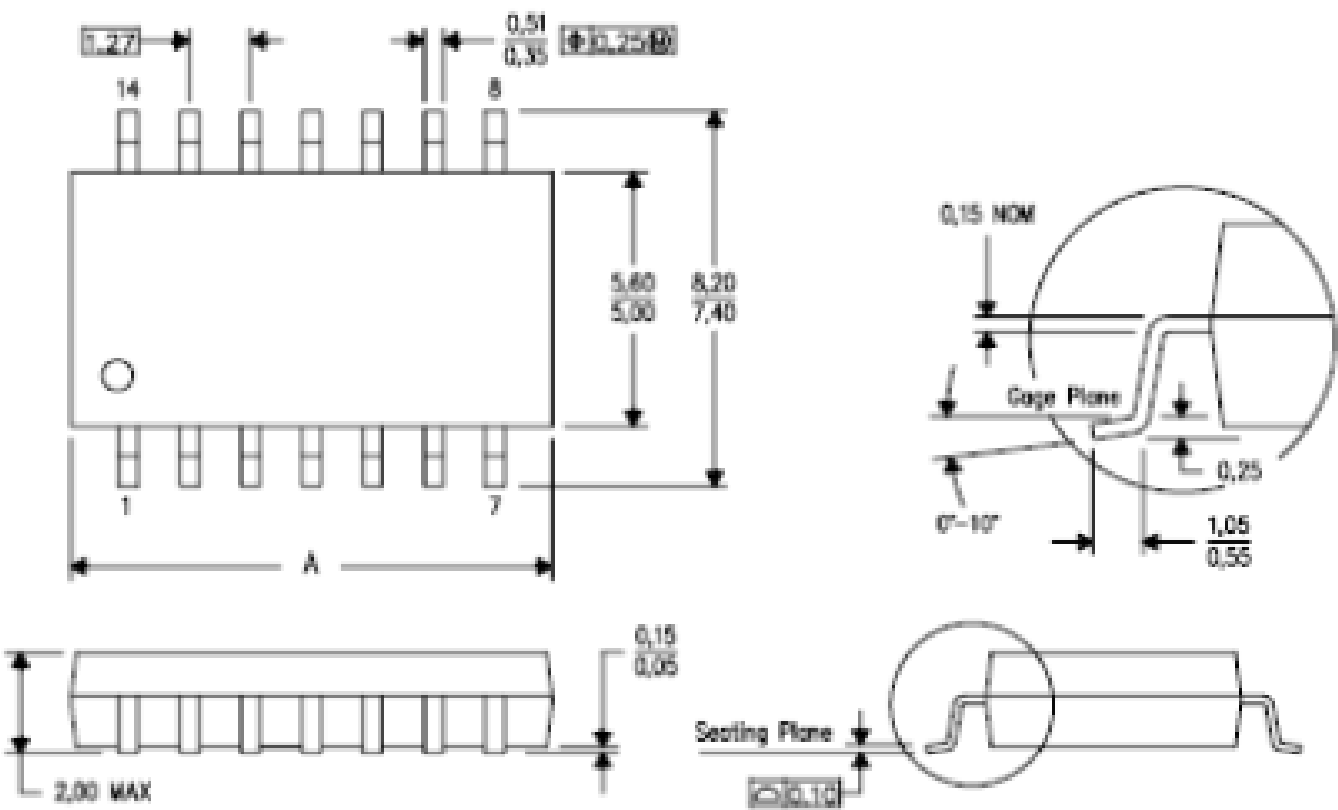

\begin{tabular}{|c|c|c|c|c|}
\hline PWNS ** & 14 & 15 & 20 & 24 \\
\hline A vaX & 1050 & 10,50 & 12,90 & 15,90 \\
\hline A UK & 9,90 & 9,90 & 12,90 & 14,70 \\
\hline
\end{tabular}

Notes. A. Al lineor demaicns ore in malmeters.

Q. Dis drowng is subject to change withoul netice.

C. Bedy dmeniloss de net holuse mold fas or zrotrusion, not to weed 0.15 

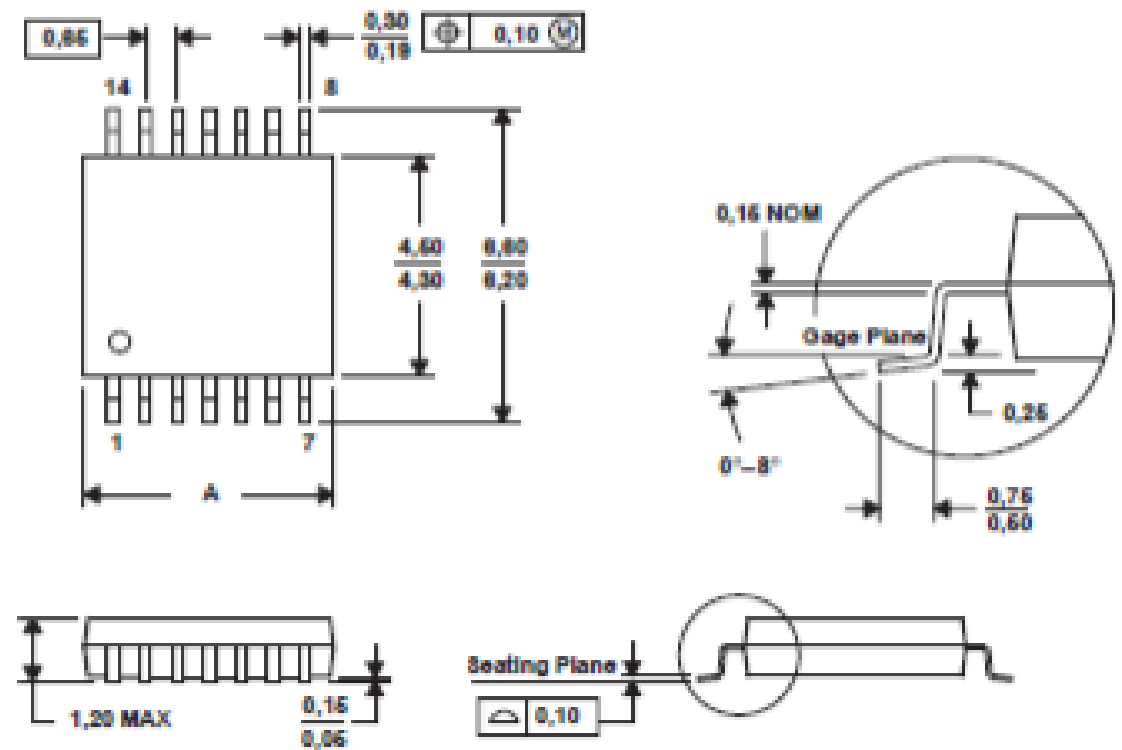

\begin{tabular}{|c|c|c|c|c|c|c|}
\hline DiM PIN +4 & 8 & 14 & 18 & 20 & 24 & 28 \\
\hline A MNX & 3,10 & 5,10 & 5,10 & 6,60 & 7,90 & 9,80 \\
\hline A MIN & 2,90 & 4,90 & 4,90 & 6,40 & 7,70 & 9,60 \\
\hline
\end{tabular}

4040064F 01/87

NOTES: A. Al inear dimensions are in millmeters.

E. This drasing is subject to change w thout notice.

C. Body dimentions do not include moid fash or protruaion not to erceted 0,15 .

D. Fals within JEDEC MO-153 


\section{IMPORTAUT NOTICE}

Texas instruments incorporaled and its subsidares (T) reserve the nght to make corrections, modtcations, enhancements, improvements, and other changes to ts products and services at any time and to disconthue any product or service whout notce. Customers should obtain the latest relevart information before placing crders and should verty that such information is current and complele. Al products are soid subject to Trs terms and condibons of sale suppled at the time of order acknouledgment.

$\mathrm{Tl}$ warrants performance of its hardware products to the specifications applicable at the time of sale in accordance wth Tr's standard warranty. Testing and other quailty cortrol techniques are used to the extent TI deems necessary to support this warranty. Except where mandated by govemment requirements, testing of al parameters of each product is not necessarly performed.

TI 3ssumes no liablity for applications assistance or customer product design. Customers are responsible for their products and apolications using $\mathrm{TI}$ components. To minimize the risks associated with customer products and applicabons, cusiomers should provide adequate design and operating sateguards.

n does not warrant or represent that ary license, emer erpess $\alpha$ implied, is granted under any $\mathrm{T}$ patent nght. copyright max woa nght, $\alpha$ oher TI ntelectud propeny ingt reiath to any combinaton, machine, or process in which $\mathrm{TI}$ proaucts $\alpha$ iervices are used. intornubon publsied by 71 regarding third-party prooucts or services does not consthte a license from $T$ to use such proousts or services of a warranty or endorsement thereot. Use of wach intormuton may require a lioense fom a trind party under the pabents or cher intelechax property of the thrid pany, or a licenie from Ti under the paterts or cother inteliectual property of $\mathrm{TL}$.

Reproducton of intormation in $\mathrm{Tl}$ data books or dat sheets is permissibie only if reproducton is withost aleraton and is accompanied by al astodated warrartes. condrions, limitations, and notices. Reproouction of tris intormaton whth ateraton is an urfar and deceptive business practice. TI is not responsbie or labie for such altered socumentation.

Resale of $T$ prooucts or services wih statements afferent fon or beyond the parameters stated by TI for that product or service volds al express and any impled varantes for the assoclated $\mathrm{Tl}$ proouct or service and is an urfair and deceptive business practice. Th is not responsbie or liable for any such statements.

Following are URLs where you can obtain infomation on other Texas Instruments products and application solutions:

Products

Ampinters

Data Conventers

DSP

Intertace

Loge

Power Mgnt

Microcorteden

amplifier.ti.com
dataconverter.t.com
dsp.ti.com
intertace.tl.com
isgct.com
power.tl.com

microcontrotect. $\mathrm{com}$
Applleations

Audio

Automotive

Broadeand

Digta Contro:

Mieny

Optcas Netwoning

security

Tetephony

Vioe $t$ imaging

Whreless waw.t.com/audlo

waw.t.com/automotive

waw t combroachand

waw th com/dgtacortra

waw. cominultay

waw. 1 comopticainetwon

wuw.t.comseartiy

WwW 1 comtelephony

waw 2 comvideo

waw : comwiretess

Maling Adoress: Texas instruments

Post Omce Box 655303 Dalas, Teras 75265

Copyright 12005 , Texas instuments incorporated 